\title{
MSIS 2016 \\ Global Competency Model for Graduate Degree Programs in Information Systems
}

December 5, 2016

\section{The Joint ACM/AIS MSIS 2016 Task Force}

Topi, Heikki (Bentley University; ACM, co-chair; htopi@bentley.edu)

Karsten, Helena (Åbo Akademi University; AIS, co-chair; ekarsten@abo.fi)

Brown, Sue (University of Arizona; AIS)

Carvalho, João Alvaro (Universidade do Minho; AIS)

Donnellan, Brian (Maynooth University; ACM)

Shen, Jun (University of Wollongong; ACM)

Tan, Bernard (National University of Singapore; AIS)

Thouin, Mark (University of Texas at Dallas; ACM)

\section{Sponsoring Societies}

This report was made possible by financial support from the following societies: 



\section{Foreword}

This document, MSIS 2016: Global Competency Model for Graduate Degree Programs in Information Systems, is the latest in the series of reports providing guidance for degree programs in the academic field of Information Systems (IS). The first of these reports (Ashenhurst 1972) was published in the early 1970s, and the work has continued ever since, both at the undergraduate and master's levels. Association for Computing Machinery (ACM) has carried a responsibility as a sponsoring organization from the beginning. Since Association for Information Systems (AIS) was established in the mid-1990s, the two organizations have collaborated in an important way. At the undergraduate level, both Association for Information Technology Professionals (AITP) (formerly DPMA) and IFIP have also made significant contributions to the curriculum recommendations.

MSIS 2016 is the seventh collaborative effort between ACM and AIS (following IS'97, IS 2002, and IS 2010 at the undergraduate level; MSIS 2000 and MSIS 2006 at the graduate level; and CC 2005 as an integrative document). Both ACM and AIS are global organizations working to advance computing and its transformative uses. ACM's membership includes industry professionals, academics, and students worldwide, and it works in a broad spectrum of areas within computing. AIS is the premier global society for faculty members affiliated with IS, and it also serves students through a student chapter structure. The organizations complement each other's strengths and have been strong partners in educational initiatives since the 1990s.

As will be discussed in more detail within the document, MSIS 2016 is the first curriculum guidance document in IS that has been developed with a truly global process for a global audience. Earlier reports have been used around the world, but a US-based task force developed the reports with assumptions that were mostly aligned with the North American educational system. MSIS 2016 is also the first document of its kind that does not provide a predefined curriculum model (and thus, it is not called a curriculum recommendation). Instead, it focuses on the articulation of competencies that graduates should attain by the completion of their degree programs. The task force believes that this approach is particularly suitable for a document that is designed to serve a broad range of degree programs around the world.

Recommendations such as MSIS 2016 have a variety of uses. For some institutions, MSIS 2016 can provide detailed guidance and a specific foundation for a curriculum. For others, this document may serve in a variety of supporting roles: it can be a starting point for internal conversations, a source of ideas in situations when new perspectives are necessary, a benchmark for an internal development effort, and a structural guide. We strongly advise all users of this document to adapt its recommendations based on the needs of each local program, and we believe that it can best serve in a role of a guide and advisor. In addition to providing information to universities and their units, this document provides highly useful information regarding the nature and identity of MS degree programs in IS to a number of other 
stakeholder groups, such as prospective and current students, employers, university administrators, and policymakers.

We hope that this document will also contribute to the global IS community's ongoing process of self-reflection and continuous improvement. First and foremost, however, we hope that MSIS 2016 will serve as many schools and programs as possible in their continuous efforts to offer their students as strong, innovative, and long-lasting educational experience as possible. We encourage you to share your experiences with the MSIS 2016 model with the rest of the global IS communityplease see msis2016.org to find the best ways to do so.

\section{Acknowledgements}

The MSIS 2016 task force is very thankful for the work of numerous faculty members from around the world who ultimately made this document possible! Specifically, we want to thank the following groups and individuals:

- ACM Education Council and Board (Jane Prey and Mehran Sahami, co-chairs; Andrew McGettrick, past chair) and AIS Council (Jason Thatcher, president; Jae Kyu Lee, immediate past president; Helmut Krcmar and Jane Fedorowicz, past presidents) for their feedback, encouragement, and willingness to sponsor this project and approve the final deliverable.

- AIS VP of Education Jan vom Brocke for his detailed comments and edits that greatly helped us improve the document.

- Members of the AIS Education Committee for their feedback and guidance.

- Active and supportive participants of panels, special sessions, and other presentations at numerous conferences for their insightful comments and constructive feedback.

- Numerous faculty members who answered our surveys and provided qualitative feedback regarding various drafts of this document.

\section{Executive Summary}

MSIS $^{1} 2016$ is a competency model for master's level degree programs in Information Systems (IS). It builds on the foundation of four earlier graduate IS curriculum recommendations (Ashenhurst 1972; Nunamaker, Couger, and Davis 1982; Gorgone et al. 2000; Gorgone et al. 2006). MSIS 2016 does, however, break new ground in a number of important ways, most importantly by focusing on graduate competencies and competency ${ }^{2}$ areas and categories as its basic

\footnotetext{
${ }^{1}$ Master of Science in Information Systems

2 We recognize that in some research traditions, the words "competency" and "competence" are used to denote different constructs. In this context, they represent different spellings of the same construct; we are using "competency" with essentially the same meaning as "competence" in the European e-Competence Framework (ECF).
} 
architectural building blocks and by providing a recommendation that has been specifically designed for the global IS community by a broadly representative task force. In addition, MSIS 2016 explicitly recognizes that business is not the only possible domain of practice and considers alternatives such as health care, government, education, and law.

MSIS 2016 is based on a set of core premises, the most important of which are listed below.

1. MSIS is a professional practice master's degree that always integrates the development of competencies in the realms of information systems (including both computing ${ }^{3}$ and IT and IS management), a specific domain of practice, and individual foundational competencies.

2. MSIS is based on a completed undergraduate degree that provides a foundation in all three major competency realms (see \#1 above). Missing competencies can be developed with pre-program bridge courses.

3. MSIS does not have any general expectations regarding prior professional experience (although an individual program can set its own professional experience requirements).

4. The central element of this recommendation consists of specifications for a hierarchy of competency areas, competency categories, and sample competencies for IS. In addition, it provides general descriptions of required areas of individual foundational competencies and examples of areas of domain of practice competencies.

5. The target professional profiles of various MSIS programs vary, sometimes significantly.

6. Different professional profiles require different sets of competencies. MSIS 2016 specifies four levels at which a student can attain competencies within a category: Awareness, Novice, Supporting [role], and Independent [contributor]. A competency profile specifies for each competency category the level the graduates of a program should attain.

7. A program can demonstrate compatibility with MSIS 2016 by showing that all of its graduates attain at least the minimum level of competency specified in this recommendation in each of the categories.

8. Competency categories and their attainment levels form the foundation for determining modules (courses and equivalents) and their learning objectives. The structure, delivery modes, pedagogy, and content of the modules will be highly dependent on program-specific conditions and requirements.

\footnotetext{
${ }^{3}$ We recognize that "computing" is used more frequently in North America than in other parts of the world. In Europe and in Asia, "ICT" or "informatics" would often be more familiar synonyms.
} 
MSIS 2016 comprises nine IS competency areas ${ }^{4}$ (all are preceded by the phrase "competencies in," but we are not repeating it for the sake of brevity):

- Business Continuity and Information Assurance;

- Data, Information, and Content Management;

- Enterprise Architecture;

- Ethics, Impacts, and Sustainability;

- Innovation, Organizational Change, and Entrepreneurship;

- IS Management and Operations;

- IS Strategy and Governance;

- IT Infrastructure; and

- Systems Development and Deployment.

The areas are divided into competency categories. Categories, in turn, include the actual competencies, which are significantly more fluid than the areas and categories; therefore, competency-level specifications should be interpreted as examples.

The areas of individual foundational competencies chosen to be included in MSIS 2016 are Critical Thinking, Creativity, Collaboration and Teamwork, Ethical Analysis, Intercultural Competency, Leadership, Mathematical and Statistical Competencies, Negotiation, Oral Communication, Problem-solving, and Written Communication.

Domain competencies specify the key competency areas related to a domain of practice with which the degree program is associated. In addition to business, which has traditionally been the most common domain of practice, MSIS degree programs can be and have been built to be aligned with many other domains (such as health care, law, government, education, etc.).

The overall competency structure of MSIS 2016 is described in figure ES1.

MSIS programs use various mechanisms to determine the professional profiles for which they prepare their graduates. This document uses a subset of profiles specified in the CEN Workshop Agreement on European ICT Professional Profiles (CEN 2012) as an example, but only as such. This list is not intended to be exhaustive; on the contrary, it is expected that programs will develop and adapt target profiles that fit their specific needs.

MSIS 2016 demonstrates the importance of a mapping between the competency categories and the professional profiles. Programs using MSIS 2016 can use the competencies determined based on the target profile(s) to build a set of modules (courses and equivalents) that will form the structure for students' learning experiences. MSIS 2016 does not attempt to specify how a master's degree program in IS should be implemented nor will it specify how exactly specific graduate

\footnotetext{
${ }^{4}$ Many readers will find that an area or areas important for them may appear to be missing from this set. It is very likely that they are included in the document, either as part of a competency category or a competency.
} 
competency levels should be achieved. Instead, the recommendation provides process guidance for moving from competencies to an implementable curriculum.

\section{Specialized Competencies}

Specialized Competencies consist of additional Information Systems competencies that build on the core competencies and allow the graduates to perform more sophisticated tasks and act in more specialized professional roles.

\begin{tabular}{|c|c|c|}
\hline & Core Competencies & \\
\hline $\begin{array}{c}\text { Areas of } \\
\text { Information Systems } \\
\text { Competencies }\end{array}$ & $\begin{array}{c}\text { Areas of } \\
\text { Individual Foundational } \\
\text { Competencies }\end{array}$ & $\begin{array}{c}\text { Areas of } \\
\text { Domain } \\
\text { Competencies }\end{array}$ \\
\hline $\begin{array}{l}\text { - Business Continuity and } \\
\text { Information Assurance } \\
\text { - Data, Information, and } \\
\text { Content Management } \\
\text { - Enterprise Architecture } \\
\text { - Ethics, Impacts and } \\
\text { Sustainability } \\
\text { - Innovation, } \\
\text { Organizational Change } \\
\text { and Entrepreneurship } \\
\text { - IS Management and } \\
\text { Operations } \\
\text { - IS Strategy and } \\
\text { Governance } \\
\text { - IT Infrastructure } \\
\text { - Systems Development } \\
\text { and Deployment }\end{array}$ & $\begin{array}{l}\text { - Critical Thinking } \\
\text { - Creativity } \\
\text { - Collaboration and } \\
\text { Teamwork } \\
\text { - Ethical Analysis } \\
\text { - Intercultural Competency } \\
\text { - Leadership } \\
\text { - Mathematical and } \\
\text { - Statistical Competencies } \\
\text { - Negotiation } \\
\text { - Oral Communication } \\
\text { - Problem-solving } \\
\text { - Written Communication } \\
\text { Graduate competencies } \\
\text { developed building on the } \\
\text { foundation of competencies } \\
\text { attained in prior studies and } \\
\text { work/life experience }\end{array}$ & $\begin{array}{l}\text { Core competencies in a } \\
\text { domain of human activity } \\
\text { such as business, } \\
\text { government, health care, } \\
\text { law, a field of scientific } \\
\text { research, etc. }\end{array}$ \\
\hline
\end{tabular}

\section{Areas of Information Systems Competencies with Pre-Master's Elements}

- Data, Information and Content Management - IT Infrastructure

- IS Management and Operations - Systems Development and Deployment

- Role of Information Systems in Organizations (Foundational Understanding of IS)

Figure ES1. MSIS 2016 Competency Structure 


\section{Table of Contents}

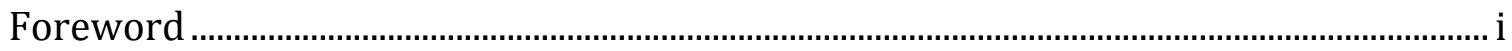

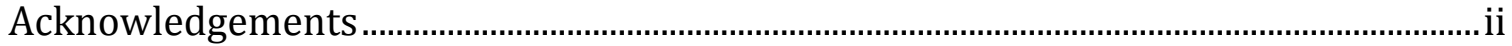

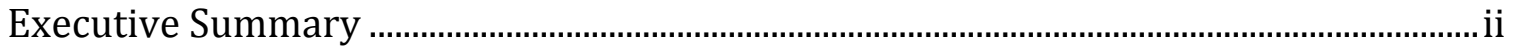

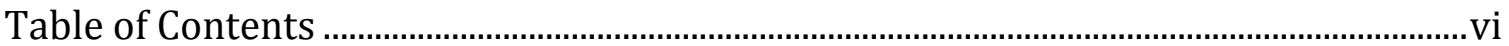

\section{Part A: MSIS 2016: Principles and Premises}

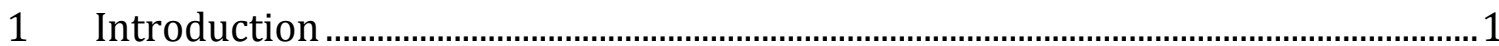

2 Principles and Premises Underlying the MSIS Degree and the IS Profession .......2

2.1 Degree Entry Conditions and Pre-Program Leveling Experiences .....................2

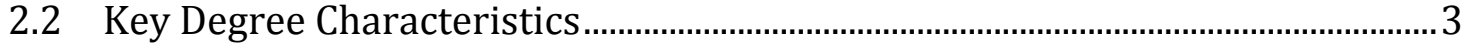

2.3 Post-Experience Degrees...............................................................................................6

Part B: The MSIS 2016 Competency Model

3 Architecture of the MSIS 2016 Competency Model ............................................................

4 Overview of the MSIS 2016 Graduate Competencies.................................................10

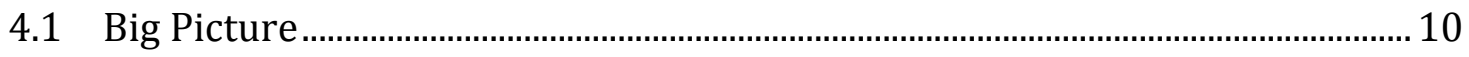

4.2 Areas of Information Systems Competencies...................................................... 11

4.3 Areas of Individual Foundational Competencies .................................................. 12

4.4 Areas of Domain Competencies ............................................................................... 12

4.5 Areas of Prerequisite Competencies with Pre-Master's Elements .................... 12

4.6 Specialized Competencies ……………………………………………………….....13

4.7 Impact of Professional Profiles on Competency Categories................................ 14

5 MSIS 2016 Competency Specifications........................................................................ 14

5.1 Specifications of Competency Areas, Competency Categories, and

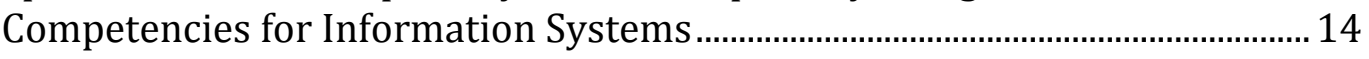

5.1.1 Competency Area Specifications …………………………………………….. 16

5.1.2 Competency Categories ...................................................................................2 20

5.2 Specifications of Individual Foundational Competencies .................................... 23

5.3 Role of Domain Competencies in MSIS 2016 …………………………………..25

5.3.1 Business............................................................................................................ 25 


\section{Part C: Using MSIS 2016}

6 Developing a Curriculum Based on MSIS Competency Specifications. 27

6.1 From Competencies to Curriculum ...................................................................... 27

6.2 MSIS Curriculum Architectures .......................................................................... 27

6.2.1 U.S. Model ...................................................................................................... 28

6.2.2 European Model........................................................................................... 30

6.3 Role of Target Profiles in Designing the Curriculum …………………………...... 31

6.4 Process for Deriving Courses from Competency Specifications.......................... 33

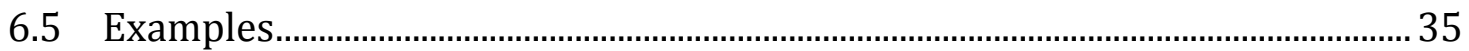

6.5.1 Program Focusing on an IT Consultant/Systems Analyst profile ............. 35

6.5.2 Program Focusing on the Project Manager profile......................................... 36

6.5.3 Program focusing on Analytics Specialist Profile........................................... 37

6.5.4 Program Focusing on Start-up Entrepreneur profile .................................... 38

6.6 Teaching and Learning Strategies for Building Competencies ........................... 40

6.7 Master's Thesis or a Research Project as Form of Pedagogy ............................... 41

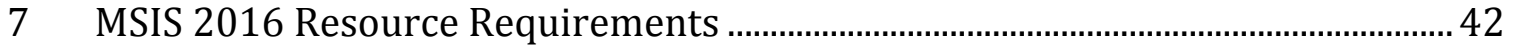

7.1 Faculty Expertise and Development...................................................................... 43

7.2 Internet and Library Resources................................................................................. 43

7.3 Computing Infrastructure and Laboratory Resources ........................................ 44

7.4 Pedagogical Support Resources............................................................................... 44

\section{Part D: Justification, History, and Current Status}

8 Why an MS in Information Systems? ........................................................................ 46

9 Expectations for an MS in Information Systems .................................................... 48

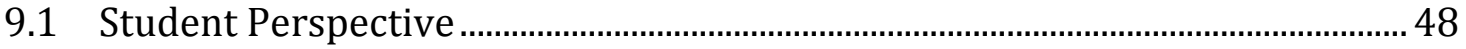

9.2 University, School, and Department Perspectives............................................... 49

9.3 Employer Perspective.......................................................................................... 49

9.4 Quality Control Perspective ............................................................................ 50

9.5 Societal Perspective _............................................................................................ 51

10 Uses of the MSIS 2016 Competency Model............................................................... 51

11 Information Systems Curriculum Guidance - History and Background............... 53 
12 Current Status - Review of Global IS Master's Degree Program Practices by Global Region.............................................................................................................. 54

12.1 Students Entering the Programs ……………………………………………… 54

12.2 Length of Program and Amount of Student Work.............................................. 55

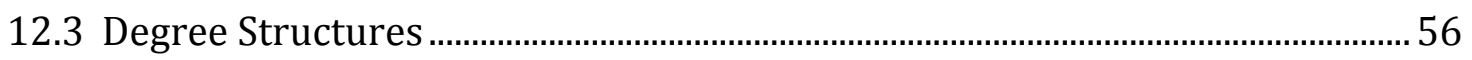

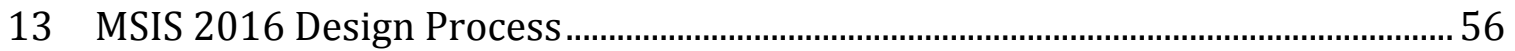

14 Key Differences between MSIS 2006 and MSIS 2016 ........................................... 58

14.1 Geographic Scope................................................................................................ 58

14.2 Broader Range of Domains of Practice ..................................................................59

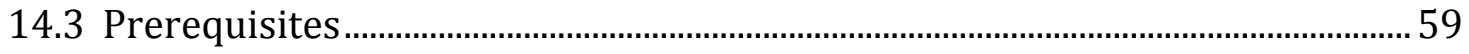

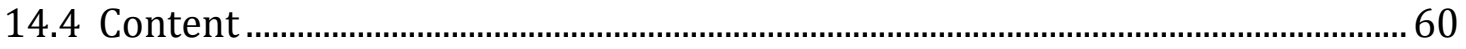

15 Maintaining the Currency of MSIS 2016 ……………….......................................... 60

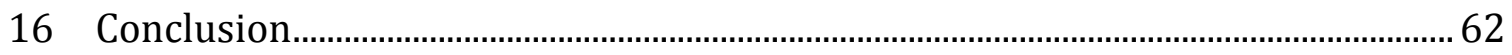

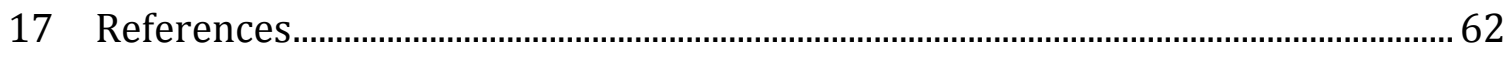

Appendix A: Detailed Competency Specification

Appendix B: Detailed Profile-Competency Models 


\section{Part A: MSIS 2016: Principles and Premises}

\section{Introduction}

MSIS 2016 is a competency specification for master's level degree programs in Information Systems (IS). It builds on the essential foundation of four earlier graduate IS model curricula (Ashenhurst 1972; Nunamaker, Couger, and Davis 1982; Gorgone et al. 2000; Gorgone et al. 2006). At the same time, it represents in several ways a departure from them. Instead of prescribing a curriculum course model, this document specifies a set of Master of Science in Information Systems (MSIS) graduate competency requirements. This recommendation is the result of the work by a global task force for the purposes of the global IS community, a clearly different approach compared to the North American focus of the earlier curricula.

Compared to earlier models, this recommendation offers a significantly stronger focus on three of the nine competency areas: Innovation, Organizational Change, and Entrepreneurship; Ethics, Impacts, and Sustainability; and Enterprise Architecture. The others include Business Continuity and Information Assurance; Data, Information, and Content Management; IS Management and Operations; IS Strategy and Governance; IT Infrastructure; and Systems Development and Deployment.

MSIS 2016 focuses on capabilities that enable graduates to contribute to positive transformation of various goal-oriented human activities through digitalization. This document explicitly recognizes that master's degree programs in IS can be offered in the context of multiple types of domains of practice (not only business).

Chapter 2 of this document provides an essential foundational conversation regarding the principles and assumptions that underlie the MSIS degree and the IS profession. Chapters 3, 4, and 5 form the core of the document, first describing the architecture of the competency model, then providing an overview of the graduate competencies, and finally specifying the expected graduate competencies at a detailed level. Chapter 6 offers guidance for developing a curriculum based on target competencies, and Chapter 7 discusses the resources that a high-quality MSIS program requires.

The remaining chapters discuss the justification, history, current status, and future of MSIS 2016. Chapter 8 presents a broad range of reasons why various stakeholders find an MS degree in IS useful, followed by Chapter 9, which describes the specific goals for the MSIS from the perspective of these same stakeholder groups. In Chapter 10, the document discusses a variety of uses for MSIS 2016. Chapter 11 presents a brief history of the earlier curriculum recommendations as background for this effort. Chapter 12 reviews the existing MSIS program practices globally by region. Next, in Chapter 13, the document describes the process through which this recommendation was created. Chapter 14 analyzes MSIS 2016 compared 
to MSIS 2006 and describes several major differences between the two documents. Chapter 15 describes the processes that will be needed to maintain the currency of MSIS 2016. Chapter 16 concludes the report.

\section{Principles and Premises Underlying the MSIS Degree and the IS Profession}

The MSIS 2016 competency model is based on the following premises regarding the MSIS degree:

1. MSIS is a professional practice master's degree that focuses on the development of specialized competencies in IS. In addition, an MSIS degree can provide a foundational preparation for academic research; the programs choosing this emphasis typically require a research thesis. An MSIS degree focuses on the development of competencies that are aligned with a specific domain of practice (such as business, health care, law, government, education, etc.).

\subsection{Degree Entry Conditions and Pre-Program Leveling Experiences}

2. An MSIS degree is based on a completed undergraduate degree that provides a foundation in the core IS competencies, as defined in IS 2010 (Topi et al. 2010). The length of the prior undergraduate degree in IS may vary depending on the national or regional educational system (for example, in many European countries an undergraduate degree can be a three-year degree, leading to a two-year master's, while in North America a typical undergraduate degree is a four-year degree). MSIS 2016 does not, however, require all the competencies developed by a typical undergraduate degree in IS as its entry requirements, just a subset of the core competencies as specified in Section 4.5.

3. It is possible for those without an undergraduate degree specified in \#2 above to enter an MSIS degree program. These students will, however, need additional preparation that provides the equivalent of an undergraduate preparation in the IS topics specified below. This preparation is often offered in the form of educational experiences that are called, for example, bridge modules ${ }^{5}$, foundations modules, or pre-program leveling courses. The topic areas of these modules (together with the references to IS 2010) are

a. Foundations of Information Systems (IS 2010.1);

b. Data and Information Management (IS 2010.2);

c. IT Infrastructure (IS 2010.5); and

d. Systems Analysis \& Design (IS 2010.6).

\footnotetext{
5 The word "module" is used throughout the document to denote various types of structured collections of learning experiences, such as courses, seminars, internships, theses, large-scale projects, etc.
} 
The competencies expected from these learning experiences are specified further in Chapter 5.

4. An MSIS degree requires foundational studies in its specified domain of practice as a program prerequisite or developing the same competencies through bridge modules.

The most common domain of practice is currently business, but the integration between technology understanding and domain expertise is useful and can be achieved in many other domains, too. Examples of such domains include government and public administration, non-governmental organizations and other non-profits, health care, education, law, services in general, and many fields of science.

Domains of practice are discussed in more detail in Chapter 5.

5. A student entering an MSIS degree program is required to have at least one university-level module in statistics or analytics.

6. An MSIS degree program has no expectations regarding prior professional experience. Therefore, no competency expectations for graduates can be built based on prior professional experience. It often is, however, valuable for students to have relevant professional experience as it could help overcome shortcomings in domain knowledge and/or an undergraduate degree (if, for example, the professional experience is in a computing field). It is possible and fully acceptable that individual schools or departments create MSIS programs targeted to experienced professionals that require a pre-specified level of professional experience.

\subsection{Key Degree Characteristics}

7. An MSIS degree provides competencies in three realms (see figure 1):

a. Information Systems, including both computing $6 /$ information technology (IT) and IS management dimensions

b. Domain of Practice (see discussion above in \#4)

c. Individual Foundational competencies (such as written and oral communication, critical thinking, ethical analysis, teamwork, leadership, etc.)

The competency category specifications for Information Systems and specifications for areas of individual foundational competencies are the essential elements of MSIS 2016. In addition, this document provides examples of competency area specifications for two domains of practice. These details are discussed in Chapter 5.

\footnotetext{
${ }^{6}$ We recognize that "computing" is used more frequently in North America than in other parts of the world. In Europe and in Asia, "ICT" or "informatics" would often be more familiar synonyms.
} 


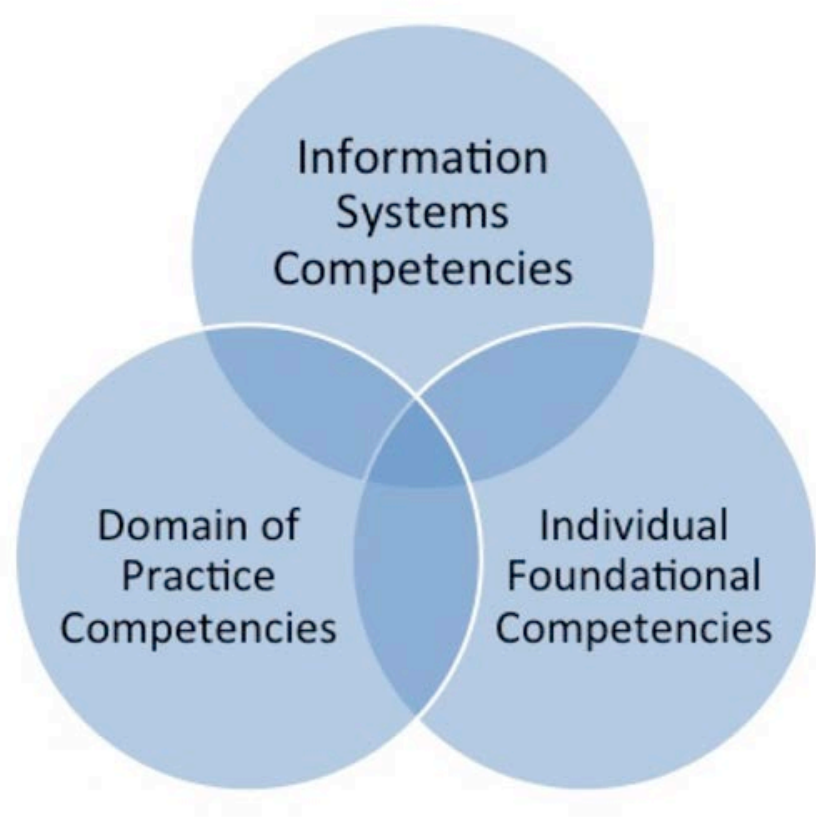

Figure 1. MSIS 2016 High-Level Realms

The emphasis on or balance of competencies within these realms varies depending on the program. All of them should, however, be included in every MSIS degree program.

8. Universities around the world are offering an increasing number of highly specialized master's degrees in IS, focusing on specific technical competency areas, such as analytics or security. Whether or not such degrees can be considered MSIS degrees depends on the relative proportion of specialized content to core competency areas. Any MSIS degree should support the development of competencies in all of the four areas discussed above. If the specialty dominates the degree so significantly that the core competency categories specified later in this document are not all covered at the minimum required level, the degree does not fit under the MSIS umbrella.

9. All MSIS degrees will share the same core competency areas, but program implementations will vary in terms of their emphasis on specific competency categories. The selection of categories emphasized by a specific program will depend on the target professional profiles (or personas). One possible source of such profiles is the latest version of the CEN Workshop Agreement on European ICT Professional Profiles (CEN 2012). The MSIS Task Force evaluated these profiles and agreed that they have broad global applicability. The task force selected six of the 23 ICT Professional Profiles as the primary MSIS target profiles: Business Information Manager, Project Manager, 
Business Analyst, Systems Analyst, Enterprise Architect, and IT Consultant ${ }^{7}$. For example, an MSIS program that primarily focuses on preparing its graduates for the integrated Systems Analyst/IT Consultant role will have a different target competency profile compared with the programs that focus on the Project Manager roles (these will be featured as examples in Chapter 6). We will also provide examples of two profiles outside the CWA model: one for a digital entrepreneur and another for an analytics professional.

The list specified above is not exclusive: it is perfectly reasonable for a university to offer a master's degree in IS that prepares its graduates for careers as CIOs or, by contrast, developers or database administrators. It is, however, likely that these types of programs will have additional background requirements, such as significant work experience as an IS manager for the CIO preparation or a much stronger technical preparation for developers or database administrators. These program types will still have to attain the core MSIS competencies at levels specified in Chapter 5.

10. MSIS 2016 uses four different levels to specify the extent to which a particular professional profile requires that a competency category be attained. These levels are called Awareness, Novice, Supporting [role], and Independent [contributor]. These levels are described in more detail in Chapter 3. An association between competency categories and corresponding competency attainment levels is called a competency profile.

\section{An MSIS degree consists of at least 30 semester hours (USA)/60 ECTS} credits (Europe) requiring at least 11 months of full-time study (or an equivalent amount of part-time work). Possible bridge modules in IS and/or the domain of practice should not be included in this total.

12. When evaluating the required competencies when a student graduates from an MSIS program, it is essential to take into account not only the MSIS program components, but also the graduate competencies attained before they enter the degree program. This sounds trivial but is easy to ignore in practice.

13. When determining the expected graduate competencies for an MSIS program, it will be useful to utilize professional competency models developed during the recent years by multiple regional or national governmental organizations (such as the European e-CF competence framework) or industry organizations (such as UK-based SFIA). The work of the task force has been inspired by key elements of these models. The underlying competency model is also aligned with the international TUNING

\footnotetext{
7 These profiles are described at http://relaunch.ecompetences.eu/wpcontent/uploads/2013/12/EU_ICT_Professional_Profiles_CWA_updated_by_e_CF_3.0.pdf.
} 
process and the primarily US-based Degree Qualifications Profile (DQP) model supported by the Lumina Foundation (Adelman et al. 2014).

\subsection{Post-Experience Degrees}

Many master's degree programs in IS require students to have experience as IS professionals before and/or during the graduate program and depend on this experience as an essential element of the program. These programs can be highly valuable and lead to excellent outcomes. Master's degree programs that are highly individualized, address just-in-time professional needs, and consist of components collected over a long period of time could become a very popular or even a dominant program model in the future. It would, however, be very difficult to build a curriculum or competency recommendation for these programs, given the significant differences between students' backgrounds and program expectations regarding these backgrounds. Programs targeted primarily to pre-experience students may, naturally, let a student with relevant professional experience adjust his/her curriculum so that it better fits the student's existing competencies. For example, an experienced network/systems administrator may have competencies that allow him/her to take an advanced elective instead of an intermediate course in IT infrastructure.

The IS community would likely benefit from a mechanism that allows IS professionals to acquire and collect educational experiences over their professional careers and build recognized credentials based on them. We do, however, recommend that this type of degree be built separately with an identity that is different from that of an MSIS (it could, for example, be an executive master's consisting of multiple certificates). This type of separation would likely benefit both the pre-experience MSIS and the post-experience degree. All of these are mechanisms through which IS professionals acquire new competencies or strengthen existing ones as part of their lifelong learning process. Offering them can, however, be an important part of a university's mission, but it is clearer if a separate degree type is specified for them.

In addition, we recognize the existence of MBA concentrations in IS as a separate entity from master's degrees in IS. An MBA is a generalist degree designed to focus primarily on the development of managerial capabilities, and an MBA concentration seldom provides the type of technical depth expected from a specialized master's in IS. 


\section{Part B: The MSIS 2016 Competency Model}

\section{Architecture of the MSIS 2016 Competency Model}

In this chapter, we will discuss the underlying conceptual structure of the MSIS 2016 competency model. In brief, the model is specified using graduate competencies as its foundational element, instead of courses/modules or knowledge areas, units, and topics.

Historically, most computing curriculum documents have been built around a typically hierarchical Knowledge Area-Knowledge Unit-Topic (KA/KU/Topic) structure that forms a Body of Knowledge (BoK). For example, the most recent Computer Science curriculum recommendation (CS2013) has 18 knowledge areas, each of which contain 5-12 knowledge units. Each knowledge unit, in turn, is divided into topics. For example, the Information Management knowledge area has 12 knowledge units, such as Relational Databases. This knowledge unit has 11 topics, which are very familiar to those who teach IS courses in this area, including mapping conceptual schema to relational schema, entity and referential integrity, etc.

A potential problem with the $\mathrm{KA} / \mathrm{KU} / \mathrm{Topic}$ structure is, however, that it focuses mostly on cognitive aspects of learning and leaves experiential elements out. A curriculum based on a knowledge area structure conveys relatively little on what the graduates are able to do at the time of graduation. Some observers might find this perfectly acceptable because they don't view applicable skills and attitudes as a goal of university education; for others, it is a major problem because they hold a broader view of the goals of a university degree.

Prior IS model curricula have always included some type of a representation of an IS BoK, but none of the IS curricula has been structured around the BoK structure in the same way as the other computing curricula are. Instead, the IS curricula have been represented mainly through courses (both core and elective/specialized) with learning objectives and topics, as specified in the right-side panel of figure 2. This approach has been used in IS 2002 (Gorgone et al. 2002), IS 2010 (Topi et al. 2010a), MSIS 2000 (Gorgone et al. 2000), and MSIS 2006 (Gorgone et al. 2006). The main challenge of this approach is that it typically presents a course-specific view without providing a detailed program-level representation of expected graduate capabilities. Some of these curricula-particularly IS 2010-dedicate significant attention to the specification of program-level graduate capabilities at a high level of abstraction, but even IS 2010 never maps the course level with the program level to analyze or demonstrate how the courses contribute to the way in which students achieve the program-level objectives. 


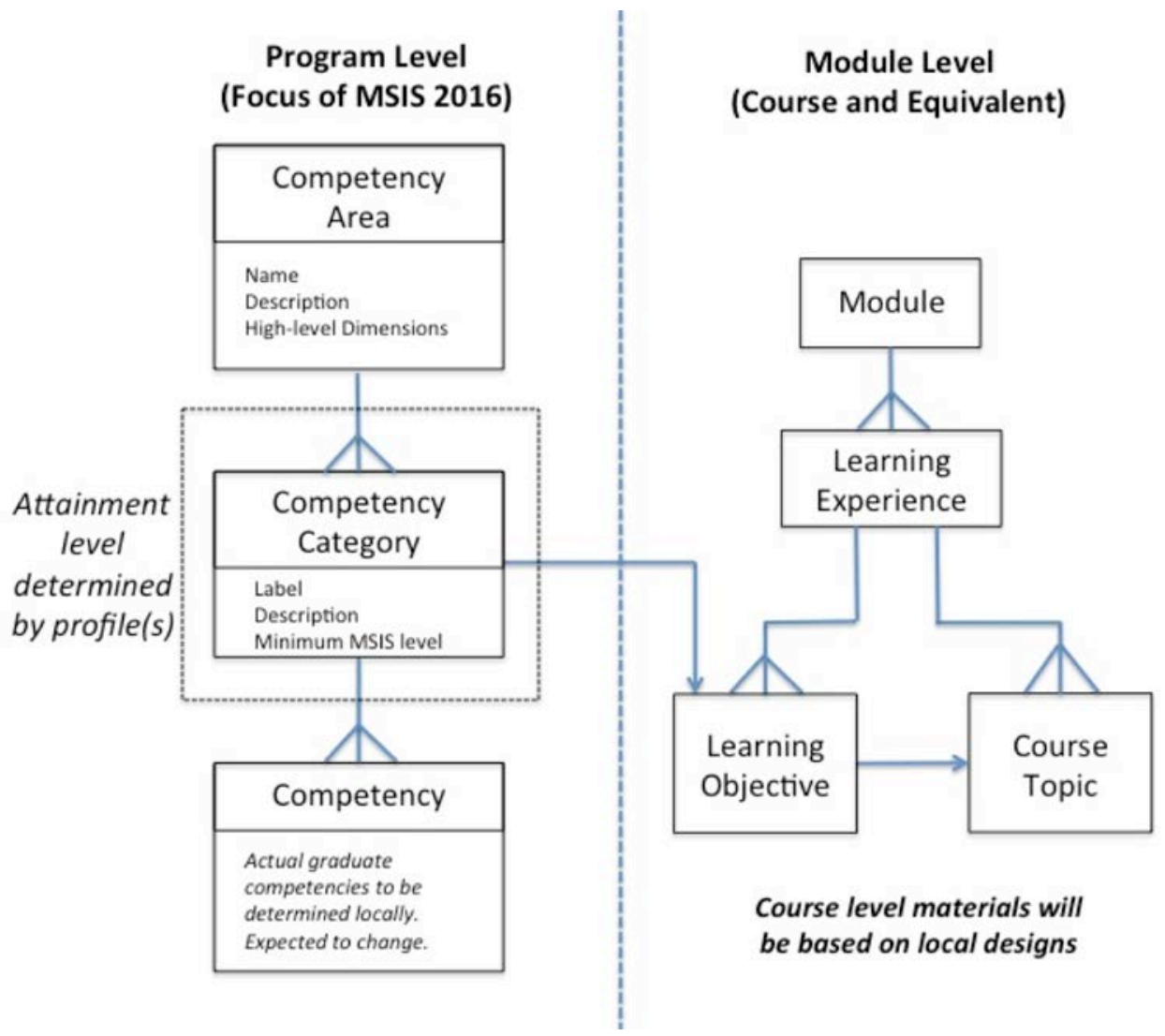

Figure 2. MSIS 2016 Program-Level Graduate Competencies vs. Module-Level Topics and Learning Objectives

From the beginning of the project, the MSIS 2016 task force has followed a third and increasingly commonly used model, illustrated on the left panel of figure 2. Instead of specifying a body of knowledge or a set of courses, this model identifies a set of graduate competencies. In this context, we use the term "competency" to refer to graduate ability to use knowledge, skills, and attitudes to perform specified tasks successfully. Using more refined language, Lockoff et al. $(2010,21)$ define competencies:

Competencies represent a dynamic combination of cognitive and metacognitive skills, demonstration of knowledge and understanding, interpersonal, intellectual and practical skills, and ethical values.

We are aware of the complex discussion associated with the term "competency" (see Hoffmann 1999 and Paquette 2007). In this context, it is not our intent to contribute to that conversation but to simply specify competency as an integrative concept that brings together graduate knowledge, skills, and attitudes.

The MSIS 2016 competency model specifies competency areas as the highest-level categorization of competencies. The areas are, in turn, divided into competency categories, and the actual competencies are specified under the categories. Competency areas and competency categories are much more stable and less technology-dependent than the competencies themselves. In addition, there will be 
much more local variation in the competencies than at the higher levels. Therefore, the competencies should be primarily seen as current examples.

Each competency area has a name, a brief (paragraph-long) description, and three to five high-level dimensions. Each category is specified with a name and a brief description, as is each competency within a category.

All programs will not, however, prepare students to attain competencies at the same level in all competency categories. Different professional profiles have different competency needs, and the professional profiles that a program desires its graduates to be able to achieve determine the level at which a program should enable its graduates to attain each of the competency categories.

MSIS 2016 specifies four different levels of competency category attainment: Awareness, Novice, Supporting [role], and Independent [contributor]. We define these levels as follows:

- At Awareness level, a graduate knows that the competency category exists and is aware of the reasons why it is important for the domain of practice and individual organizations that are using information systems to achieve their goals. Graduates at this level have not yet reached SFIA Level of responsibility 1 (SFIA 2016, 15-18).

- At Novice level, a graduate is able to effectively communicate regarding matters related to the competency, perform component activities under supervision, and develop on-the-job experience related to the competency. This level corresponds closely to SFIA Level of responsibility 1.

- At Supporting [role] level, a graduate has achieved a level of knowledge and skill that allows him/her to collaborate effectively in a supporting role with colleagues who have achieved a higher level of the competency to produce the desired outcomes. This level corresponds closely to SFIA Levels of responsibilities 2 and 3 .

- At Independent [contributor] level, a graduate has achieved a level of knowledge and skills that allows the graduate to perform without continuous support/supervision the tasks required to produce the desired competency outcomes. This level corresponds closely to SFIA Level of responsibility 4.

Higher levels of competencies do exist and could be considered (such as an expert level). A master's degree program alone cannot, however, bring a student to the highest levels of competency and thus are not included as targets for general MSIS programs. There are, of course, examples of master's programs for experienced professionals that are carefully designed to integrate academic content, pedagogy, and professional experience so that students can attain the highest levels of learning. This cannot, however, be used as a general requirement.

In their seminal book, Dreyfus and Dreyfus (1986; see also Dreyfus \& Dreyfus 2005) articulate a five-stage model of skill acquisition (novice, advanced beginner, competent, proficient, expert). Although the levels are not directly applicable to the development of professional competencies, there are at least two specific aspects of 
the Dreyfus \& Dreyfus model that are highly relevant: 1) It is not possible to develop human competencies beyond the novice level only based on abstract knowledge without a close association with a context. Developing situational awareness requires learning through experience. 2) Gaining the highest levels of skill achievement requires highly involved engagement in a variety of situations relevant to the skill of interest.

All MSIS 2016 degree programs are expected to enable their graduates to attain a total of 88 competency categories at least at the Awareness level, and for many categories, the required minimum level is higher. The minimum required MSIS 2016 achievement levels for each competency category are identified in Chapter 5.

\section{Overview of the MSIS 2016 Graduate Competencies}

\subsection{Big Picture}

Most importantly, the MSIS is a degree at the master's level and as such, MSIS graduates should exhibit general characteristics of master's program graduates, as specified in the Dublin Descriptors (Bologna Follow-up Group 2005):

- "have demonstrated knowledge and understanding that is founded upon and extends and/or enhances that typically associated with Bachelor's level, and that provides a basis or opportunity for originality in developing and/or applying ideas, often within a research context;

- can apply their knowledge and understanding, and problem-solving abilities in new or unfamiliar environments within broader (or multidisciplinary) contexts related to their field of study;

- have the ability to integrate knowledge and handle complexity, and formulate judgments with incomplete or limited information, but that include reflecting on social and ethical responsibilities linked to the application of their knowledge and judgments;

- can communicate their conclusions, and the knowledge and rationale underpinning these, to specialist and non-specialist audiences clearly and unambiguously; and

- have the learning skills to allow them to continue to study in a manner that may be largely self-directed or autonomous."

Overall, an MSIS program develops competencies within three realms: Information Systems Competencies, Individual Foundational Competencies, and Domain Competencies (see also figure 1 on page 4). Figure 3 presents an overview of the MSIS competency area structure. The rest of this section discusses its elements in more detail. 


\section{Specialized Competencies}

Specialized Competencies consist of additional Information Systems competencies that build on the core competencies and allow the graduates to perform more sophisticated tasks and act in more specialized professional roles.

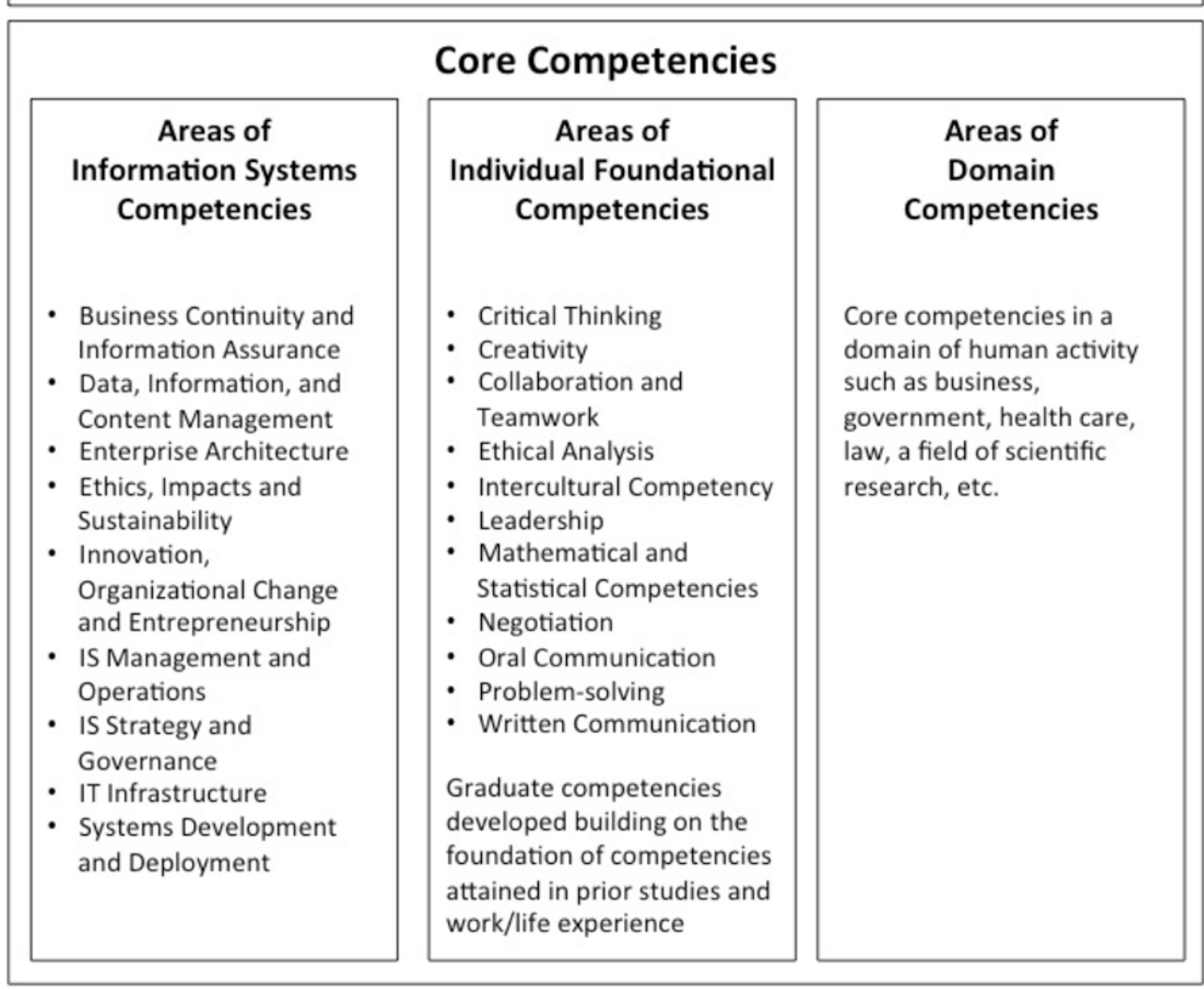

\section{Areas of Information Systems Competencies with Pre-Master's Elements}

- Data, Information and Content Management

- IS Management and Operations
- IT Infrastructure

- Systems Development and Deployment

- Role of Information Systems in Organizations (Foundational Understanding of IS)

Figure 3. MSIS 2016 Competency Structure

\subsection{Areas of Information Systems Competencies}

IS competencies (including both computing/IT and IS management dimensions) form the center of the MSIS competency specification: the competencies included in this element are distinctively our discipline's own competencies. Individual foundational competencies and domain competencies (see 4.3. and 4.4, 
respectively) are, in practice, shared as outcomes with many other program types. Most of this document will be dedicated to providing a more detailed review of the competency areas, categories, and sample competencies within the IS competencies element. The list of the competency areas is included in figure 3. These areas, categories, and competencies are specified at a significantly more detailed level in Section 5.1 and illustrated in figure 4 and table 1 in Chapter 5.

\subsection{Areas of Individual Foundational Competencies}

Individual foundational competencies are those competencies necessary for all knowledge professionals in a variety of professions, such as communication, collaboration, and problem-solving. They are specified only at the highest level of abstraction per area level. The specific areas of competencies chosen for MSIS 2016 are an extended version of the set articulated in IS 2010. This list has been modified by separating competencies that were presented together in IS 2010. The list of these competencies is included in figure 3 and specified in more detail in Section 5.2.

\subsection{Areas of Domain Competencies}

The MSIS is a professional practice master's degree that always integrates Information Systems with a specific domain of practice (such as business, health care, legal environment, government, $\mathrm{K}-12$ education, higher education, etc.). MSIS 2016 will not articulate a set of detailed competencies for any single domain of practice to avoid the impression of giving one domain a priority status, but it will provide examples of competency areas for two domains in Section 5.3.

\subsection{Areas of Prerequisite Competencies with Pre-Master's Elements}

Most computing curricula are targeted to the undergraduate level, so the entering student's qualifications for these curricula are typically defined as a secondary education (e.g., high school) degree. As a master's degree, MSIS has to consider additional dimensions of the incoming student background. The first requirement for incoming MSIS students is an earned bachelor's degree. In most contexts, a bachelor's degree requires about 120 semester credit hours or 180-240 ECTS credits (3-4 years of full-time work). This is, however, just a basic technical requirement.

In addition, for an MSIS degree to achieve its objectives regarding graduate competencies, it is important that incoming students have already acquired a certain set of prerequisite competencies related to IS. In earlier versions of the MSIS curriculum, these have been specified as prerequisite courses. In MSIS 2006, these courses included IS Fundamentals and Programming, Data, Files, and Object Structures (both specified as IS 2002 courses).

In MSIS 2016, the task force has moved to a model that specifies a set of prerequisite competencies. A necessary but not sufficient prerequisite is foundational understanding of IS - that is, understanding the role of information systems in organizations. We recommend a literature-based examination or a bridge course to ensure sufficient coverage of basic understanding that IS constitutes not only 
technologies and software, but also a whole system with users and their activities. The theoretical approach to cover is the general systems theory (e.g., Bertalanffy 1968), because it helps to structure the area and is a vital tool in problem-solving activities in complex environments. Systems theory is also a helpful viewpoint into the complexities in all competency areas. Many of the prerequisite competencies are within the same competency areas that include competencies specified for MSIS graduates but to be gained at an earlier stage. Specifically, the prerequisite competencies are included in the Data, Information, and Content Management; IT Infrastructure; and Systems Development and Deployment areas (figure 3; see also Chapter 5 for details).

As for the individual foundational competencies, MSIS 2016 does not make specific assumptions regarding the competencies that incoming students have. It does, however, assume that the undergraduate/first cycle degree requirement has given students competencies in oral communication, written communication, leadership and collaboration, negotiation, analytical and critical thinking, creativity, ethical analysis, and problem-solving (as specified, for example, in IS 2010). As a master's degree, MSIS 2016 will be building on these competencies, strengthening and bringing them to a level compatible with master's level expectations.

Please note that MSIS 2016 will not take a position regarding the preferred way in which the prerequisite competencies should be acquired. Clearly one way to get them is to have an undergraduate degree in IS or in a related applied computing discipline. It is also possible that an incoming student has acquired the required competencies through work experience (which, of course, needs to be verified with appropriate testing). Finally, the prerequisite competencies can be achieved by taking bridge modules before the actual graduate program starts. Whichever mechanism is used, it is essential that the competencies are attained in a way that allows the student to fully use the prerequisite competencies as part of the master's level study process-the master's program should be built on the assumption that all students have the prerequisite competencies and are able to use them.

\subsection{Specialized Competencies}

As indicated in figure 3, specialized competencies consist of additional IS competencies that build on the program's chosen core competencies and allow the graduates to perform more sophisticated tasks and act in more specialized professional roles. Specialized competencies may also create differentiation between career tracks, in addition to the differences specified with the secondary core competencies. The specialized competencies enable MSIS graduates to serve in roles that require competencies in a specific area of technical expert knowledge, such as security or analytics. Not all specialized master's degrees leading to specialized IS competencies are MSIS degrees-an MSIS requires that in addition to the specialized competencies, the program enables its graduates to attain all core competencies at the minimum at a level specified in table 1 below (in Section 5.1.2). 


\subsection{Impact of Professional Profiles on Competency Categories}

This recommendation recognizes that there are significant differences between MSIS programs. One of the most important dimensions is related to the expected professional profiles of the graduates. It is unlikely that any MSIS program would only prepare its graduates for one specific profile, but target profiles vary and the chosen profile(s) have an impact on the expected graduate competencies and through these, the curriculum.

CEN (2012) includes detailed descriptions of the six professional profiles that have been chosen as the most likely targets for MSIS programs: Business Analyst, Business Information Manager, Enterprise Architect, IT Consultant, (IT) Project Manager, and Systems Analyst. It is clear that the specific definitions of these profiles vary depending on the regional, national, and local requirements, but it is likely that the general characteristics of each profile are close to each other regardless of the location.

As mentioned above, all 88 competency categories belong to the core of the MSIS because all MSIS programs should enable their graduates to attain them at least at the Awareness level (see Chapter 3 for the definition of the levels). In addition, this recommendation specifies for each of the competency categories the minimum level that all graduates should attain. For 22 competency categories, the minimum level has been specified as Awareness, for 46 categories as Novice, and for 20 categories as Supporting. No minimum levels have been specified as Independent. We recognize that many programs prepare their graduates to achieve this level with some or even many competencies, but this document recognizes that particularly with programs targeted to students with little or no work experience this level is very difficult to achieve.

Section 5.1 below specifies the competency categories (and within each, a set of competencies that should be viewed as examples) and for each of the categories the minimum level at which each MSIS degree program need to enable the attainment of this competency category.

\section{MSIS 2016 Competency Specifications}

This section will provide additional contextual information for the nine competency areas within IS competencies (overview in figure 4; details in Section 5.1), 11 areas of individual foundational competencies (Section 5.2), and competency area examples for two domains of practice (Section 5.3).

\subsection{Specifications of Competency Areas, Competency Categories, and Competencies for Information Systems}

The task force has benefited significantly from the following sources when developing the competency structure outlined in this section: 


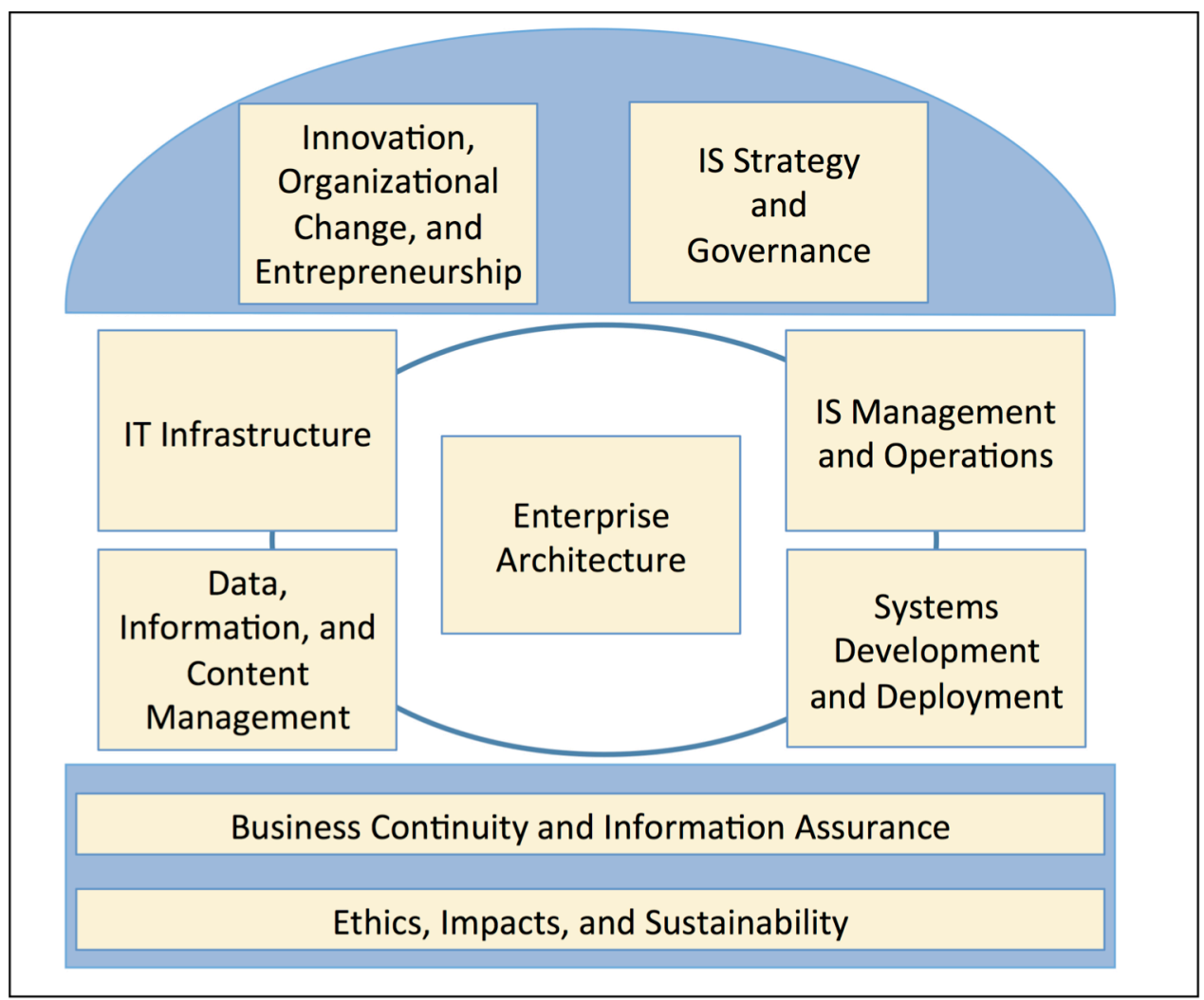

Figure 4. MSIS 2016 Areas of Information Systems Competencies

- The European e-Competence Framework (e-CF) 3.0: a Common European Framework for ICT Professionals in All Industry Sectors (www.ecompetences.eu)

- The Skills Framework for the Information Age (SFIA) (www.sfiaonline.org/en)

- O*NET (Occupational Information Network) (www.onetonline.org)

- 2012 Clinger-Cohen Core Competencies \& Learning Objectives (https://cio.gov/wp-content/uploads/downloads/2013/02/2012-LearningObjectives-Final.pdf)

The task force gratefully acknowledges the significant impact of all these outstanding specifications of IT professional competencies on the process of MSIS 2016 competency development. In addition to these specifications, the task force utilized primary data collected from MSIS program directors, current students, alumni, and corporate stakeholders regarding graduate competency priorities.

Material from all these sources was integrated in a multi-staged grouping process that took place at the competency category level: the categories were first grouped into competency areas, and then individual competencies were articulated for each 
of the competency categories. As discussed above, the individual competencies are less stable than the areas and categories, and they are not intended to be exhaustive.

The competency areas are summarized in figure 4 and documented in this section with two tables and a narrative description of the areas. First, we present a narrative description of the areas and high-level dimensions of the areas. After that, table 1 includes a summary of the competency areas and categories and provides a convenient overview of the IS competencies. Finally, the detailed competency examples are included in Appendix A of this recommendation.

\subsubsection{Competency Area Specifications}

\section{Competencies in the area of Business ${ }^{8}$ Continuity and Information Assurance (BCIA)}

Area Description: Business Continuity and Information Assurance competency area mainly concerns the continuity, auditing, and assurance of information systems. It generally covers areas such as risk avoidance and security management as well as quality auditing. The challenging issues related to business continuity and information assurance span from tactical and strategic to technical and operational levels. They often involve a range of processes from management, such as policy and standard setting, to hands-on skills, such as system contingency and recovery planning.

High-level area dimensions: The graduates will be able to

1. Create policies and standards for business continuity and information assurance.

2. Plan and implement procedures, operations, and technologies for managing risk and trust, security, and safety as well as business continuity and disaster recovery.

3. Monitor, control, and institutionalize the protection and growth of the hardware, software, and information assets within information systems.

\section{Competencies in the area of Data, Information, and Content Management (DATA)}

Area Description: Data, Information, and Content Management area covers competencies that enable the graduates to be effective contributors in processes that improve the domain's ability to achieve its goals using structured and unstructured data and information effectively.

High-level area dimensions: The graduates will be able to

1. Identify data and information management technology alternatives, select the most appropriate options based on the organizational information needs, and manage the implementation of the selected options.

\footnotetext{
${ }^{8}$ We use the term Business Continuity here because of its longstanding use to refer to the continuity of all types of domain activities.
} 
2. Identify, create, and manage organizational policies and processes related to data and information management by balancing multidimensional requirements, such as legal and regulatory requirements, ethical considerations and implications of technology decisions, organizational business requirements, data quality issues, and requirements of operating in an international environment.

3. Analyze the needs of a domain and determine how those needs can be best addressed with data, information, and content management solutions.

\section{Competencies in the area of Enterprise Architecture (EARC)}

Area Description: Enterprise architecture has two aims: managing the complexity of information systems and technologies and aligning these with the organization's strategy. The area covers competences that enable graduates to participate in planning, building, using, maintaining, and evaluating architectures.

High-level area dimensions: The graduates will be able to

1. Design an enterprise architecture (EA). This involves identifying and applying a formal approach to EA development, performing the multistage process of developing an EA, identifying the EA change needs, and applying them to the EA. Graduates are able to incorporate information, domain activity processes, technology platforms, applications, software, and hardware in the EA while considering the alignment between domain requirements and technology development.

2. Deploy and maintain an EA. This involves conveying the architecture to domain process owners, software development and maintenance projects, and infrastructure planners and taking into account the current status of the projects and infrastructure. This also includes gathering input from the enterprise and from technology developments for maintaining the architecture and performing architecture maintenance.

\section{Competencies in the area of Ethics, Impacts and Sustainability (ETIS)}

Area Description: The ethics and impacts competency area covers the conceptualization and implementation of environmentally and socially sustainable IT solutions that are aligned with the responsibilities of organizations as well as in compliance with legislative and regulatory requirements and industry standards. This competency area addresses key questions such as environmental and social sustainability, safety and health, privacy and integrity. It also covers the impact of IT on the nature of work and workplaces and explores how culture and ethics (internal pertaining to organizations and external pertaining to stakeholders) shape behavior. These areas tend to be aligned with a strategic or a tactical level of organizational decision-making.

High-level area dimensions: The graduates will be able to 
1. Apply sustainable approaches for IT solutions development, IT procurement, IT operations, IT resources management, and other IT practices.

2. Ensure safety and avoid health hazards for contract arrangements with external parties and internal systems development, maintenance, and reuse.

3. Ensure that privacy and integrity guide all IT practices.

4. Interpret and comply with legislative and regulatory requirements governing IT practices as well as industry standards for IT practices. Understand how culture and ethics shape compliance behavior.

\section{Competencies in the area of Innovation, Organizational Change, and Entrepreneurship (IOCE)}

Area Description: Innovation, organizational change, and entrepreneurship are concerned with the capability to recognize and exploit the potential afforded by current and upcoming technologies to address existing and new business opportunities. It also includes competencies required to understand and to intervene in different forms of domain activities (e.g., work units, work teams, processes, organizations, markets, society setting) in order to make use of information technologies to improve the way those business activities are structured and are performed.

High-level area dimensions: The graduates will be able to

1. Monitor the environment in order to identify and evaluate new IS methods and trends in terms of their appropriateness for an organization.

2. Develop innovative domain activity models relying on new uses of existing technology or new technologies themselves.

3. Develop a plan to exploit new and emerging methods and technologies for new purposes in an organization.

4. Devise new ways of structuring and performing domain activities at different levels (individual, team, process, and organization), taking into consideration the enabling and enhancing effects of information technology applications.

5. Estimate the benefits of the new designs, assess the consequences of their implementation, and anticipate potential adverse consequences.

\section{Competencies in the area of IS Management and Operations (ISMO)}

Area Description: IS Management and Operations are concerned with the capability to develop, maintain, and consistently improve domain performance while providing appropriate information systems, services, and infrastructure. The capability focuses externally on creating value for the domain and internally on IS staff motivation, performance, and accountability.

High-level area dimensions: The graduates will be able to

1. Apply professional management skills to design and manage an effective IS organization.

2. Ensure operational efficiency and effectiveness in service delivery. 
3. Govern IS project management principles and support their use in the organization.

4. Manage information systems use.

5. Manage information resources together with line management.

\section{Competencies in the area of IS Strategy and Governance (ISSG)}

Area Description: IS strategy is concerned with the creation and implementation of long-term plans for designing, delivering, and using organizational information systems to achieve strategic domain goals and objectives. IS governance is concerned with monitoring and controlling organizational IS resources to ensure alignment with and achievement of strategies, goals, and objectives.

High-level area dimensions: The graduates will be able to

1. Analyze the effect and impact of IS on industries, firms, and institutions; develop and implement plans of action for maximizing firm benefits associated with IS design, delivery, and use; and manage IS resources financially.

2. Create and manage the oversight mechanisms by which an organization evaluates, directs, and monitors organizational IT. These mechanisms may leverage one or more governance frameworks; hence, understanding the process of applying and analyzing a framework is a critical competency. Distribution of decision rights and organizational decision-making practices are other key components of this competency area.

3. Establish practices for minimizing environmental impacts and planning for long-term firm viability.

\section{Competencies in the area of IT Infrastructure (INFR)}

Area Description: The IT Infrastructure area covers competencies that allow graduates to contribute to needs analysis for and design and implementation of effective, technically correct IT infrastructure solutions.

High-level area dimensions: The graduates will be able to

1. Design integrated communication networks for small- and medium-size organizations, including local area networks and the use of wide-area network technologies to connect the local networks.

2. Specify requirements for large-scale network solutions.

3. Design an implementation architecture for organizational data processing and system solutions, using both internal hardware resources and external service solutions.

4. Negotiate and enforce contracts with providers of IT infrastructure services.

\section{Competencies in the area of Systems Development and Deployment (SDAD)}

Area Description: Systems Development and Deployment encompasses the design of information systems and services, including the design of how humans interact with 
and how they experience IT artifacts. It also includes competencies related to systems implementation and the deployment of systems to organizational use.

High-level area dimensions: The graduates will be able to

1. Analyze and specify requirements for IT artifacts through study and documentation of the whole or of part of some form of domain activities (e.g., work unit, work team, process, organization, market, society setting) in terms of the actions they involve and the information they deal with. Define requirements for IT artifacts that are capable of enhancing the way existing domain activities are structured and performed or enabling new forms of domain activities

2. Design and document IT artifacts that meet specified requirements taking into account non-functional requirements (including user experience design) and organizational, technical, infrastructural, and other constraints.

3. In the context of iterative processes that integrate analysis, design, implementation, and operations, develop and deploy IT applications that satisfy user needs.

\subsubsection{Competency Categories}

Table 1 below provides a more detailed description of the competency areas specified above in Section 5.1.1 by listing the competency categories for each of the areas and specifying the minimum required level of attainment for each of the categories.

As mentioned earlier, Appendix A provides further details by providing 4-6 specific competency examples for each of the competency categories. 
Table 1. MSIS 2016 Global Competency Model

for Graduate Degree Programs in Information Systems
Minimum required level

Awareness

Novice

Supporting

Independent

\section{Competencies in the area of Business Continuity and Information Assurance}

(BCIA)

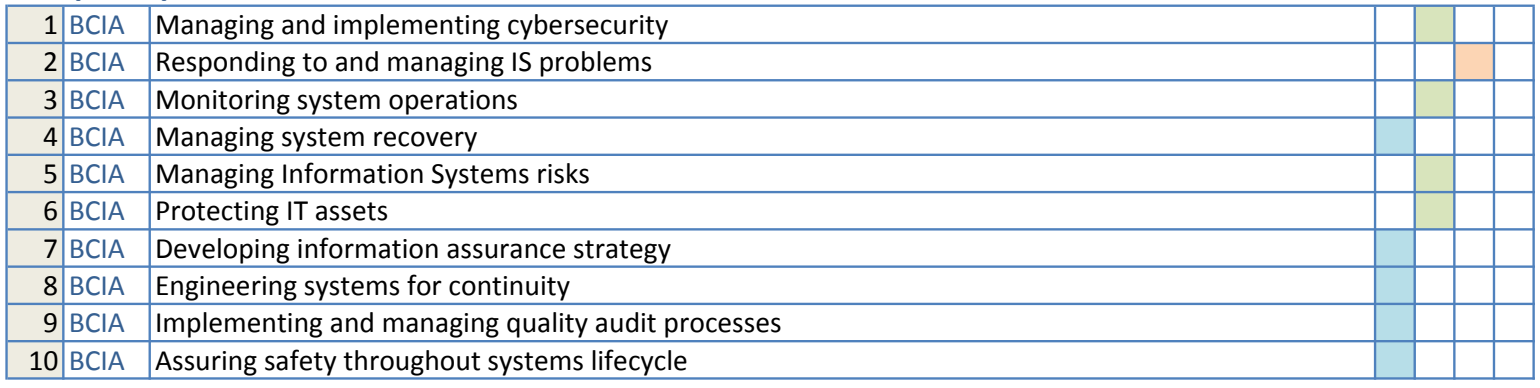

\section{Competencies in the area of Data, Information and Content Management}

\section{(DATA)}

11 DATA $\mid$ Explaining key data and information concepts and the data and information management lifecycle

12 DATA Capturing and structuring data and information requirements using appropriate conceptual

modeling techniques

13 DATA Developing a logical level representation of data based on a conceptual model

14 DATA Implementing a database solution to serve systems consisting of multiple applications

15 DATA Using a contemporary data manipulation and retrieval language effectively

16 DATA Selecting appropriate data management technologies based on the needs of the domain

17 DATA Securing domain data and protecting user privacy and organizational intellectual property using

18 DATA Designing and implementing a data warehouse using a contemporary architectural solution

19 DATA Creating a scalable infrastructure for large amounts of data using parallel and distributed technologies

20 DATA Developing and implementing organizational information management policies and processes

21 DATA Creating an information architecture for an organization

22 DATA Integrating and preparing data captured from various sources for analytical use

23 DATA Selecting and using appropriate analytics methods

24 DATA Analyzing data using advanced contemporary methods

25 DATA Designing and implementing architectures for organizational content management systems

\section{Competencies in the area of Enterprise Architecture (EARC)}

26 EARC $\quad$ Explaining enterprise architecture principles to justify the value EA provides to organizations within various types of domains

27 EARC Designing, building and maintaining an enterprise architecture

28 EARC Communicating and deploying an enterprise architecture

29 EARC Using an enterprise architecture to influence IS related organizational improvement projects

Competencies in the area of Ethics, Impacts and Sustainability (ETIS)

\begin{tabular}{|l|l|l|l|l|}
30 & ETIS & Designing and managing sustainable IT operations & & \\
\hline 31 & ETIS & Aligning IT with organizational sustainability policy & & \\
\hline 32 & ETIS & Managing IT facilities sustainably & & \\
\hline 34 & ETIS & Managing sustainable procurement practices & & \\
\hline 35 & ETIS & Maintaining compliance with legislation, regulations, and standards & & \\
\hline 37 & ETIS & Ensuring that protection of privacy and integrity guides all IS practices & & \\
\hline 38 & ETIS & Considering ethical implications of IS decisions & & \\
\hline
\end{tabular}

Competencies in the area of Innovation, Organizational Change, and

Entrepreneurship (IOCE)

39 IOCE Monitoring the technology environment

40 IOCE Engaging in entrepreneurial thinking 


\begin{tabular}{|r|l|l|l|l|l|}
\hline 41 & IOCE & Developing a business plan & & \\
\hline 42 & IOCE & Innovating by exploiting an emerging method or technology & & & \\
\hline 43 & IOCE & Promoting diffusion by leveraging differences between adopter groups & & \\
\hline 44 & IOCE & Applying creative problem solving to technology-related issues & & & \\
\hline 45 & IOCE & Contributing to organizational development and change management & & & \\
\hline 46 & IOCE & Analyzing and documenting business activities & & \\
\hline 47 & IOCE & Identifying opportunities for and designing process improvement & & & \\
\hline
\end{tabular}

\section{Competencies in the area of IS Management and Operations (ISMO)}

\begin{tabular}{|r|l|l|l|l|}
\hline 48 & ISMO & Applying broadly used Project Management tools and techniques & & \\
\hline 49 & ISMO & Managing the IS function & & \\
\hline 50 & ISMO & Managing IS staff & & \\
\hline 51 & ISMO & Managing IS service production & & \\
\hline 52 & ISMO & Managing IS sourcing models & & \\
\hline 53 & ISMO & Managing and coordinating information resources & & \\
\hline 54 & ISMO & $\begin{array}{l}\text { Implementing relevant IT governance frameworks within the organization based on strategic } \\
\text { guidance }\end{array}$ & & \\
\hline 55 & ISMO & Complying with laws and regulations directly affecting IS management and operations & & \\
\hline 56 & ISMO & Managing IS projects and programs & & \\
\hline 57 & ISMO & Managing IS project portfolios & & \\
\hline 58 & ISMO & Managing software and hardware development and maintenance & & \\
\hline
\end{tabular}

\section{Competencies in the area of IS Strategy and Governance (ISSG)}

\begin{tabular}{|l|l|l|l|l|l|}
59 & ISSG & Conducting IS strategic analysis & & \\
\hline 60 & ISSG & Making a financial case for IS & & & \\
\hline 61 & ISSG & Managing IS/IT sourcing strategies & & \\
\hline 62 & ISSG & Engaging in IS strategic planning & & & \\
\hline 63 & ISSG & Planning for and implementing IS governance & & \\
\hline 64 & ISSG & Planning for and improving sustainability & & \\
\hline
\end{tabular}

\section{Competencies in the area of IT Infrastructure (INFR)}

65 INFR Designing data communication networks and data center and server solutions

66 INFR Selecting appropriate client devices to support the needs of an application area

67 INFR $\quad$ Securing IT infrastructures

68 INFR Specifying and monitoring infrastructure contracts

69 INFR Negotiating contracts and managing infrastructure vendors

70 INFR $\quad$ Responding to Requests for Proposals (RFPs) for infrastructure solutions

71 INFR Managing infrastructure risks

72 INFR Optimizing infrastructure utilization

73 INFR $\quad$ Designing infrastructure solutions using external service provider(s) (cloud computing)

74 INFR Maintaining a set of standards and policies and understand the key laws and regulations to relevant infrastructure decisions

Competencies in the area of Systems Development and Deployment (SDAD)

\begin{tabular}{|l|l|l|l|l|l|}
\hline 75 & SDAD & Monitoring emerging technologies to understand their potential to support the domain & & \\
\hline 76 & SDAD & Documenting existing systems & & \\
\hline 78 & SDAD & Specifying and documenting systems requirements & & & \\
\hline 79 & SDAD & Iesigning systems and services & & & \\
\hline 80 & SDAD & Designing user experiences & & & \\
\hline 81 & SDAD & Implementing a systems solution using a modern programming language & & & \\
\hline 82 & SDAD & Selecting between systems development approaches & & \\
\hline 83 & SDAD & Managing plan-based, hybrid, and agile development processes & & \\
\hline 84 & SDAD & Implementing and testing an application & & \\
\hline 85 & SDAD & Installing and integrating a new application & & \\
\hline 86 & SDAD & Managing external systems development resources & & \\
\hline 87 & SDAD & Managing IS development projects & & \\
\hline 88 & SDAD & Deploying a new system to organizational use & & \\
\hline
\end{tabular}




\subsection{Specifications of Areas of Individual Foundational Competencies}

In this section, we outline a list of individual foundational competency areas that are essential for MSIS 2016 graduates. These competency areas are presented in table 2.

Table 2. Areas of Individual Foundational Competencies

\begin{tabular}{|l|l|}
\hline Critical thinking & $\begin{array}{l}\text { A definition that captures well the meaning of this } \\
\text { competency area in the MSIS 2016 context is the } \\
\text { following critical thinking definition by Halpern } \\
\text { evaluate new methods for } \\
\text { network security } \\
\text { cognitive skills or strategies that increase the } \\
\text { probability of a desirable outcome. It is used to } \\
\text { describe thinking that is purposeful, reasoned, and } \\
\text { goal directed-the kind of thinking involved in } \\
\text { solving problems, formulating inferences, } \\
\text { calculating likelihoods, and making decisions, when } \\
\text { the thinker is using skills that are thoughtful and } \\
\text { effective for the particular context and type of } \\
\text { thinking task." }\end{array}$ \\
\hline $\begin{array}{l}\text { Creativity } \\
\begin{array}{l}\text { Example in IS: devise a new } \\
\text { business model based on a } \\
\text { new or emerging technology }\end{array}\end{array}$ & $\begin{array}{l}\text { We adopt a simple but effective definition of } \\
\text { creativity for MSIS 2016 from Amabile et al. (1996, } \\
\text { 1155): "Creativity is the production of novel and } \\
\text { useful ideas in any domain." }\end{array}$ \\
\hline $\begin{array}{l}\text { Collaboration and } \\
\text { teamwork }\end{array}$ & $\begin{array}{l}\text { Our definition for collaboration is based on Stevens } \\
\text { and Campion (1994), who identified the following } \\
\text { five competency requirements for teamwork: } \\
\text { conflict resolution, collaborative problem-solving, } \\
\text { effectively in the work of a }\end{array}$ \\
$\begin{array}{l}\text { globally distributed software } \\
\text { development team }\end{array}$ & management, and planning and task coordination. \\
\hline $\begin{array}{l}\text { Ethical analysis } \\
\text { Example in IS: determine } \\
\text { whether or not a new data- } \\
\text { driven business process is } \\
\text { using customer data in an } \\
\text { ethically sustainable way }\end{array}$ & $\begin{array}{l}\text { Building on Connock and Johns (1995) and Orme } \\
\text { and Ashton (2003), we define ethical analysis } \\
\text { competency in an organizational context: ethical } \\
\text { analysis focuses on determining what is right and } \\
\text { what is wrong, and it is "about defining the practices } \\
\text { and rules that underpin responsible conduct } \\
\text { between individuals and groups" (Connock and } \\
\text { Johns 1995). Ethical competency requires "taking } \\
\text { action to ensure that these practices and rules are } \\
\text { applied consistently in all day-to-day business }\end{array}$ \\
\hline
\end{tabular}




\begin{tabular}{|c|c|}
\hline & situations" (Orme and Ashton 2003, 185). \\
\hline $\begin{array}{l}\text { Intercultural competency } \\
\text { Example in IS: negotiate a } \\
\text { contract with an outsourcing } \\
\text { partner in another country }\end{array}$ & $\begin{array}{l}\text { Our definition here is from Deardorff (2006): } \\
\text { "Intercultural competency is the ability to develop } \\
\text { targeted knowledge, skills, and attitudes that lead to } \\
\text { visible behavior and communication that are both } \\
\text { effective and appropriate in intercultural } \\
\text { interactions." }\end{array}$ \\
\hline $\begin{array}{l}\text { Leadership } \\
\text { Example in IS: lead an IS unit } \\
\text { through a transition from a } \\
\text { plan-driven development } \\
\text { approach to a hybrid } \\
\text { approach }\end{array}$ & $\begin{array}{l}\text { An old definition by Stogdill (1950) is still useful: } \\
\text { Leadership is "the process (act) of influencing the } \\
\text { activities of an organized group in its efforts toward } \\
\text { goal setting and goal achievement." Yoon et al. } \\
\text { (2010) divide leadership competencies into four } \\
\text { broad categories: supervisory/managerial, } \\
\text { organizational leadership, personal mastery, and } \\
\text { resource leadership. }\end{array}$ \\
\hline $\begin{array}{l}\text { Mathematical and } \\
\text { statistical competencies } \\
\text { Example in IS: devise a } \\
\text { method for integrated } \\
\text { analysis of heterogeneous } \\
\text { data }\end{array}$ & $\begin{array}{l}\text { For MSIS graduates, the most important } \\
\text { mathematical competency is the ability to choose } \\
\text { and apply appropriate mathematical and statistical } \\
\text { models and techniques to solve a broad range of } \\
\text { problems within the domain of practice. }\end{array}$ \\
\hline $\begin{array}{l}\text { Negotiation } \\
\text { Example in IS: negotiate a } \\
\text { contract for a cloud service } \\
\text { with a specific SLA }\end{array}$ & $\begin{array}{l}\text { Pruitt (1981) defines negotiation as "a form of } \\
\text { decision making in which two or more parties talk } \\
\text { with one another in an effort to resolve their } \\
\text { opposing interests." (xi). Armstrong }(2006,803-4) \\
\text { divides negotiation skills into five categories: } \\
\text { analytical ability, empathy, planning ability, } \\
\text { interactive skills, and communicating skills. }\end{array}$ \\
\hline $\begin{array}{l}\text { Oral communication } \\
\text { Example in IS: discuss a } \\
\text { requirement specification } \\
\text { document or a user story with } \\
\text { a user }\end{array}$ & $\begin{array}{l}\text { Based on Dublin Descriptors (Bologna Follow-up } \\
\text { Group 2005), we define oral communication } \\
\text { competency as "a student can orally communicate } \\
\text { their conclusions, and the knowledge and rationale } \\
\text { underpinning these, to specialist and non-specialist } \\
\text { audiences clearly and unambiguously." }\end{array}$ \\
\hline $\begin{array}{l}\text { Problem-solving } \\
\text { Example in IS: identify the } \\
\text { problems in the user } \\
\text { experience of a service and } \\
\text { solve them }\end{array}$ & $\begin{array}{l}\text { Jonassen }(2000,65) \text { borrows Anderson's }(1980, \\
257) \text { definition of problem-solving as "any goal- } \\
\text { directed sequence of cognitive operations," and } \\
\text { specifies two attributes for these operations: need } \\
\text { for a mental representation of the problem space } \\
\text { and activity-based manipulation of the problem } \\
\text { space. The challenge with any definition of problem- } \\
\text { solving as a competency is, of course, that the }\end{array}$ \\
\hline
\end{tabular}




\begin{tabular}{|l|l|}
\hline & $\begin{array}{l}\text { number of categories of problem-solving is very } \\
\text { broad, each of which has its own requirements. } \\
\text { Jonassen's article provides a good starting point for } \\
\text { a metatheory of problem-solving and an integrative } \\
\text { summary of the component competencies required } \\
\text { for problem-solving. }\end{array}$ \\
\hline $\begin{array}{l}\text { Written communication } \\
\text { Example in IS: write a } \\
\text { investors for a start-up }\end{array}$ & $\begin{array}{l}\text { Based on Dublin Descriptors, we define written } \\
\text { communication competency as "a student can in } \\
\text { writing communicate their conclusions, and the } \\
\text { knowledge and rationale underpinning these, to } \\
\text { specialist and non-specialist audiences clearly and } \\
\text { unambiguously." }\end{array}$ \\
\hline
\end{tabular}

\subsection{Role of Domain Competencies in MSIS 2016}

As discussed earlier in this document, an essential identifying characteristic of a degree program in IS is that the program both prepares the students with competencies in a domain of organized human activity and specifically enables the students with competencies related to the application of computing technologies within the domain. Until recently, the most common domain has been business, to the extent that MSIS 2006 explicitly expects either a business prerequisite or a set of corresponding bridge courses in business.

As with IS 2010 at the undergraduate level, MSIS 2016 specifically not only allows but also encourages the introduction of non-business domains to the family of master's degrees in IS. This does not mean that the importance of business would somehow be downgraded. Instead, new domains will be added, which will strengthen the family of IS programs as a whole. In this section, we are including high-level domain competency area descriptions for business and health care.

\subsubsection{Business}

We look to MSIS 2006's two-course business sequence to define the business competency expectations for students who do not have an undergraduate degree in business. They include the following:

1. Designing cross-functional business processes as solutions to business problems or as mechanisms to benefit from IT-enabled business opportunities.

2. Understanding the fundamental business challenges that experts in the key functional business disciplines (finance, accounting, marketing, organizational behavior, and strategy) address, the key business transactions in these functional areas, and the core concepts that the functional area experts are using while discussing their area.

3. Understanding the core concepts and processes related to formulating and enabling the execution of business strategy, particularly from the 
perspective of enabling business strategy with information systems solutions.

4. Analyzing and presenting data to provide support for effective analysis and transformation of ways in which business is conducted.

\subsubsection{Health Care}

Health care is another common example of a domain of practice for which an MS in Information Systems programs can be designed. These programs might be offered under various titles, such as MS in Health Information Systems or MS in Health Informatics.

For such a program, a possible set of domain-related competency categories could include the following (this list is informed and inspired by CDC 2009; American Medical Informatics Association 2008; and University of Michigan 2016):

1. Applying theories of human behavior at individual, group, and societal levels; organizational change; and health management relevant for achieving positive health outcomes in ways that are compatible with the culture, organizational context, and policies related to health.

2. Using scientific evidence to improve the quality of health care and to develop innovative solutions to health problems.

3. Classifying health and health care-related phenomena competently using standard approaches used by the health care community.

4. Applying appropriate ethical and legal frameworks and theories to make informed and justifiable decisions regarding health care.

5. Maintaining appropriate privacy and confidentiality of health information.

6. Communicating effectively with health care professionals using appropriate professional vocabulary, terminology, and practices.

7. Designing structures and mechanisms for maintaining appropriate records for an individual's health care interventions and outcomes history.

In addition, programs in health care informatics often have more specialized health care/medical competency requirements in areas such bioinformatics, public health, clinical informatics, or nursing (Kampov-Polevoi and Hemminger 2011). KampovPolevoi and Hemminger categorize domain-specific knowledge and competencies in health care: health care systems, public health core, advanced practice nursing, clinical sciences, life sciences, biotechnology, computational biology, and medical imaging. Competencies related to these areas are typically determined based on local needs. 


\section{Part C: Using MSIS 2016}

\section{Developing a Curriculum Based on MSIS Competency Specifications}

\subsection{From Competencies to Curriculum}

Earlier in this document, we have specified the competency categories and the minimum level that graduates need to attain to satisfy the minimum requirements of the MSIS. It is clear, however, that a collection of graduate competencies is not sufficient for implementing a degree program. Ultimately, the unit (typically a department or a school) offering an MSIS degree has to construct a set of learning experiences structured in a meaningful way into modules so that participation will enable the required learning processes. By "module," we refer to courses, seminars, theses, other major projects, and other ways to integrate learning experiences. The purpose of this section is to describe sample architectures for MSIS programs and a possible process for developing degree programs as collections of structured learning experiences based on the competency specifications.

In a significant departure from earlier documents providing curriculum guidance in IS, MSIS 2016 acknowledges the fact that the same program-level target competencies and learning objectives can be achieved in a multitude of ways. This document, which has been globally oriented from the beginning, recognizes that master's programs in IS around the world will vary depending on regional, national, and local regulatory contexts, nature of the student groups, and the technical implementation environment. No form of guidance, however well designed or forcefully articulated, can change this. Therefore, MSIS 2016 does not attempt to specify how a master's degree program in IS should be implemented, nor will it specify how exactly a specific graduate competency level should be achieved.

In this chapter, the document does, however, describe possible curriculum architecture models (Section 6.2), a process for deriving courses from the competencies (6.3), and various sample program profiles.

\subsection{MSIS Curriculum Architecture Models}

All MSIS programs have to make essential decisions regarding the architecture of the program's curriculum in the context of local requirements. In most cases, the university, the college/school, or local regulatory or competitive requirements determine important parameters for the program, such as the total number of modules or other similar units of student work. Some programs have more freedom than others, but only in rare cases can a program freely determine the required student workload. That is one of the reasons why MSIS 2016 does not prescribe a specific number of modules or a predefined workload-programs would not be able to align with a single specification even if they wanted to do so. To provide examples 
of typical scenarios, we will discuss in this section two architectural models based on different regional assumptions (North America and Europe).

This discussion will also address the role of various types of modules in the curriculum. We assume that MSIS programs will consist of the following types of main categories of course modules:

- Possible bridge modules that address the pre-program competency requirements in IS

- Possible bridge modules that address the pre-program competency requirements related to the domain of practice

- Required courses that enable students to attain the core IS competencies specified in figure 3

- $\quad$ Required courses that enable students to attain additional domain and individual foundational competencies as specified in figure 3

- Elective courses that enable students to attain specialized competencies as specified in figure 3

\subsubsection{U.S. Model}

A typical MSIS program in the U.S. consists of 10-12 three-semester credit courses (30-36 semester credits, which equals to 60-72 ECTS credits), requiring altogether the student to engage in an equivalent of 450-540 contact hours and 1350-1620 total hours of work during the degree program (the student work hours are, of course, approximations and vary depending on an individual student). If we assume that the program consists of ten courses (not including the bridge courses), one possible use of them is outlined below:

Using this model, we could, for example, build a program (see table 3) that offers

- Four bridge modules (1.5 credits each) to cover the required pre-master's competencies, such as, Fundamentals of Data Management; Fundamentals of Systems Development and Deployment; IS Management and Operations in a Data-Driven Organization; and IT Infrastructure. These would be waived if a student entering the program has the necessary background.

- Six bridge modules (1.5 credits each) to provide foundational domain competencies. Assuming the domain is business, this could, for example, consist of accounting, economics, finance, marketing, operations management, and organizational behavior/leadership. These would be waived if a student entering the program has the necessary background.

- Six required IS modules developing the competencies specified in Chapter 5 and developed using the process described in Section 6.3. 


\begin{tabular}{|c|c|c|}
\hline Module Type & Category & $\begin{array}{l}\text { Total Semester } \\
\text { Credits (ECTS } \\
\text { Credits) }\end{array}$ \\
\hline \multirow{2}{*}{$\begin{array}{l}\text { Bridge modules } \\
\text { Not included in the } \\
\text { formal degree } \\
\text { requirements; } \\
\text { included only as } \\
\text { necessary }\end{array}$} & $\begin{array}{l}\text { Bridge modules focusing on domain } \\
\text { competencies as necessary }\end{array}$ & $6-12(12-24)$ \\
\hline & $\begin{array}{l}\text { Bridge modules in information systems as } \\
\text { necessary }\end{array}$ & $6-9(12-18)$ \\
\hline \multirow[t]{2}{*}{ Required modules } & $\begin{array}{l}\text { Required modules focusing on individual } \\
\text { foundational competencies }\end{array}$ & $0-6(0-12)$ \\
\hline & $\begin{array}{l}\text { Required modules focusing on information } \\
\text { systems competencies, potentially integrated } \\
\text { with domain competencies }\end{array}$ & $18-24(36-48)$ \\
\hline Elective modules & $\begin{array}{l}\text { Elective modules focused on developing } \\
\text { specialized competencies as appropriate for } \\
\text { the goals of the program }\end{array}$ & $0-12(0-24)$ \\
\hline
\end{tabular}

- Four elective modules that form a specialization/career track, such as one focused on one of the profiles discussed in Section 6.3 or in a more specialized area, such as analytics or cybersecurity.

This describes a relatively traditional MSIS program concept in the US. To demonstrate the flexibility of the model, it could also be used to create a program with the following characteristics:

- Two integrated bridge modules (3 credits each) to cover the required premaster's competencies, Data Management and Systems Design, and Information Systems Infrastructure and Management. These would be waived if a student entering the program has the necessary background.

- Four bridge modules ( 3 credits each) to provide foundational domain competencies in health care and health care management, such as the courses specified in the example discussed in Section 5.3.2.

- Eight required IS modules (3 credits each) developing the competencies specified in Chapter 5 and developed using the process described in Section 6.4 .

- Four required modules (1.5 credits each) focusing on further development of foundational individual competencies, such as Oral Communication, Written Communication, Collaboration and Leadership, and Ethical Decision-making. 


\subsubsection{European Model}

Since 1999, European countries have joined the Bologna agreement ${ }^{9}$, according to which university education has a three-year bachelor's degree, a two-year master's degree, and a three-to-four-year doctoral degree. The qualifications at the end of each degree are expressed as learning outcomes (see Chapter 4.1 for master's level qualifications as specified in the Dublin Descriptors).

Student workload is measured in European Credit Transfer and Accumulation System (ECTS) credits. In the ECTS context, workload refers to the time required to complete all relevant learning activities (class meetings, examinations, assignments, projects, practical work, self-study, etc.) required to achieve the expected learning outcomes. One academic year corresponds to 60 ECTS, which are equivalent to 1500-1800 hours of study. One ECTS credit is 25-30 hours of work. Minimum amount for a master's degree is 60 ECTS credits; more typically, a master's degree requires 90-120 ECTS credits. A typical course is 5-6 ECTS credits, taking one quarter of the academic year. A master's thesis is typically 30 ECTS credits.

To gain access to a master's program, a bachelor's degree in the same or closely related field is required. In case bridge courses are needed in IS or in the domain, a suitable collection of intermediate level courses is included in the study plan, for example, as a minor subject.

Using this model, we could, for example, build a two-year program (See table 4) that offers

- Seven required courses (5 ECTS credits each) to cover the essential elements of the program. An alternative is to have six required courses and a capstone project (10 ECTS credits). These cover the competencies specified in Chapter 5 and developed using the process described in Section 6.3.

- Elective modules which can be, for example, four courses (5 ECTS credits each) or two courses and an internship (10 ECTS credits)

- A minor (25 ECTS credits) either in a specialized area within IS or in the domain of practice.

- In Europe, two-year programs typically include a master's thesis (70-100 pages) reporting an empirical study that the student has carried out. To support this process, each writer has a supervisor and presents the study in the seminar for discussion. A separate research methods course can be

9 The countries engaged in the Bologna Process are Albania, Andorra, Armenia, Austria, Azerbaijan, Belarus, Belgium, Bosnia-Herzegovina, Bulgaria, Croatia, Cyprus, Czech Republic, Denmark, Estonia, Finland, France, Georgia, Germany, Greece, Holy See (Vatican), Hungary, Iceland, Ireland, Italy, Kazakhstan, Latvia, Liechtenstein, Lithuania, Luxembourg, Macedonia, Malta, Moldova, Montenegro, Netherlands, Norway, Poland, Portugal, Romania, Russia Federation, Serbia, Slovak Republic, Slovenia, Spain, Sweden, Switzerland, Turkey, Ukraine, United Kingdom. Countries not engaged are Monaco, San Marino. 
offered or given during the seminar meeting hours. Academic writing gives students hands-on support with their texts. The following individual foundational competencies benefit from these modules: critical thinking, creativity, ethical analysis, oral communication, problem-solving, and written communication.

- A capstone project, if provided, also supports creativity, collaboration and teamwork, leadership, and negotiation.

Table 4. Sample MSIS Module Architecture in the Bologna Environment

\begin{tabular}{|l|l|l|}
\hline Module Type & Category & $\begin{array}{l}\text { Total ECTS } \\
\text { Credits (Semester } \\
\text { Credits) }\end{array}$ \\
\hline Required modules & $\begin{array}{l}\text { Required modules focusing on IS } \\
\text { competencies, potentially integrated } \\
\text { with domain competencies }\end{array}$ & $35(17.5)$ \\
\hline Elective modules & $\begin{array}{l}\text { Elective modules focused on } \\
\text { developing specialized competencies } \\
\text { as appropriate for the goals of the } \\
\text { program }\end{array}$ & $20(10)$ \\
\hline Minor subject & $\begin{array}{l}\text { Instead of bridge modules, a minor in } \\
\text { either domain or in IS }\end{array}$ & $25(12.5)$ \\
\hline $\begin{array}{l}\text { Modules supporting } \\
\text { research }\end{array}$ & $\begin{array}{l}\text { Academic writing skills, philosophy of } \\
\text { science, research methods }\end{array}$ & $10(5)$ \\
\hline $\begin{array}{l}\text { Master's thesis with } \\
\text { seminars }\end{array}$ & $\begin{array}{l}\text { Required module for gaining in-depth } \\
\text { knowledge in one area and to learn } \\
\text { basics of doing research }\end{array}$ & $30(15)$ \\
\hline
\end{tabular}

\subsection{Role of Target Profiles in Designing the Curriculum}

All MSIS degrees will share the same core competency areas, but various program implementations will vary in terms of their emphases on specific competency categories. The selection of categories emphasized by a specific program will depend on the target professional profiles. One possible source of such profiles is the latest version of the CEN Workshop Agreement on European ICT Professional Profiles (CEN 2012). The MSIS Task Force evaluated these profiles and agreed that they have a broad global applicability. The task force selected six of the 23 ICT Professional Profiles as the primary MSIS target profiles: Business Information Manager, Project Manager, Business Analyst, Systems Analyst, Enterprise Architect, and ICT Consultant (described below in table 5). For example, an MSIS program that primarily focuses on preparing its graduates for the Business Analyst role will have a different target competency profile compared to the programs that focus on IT Consultant or Enterprise Architect roles. 
Table 5. Descriptions of Relevant CEN Target Profiles as specified by the CEN Workshop Agreement on European ICT Professional Profiles (CEN 2012)

\begin{tabular}{|c|c|}
\hline Profile & Tasks \\
\hline Business Analyst & $\begin{array}{l}\text { Analyzes information systems for improving business } \\
\text { performance. Identifies areas where information system } \\
\text { changes are needed to support business plans and monitors the } \\
\text { impact in terms of change management. Contributes to the } \\
\text { general functional requirements of the business organization in } \\
\text { the area of ICT solutions. Analyzes business needs and } \\
\text { translates them into ICT solutions. }\end{array}$ \\
\hline $\begin{array}{l}\text { Business Information } \\
\text { Manager }\end{array}$ & $\begin{array}{l}\text { Proposes, plans, and manages functional and technical } \\
\text { evolutions of the Information System within the relevant } \\
\text { business domain. Manages and implements updates to existing } \\
\text { applications and maintenance activities guided by the needs, } \\
\text { costs, and plans agreed with internal users. Ensures quality of } \\
\text { service and internal user satisfaction. } \\
\text { Note: Instead of the ClO profile, this is more appropriate for } \\
\text { recent graduates without extensive work experience. }\end{array}$ \\
\hline Enterprise Architect & $\begin{array}{l}\text { Designs and maintains the Enterprise Architecture. Balances } \\
\text { technological opportunities with business (process) } \\
\text { requirements. Maintains a holistic view of the organization's } \\
\text { strategy, processes, information, and ICT assets. Links the } \\
\text { business mission, strategy, and processes to the IT strategy. }\end{array}$ \\
\hline Systems Analyst & $\begin{array}{l}\text { Analyzes requirements and specifies software and systems. } \\
\text { Ensures the technical design and contributes to implementation } \\
\text { of new software and/or enhancements. }\end{array}$ \\
\hline Project Manager & $\begin{array}{l}\text { Manages projects to achieve optimal performance conforming } \\
\text { to original specifications. Defines, implements, and manages } \\
\text { projects from conception to final delivery. Responsible for } \\
\text { achieving optimal results; conforming to standards for quality, } \\
\text { safety; and sustainability and complying with defined scope, } \\
\text { performance, costs, and schedule. }\end{array}$ \\
\hline ICT Consultant & $\begin{array}{l}\text { Supports understanding of how new ICT technologies add value } \\
\text { to a business. Ensures technological watch to inform } \\
\text { stakeholders of emergent technologies. Anticipates and brings } \\
\text { to maturity ICT projects by the introduction of appropriate } \\
\text { technology. Communicates the value of new technologies to } \\
\text { the business. Contributes to project definitions. }\end{array}$ \\
\hline
\end{tabular}

These profiles are, however, just examples, and actual organizational implementations can use these and others in ways that best serve local needs. For example, in Section 6.5 we will provide examples of four different program types: 
one focused on an integrated IT Consultant/Systems Analyst profile; one focused on a Project Manager profile; one emphasizing the role of an Analytics Specialist; and finally one preparing the students for entrepreneurial roles.

\subsection{Process for Deriving Courses from Competency Specifications}

In this section, we provide a framework for a process that any program desiring to be compatible with this recommendation can follow to create a verifiable link between the MSIS 2016 graduate competencies and a specific program implementation. This process shares some characteristics with the processes articulated in Squires and Larson (2009) and Pyster et al. (2015), but it was developed independently.

The process described here focuses on required IS competencies and the core courses of the program. In addition, it assumes that the unit offering the program has conducted a careful analysis of the needs of the key market(s) of the program, the internal organizational requirements in relation to the university or the school, and available resources to determine the general target characteristics (e.g., job profiles) of the graduates (step 1 in figure 5).

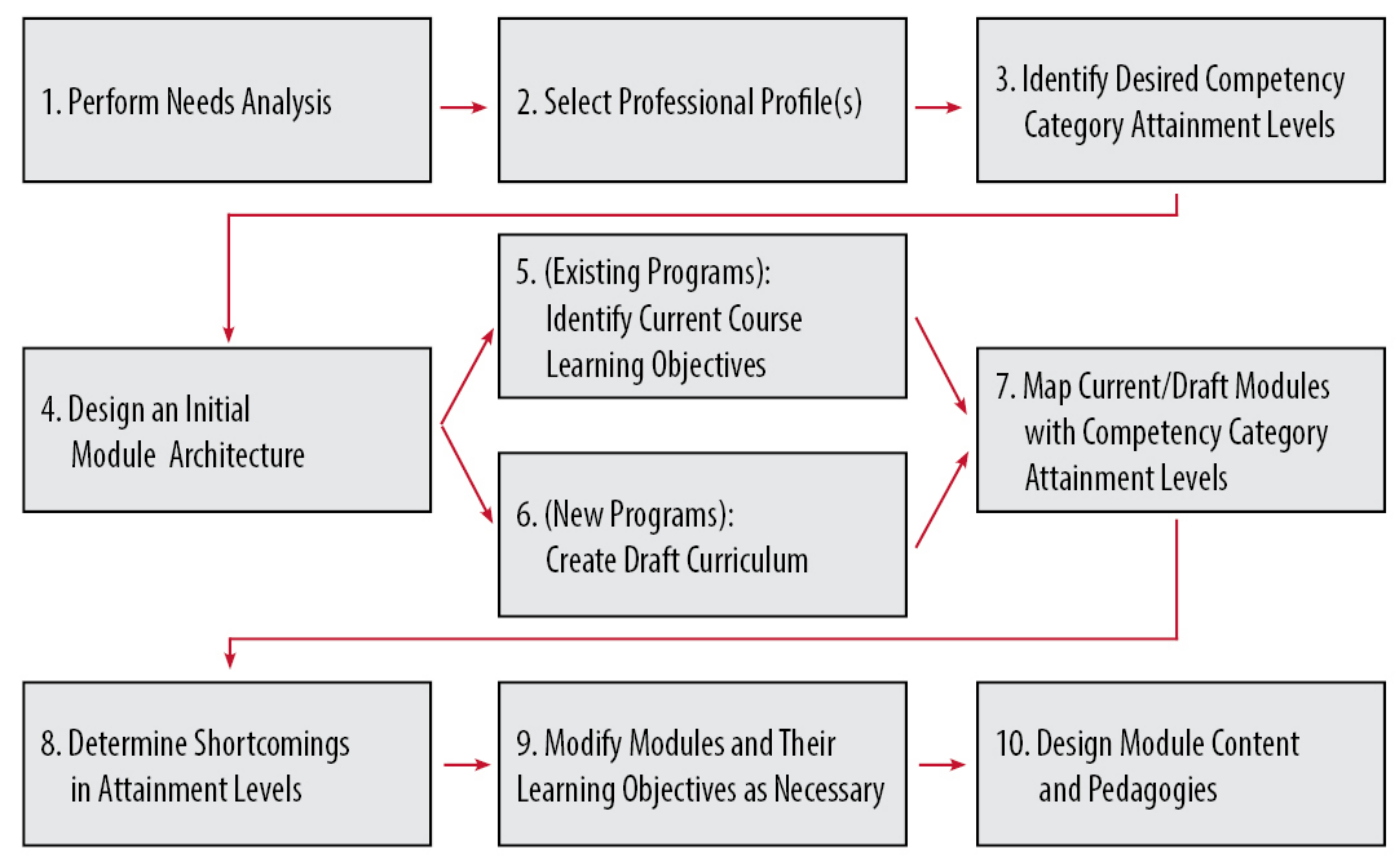

Figure 5. Process for Deriving a Curriculum from Competencies

The process is summarized in figure 5 (steps 2-10), and it includes the following stages: 
2. Finalize the decision regarding the professional profile(s) for which the program wants to prepare its graduates. MSIS 2016 includes a sample set of professional profiles for the MSIS (see Section 4.6), but it is very likely that individual programs will over time collectively develop many others.

3. Based on the professional profile(s), identify the levels (Awareness, Novice, Supporting, or Independent) at which the program desires to enable its graduates to attain each of the MSIS competency categories. Ensure that each category is specified at least at the minimum level specified in Chapter 5.

4. Make an initial architectural decision regarding the total number of modules in the program and the approximate percentage of time dedicated to core competencies and specialized competencies.

5. [For existing programs only] Ensure that the current learning objectives have been appropriately identified and documented for all current modules.

6. [For new programs only] Create a draft set of modules including module titles, brief descriptions, and learning objectives.

7. Create a mapping between current (or draft for new programs) modules and the core MSIS competency categories for the professional profiles specified above. With this mapping, the program demonstrates the extent to which the learning objectives of the current modules contribute to the achievement of each of the graduate competency categories at the desired level.

8. Based on \#6 above, identify the competency categories that the current draft module structure does not allow the students to attain adequately.

9. Based on \#7 above, determine

a. how the modules (again, into courses, projects, seminars, theses, etc.) and their learning experiences have to be changed,

b. which new modules introduced, and/or

c. how the learning experiences have to be reconfigured between the modules so that they will collectively enable the students to attain the competency category attainment levels specified above in \#8.

Repeat steps \#7-\#9 iteratively as long as necessary.

10. Determine the module content and pedagogies that are required to enable students to achieve the module level learning objectives specified in \#8 above. 


\subsection{Examples}

This section includes four program examples, two of which are based on the CEN profiles discussed in Section 6.3 and two others on currently popular program types. We recognize that the examples in this section need updating more frequently than many other elements of this document, and we propose that the sponsoring organizations consider establishing a mechanism with which this material can be updated frequently based on the emerging needs.

\subsubsection{Program Focusing on an IT Consultant/Systems Analyst Profile}

In this example, we assume that a new MSIS program has decided to focus on an integrated IT Consultant/Systems Analyst profile. Another foundational assumption is that the program will consist of 10 modules (three semester hours or six ECTS credits each), and eight of the modules will be dedicated to developing core competencies; two would be remaining for electives. Based on this profile, the program has determined that it needs to enable its graduates to attain MSIS 2016 competency categories at levels described in the Competency level for profiles(s) area in figure 7. Please note that figure 6 includes only the first page of the full model, which is included in its entirety in Appendix B.

The columns under the heading Mapping between modules/courses and competencies were developed using the iterative process described above in steps \#6 through \#9. The resulting curriculum includes eight IS modules:

- Advanced Systems Design and Development

- Creating Domain Value with Data

- Enabling Innovative Organizational Change with IT

- Enterprise Architecture and Systems Infrastructure

- Integrated Capstone

- IS Project Management

- IS Strategy and Management

- User Experience Design

In addition, it assumes that every student in the program has attained certain competencies related to Programming, Data Management, Systems Analysis and Design, and Infrastructure at the undergraduate level.

Finally, this structure leaves still two to three credit modules unspecified. They could be used to allow the student to specialize in an area of study (such as, say, security or analytics) or to take additional courses to strengthen one's background in the domain of practice. 


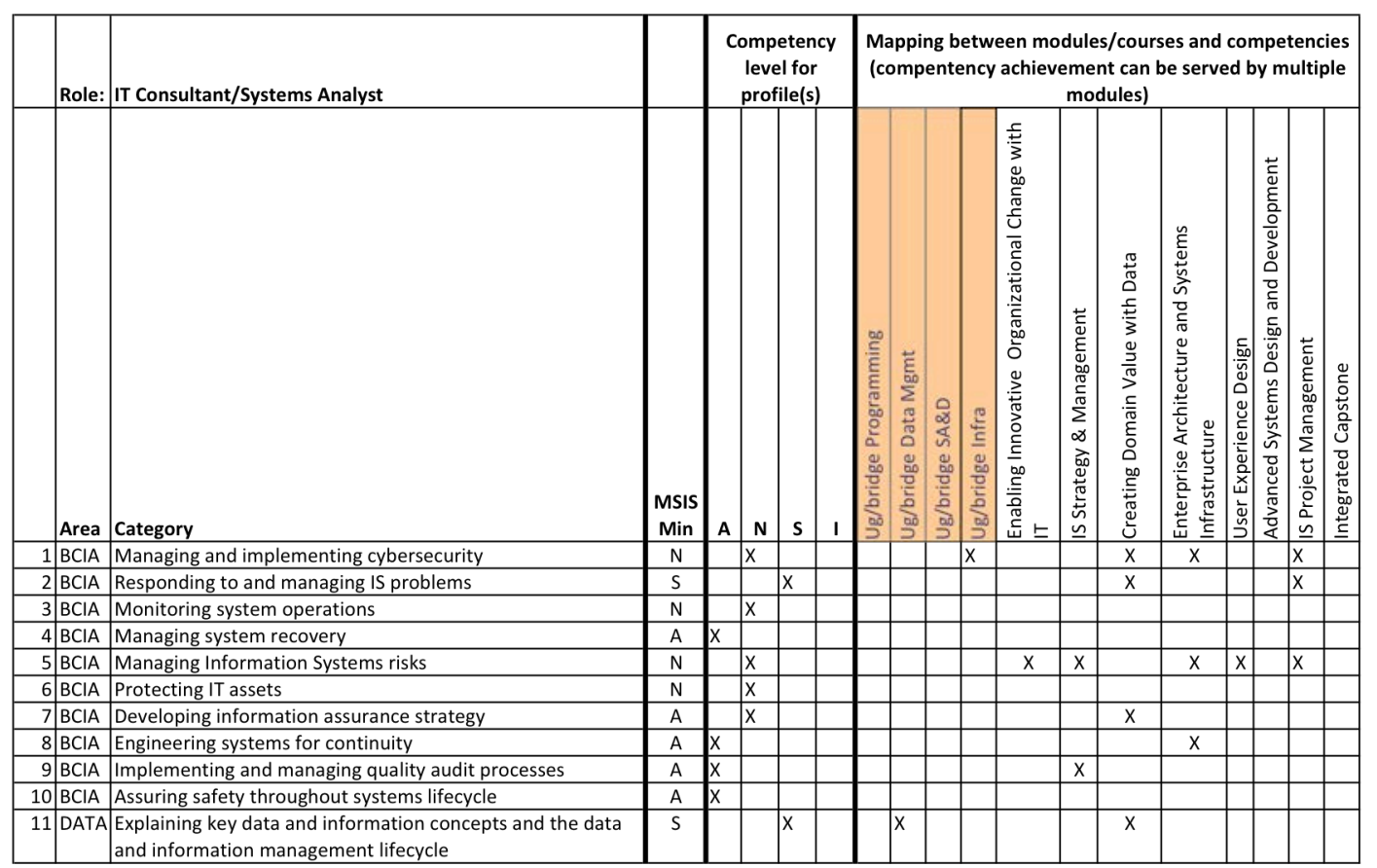

Figure 6. Partial Module-Competency Mapping for the IT Consultant/Systems Analyst Profile

The model included in figure 6 includes the mapping between the courses and the competencies, indicating which courses contribute to enabling the students to attain the specified competency level.

\subsubsection{Program Focusing on the Project Manager Profile}

This example assumes that another program following a similar fundamental architecture model has decided to focus on the Project Manager profile. The first page of the mapping model is in figure 7; the full model is available in Appendix B.

In this case, the resulting curriculum model includes six core IS modules ( 3 semester credits each):

- Creating Domain Value with Data

- Enabling Innovative Organizational Change with IT

- Enterprise Architecture and Systems Infrastructure

- Integrated Capstone

- IS Project Management

- IS Strategy and Management 


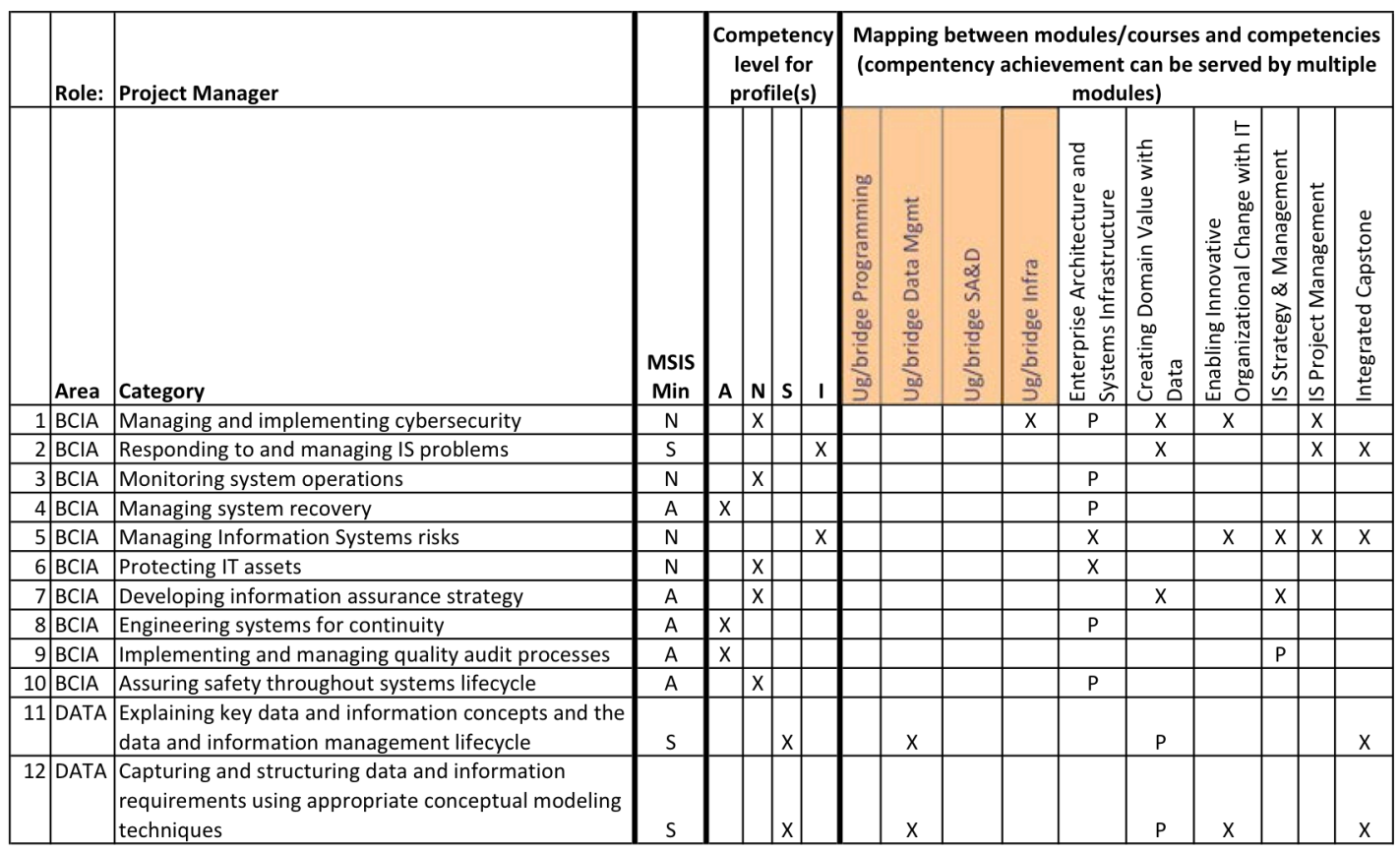

Figure 7. Partial Module-Competency Mapping for Project Manager Profile

Please note also that the model indicates for some competencies the Primary module (with letter P) that is the most important contributor to that competency.

Assuming a ten-module program, this model leaves four three-credit modules unspecified. These could, for example, be additional domain courses that focus on strengthening graduates' competencies as project managers.

\subsubsection{Program focusing on Analytics Specialist Profile}

The third example is not based on CEN (2012). Instead, it represents a case in which a general MSIS is integrated with a specialized competencies. In this case we assume that the focus is on an Analytics Specialist profile.

In this case, the resulting curriculum model includes five core IS modules which ensure the achievement of the minimum level of IS competencies achieved (3 semester credits each):

1. Creating Domain Value with Data

2. Enabling Innovative Organizational Change with IT

3. IS Strategy and Management

4. Designing advanced IT infrastructures

5. Integrated Capstone including IS Project Management

The first page of the mapping model is in Figure 8; the full model is available in Appendix B. 


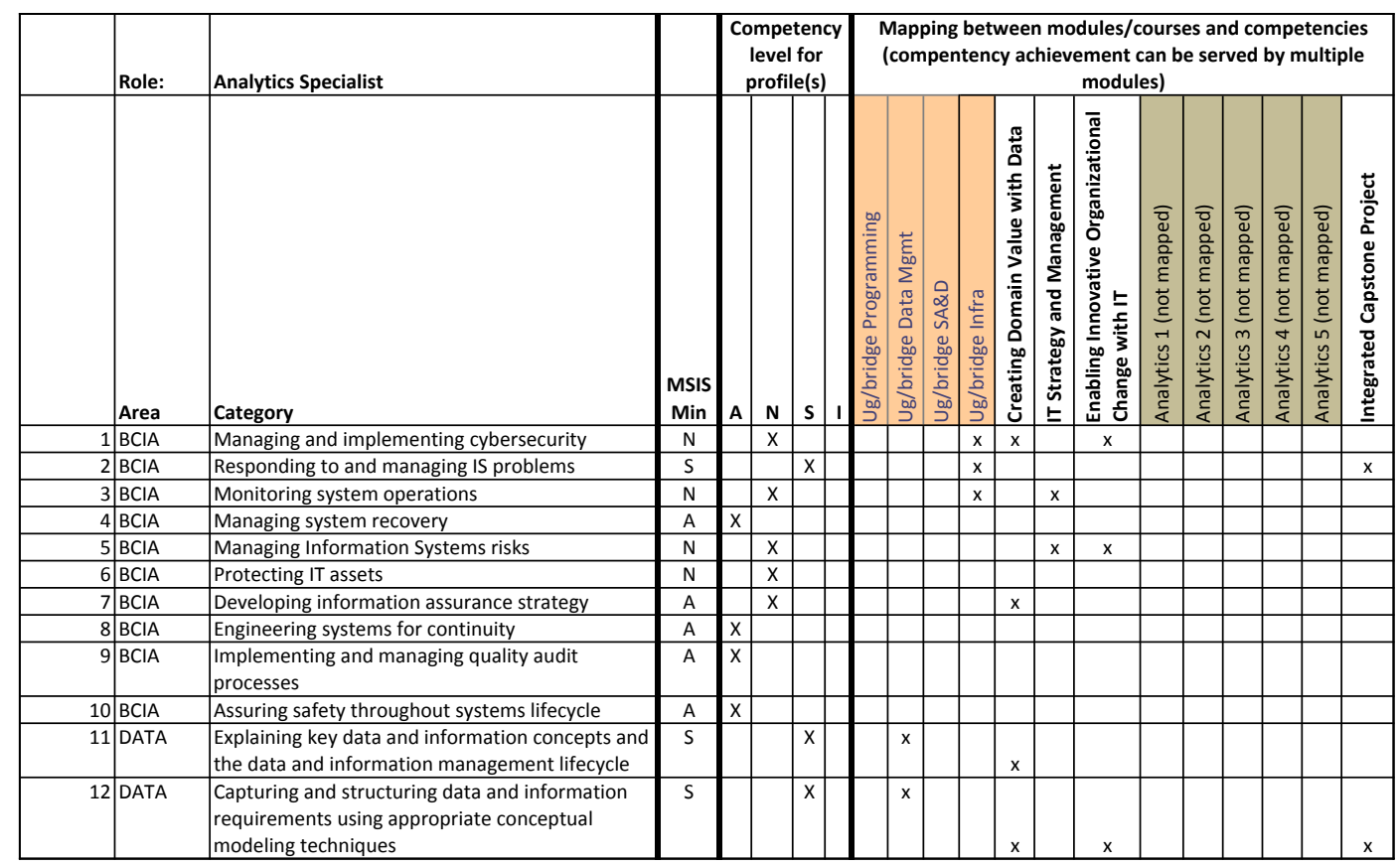

Figure 8. Partial Model-Competency Mapping for Analytics Specialist Profile

We also assume that the rest of the program consists of five modules on Analytics (also three semester credits each). Within the context of this competency model, we are not providing a specific recommendation regarding the modules that should be included in these five. Instead, we recognize that the development of specialized analytics competencies and educational experiences preparing students to attain them will need to be based on separate efforts. Excellent examples of those include Gupta, Goul, and Dinter (2015) and Chiang, Goes, and Stohr (2012).

It is also worth pointing out that this same structural model could be used for other specialized master's degree programs in IS, such as ones focused on cybersecurity or user experience.

\subsubsection{Program Focusing on Start-up Entrepreneur Profile}

The final example is also not based on CEN (2012), either. Instead, it focuses on competencies for start-up entrepreneurs with a specific focus on development of digital services. Unlike the previous one-year examples, this program follows the Bologna model of 120 ECTS credits (60 semester credits) in two years consisting of 11 modules: eight courses, two projects, and thesis. The courses can be either 5 ECTS credits (2.5 semester credits) taken during one period of 8-11 weeks or 10 ECTS credits ( 5 semester credits) taken during two periods. The first project is a hands-on development of a digital service. In the capstone project, the students will establish companies for running the digital service. The program structure is described below in more detail than in previous examples because of the richer variety of module types and credits per module. 


\begin{tabular}{|l|l|l|}
\hline Module & Module type & $\begin{array}{l}\text { ECTS } \\
\text { credits* }\end{array}$ \\
\hline Creating Domain Value with Data & Course & 5 \\
\hline Advanced Systems Development (including UX) & Course & $5+5$ \\
\hline Building Digital Services & Project & 10 \\
\hline IS Strategy and Management & Course & 5 \\
\hline Enabling Innovative Organizational Change with IT & Course & 5 \\
\hline Enterprise Architecture and Systems Infrastructure & Course & $5+5$ \\
\hline Sustainable Start-up & Course & $5+5$ \\
\hline Intellectual Property Rights & Course & 5 \\
\hline Starting a Company & Capstone project & 20 \\
\hline Research Methods & Course & $5+5$ \\
\hline Master's Thesis with Seminar & Independent work & 30 \\
\hline
\end{tabular}

*Divide by two for semester credits.

The first page of the mapping model is in figure 9; the full model is available in Appendix B.

We recognize that the master's thesis experience leads to learning outcomes and competencies that have not been specified in the IS competency model and thus are not reflected in the mapping. In addition, depending on its topic, the thesis gives an opportunity to focus on one or several of the competency areas.

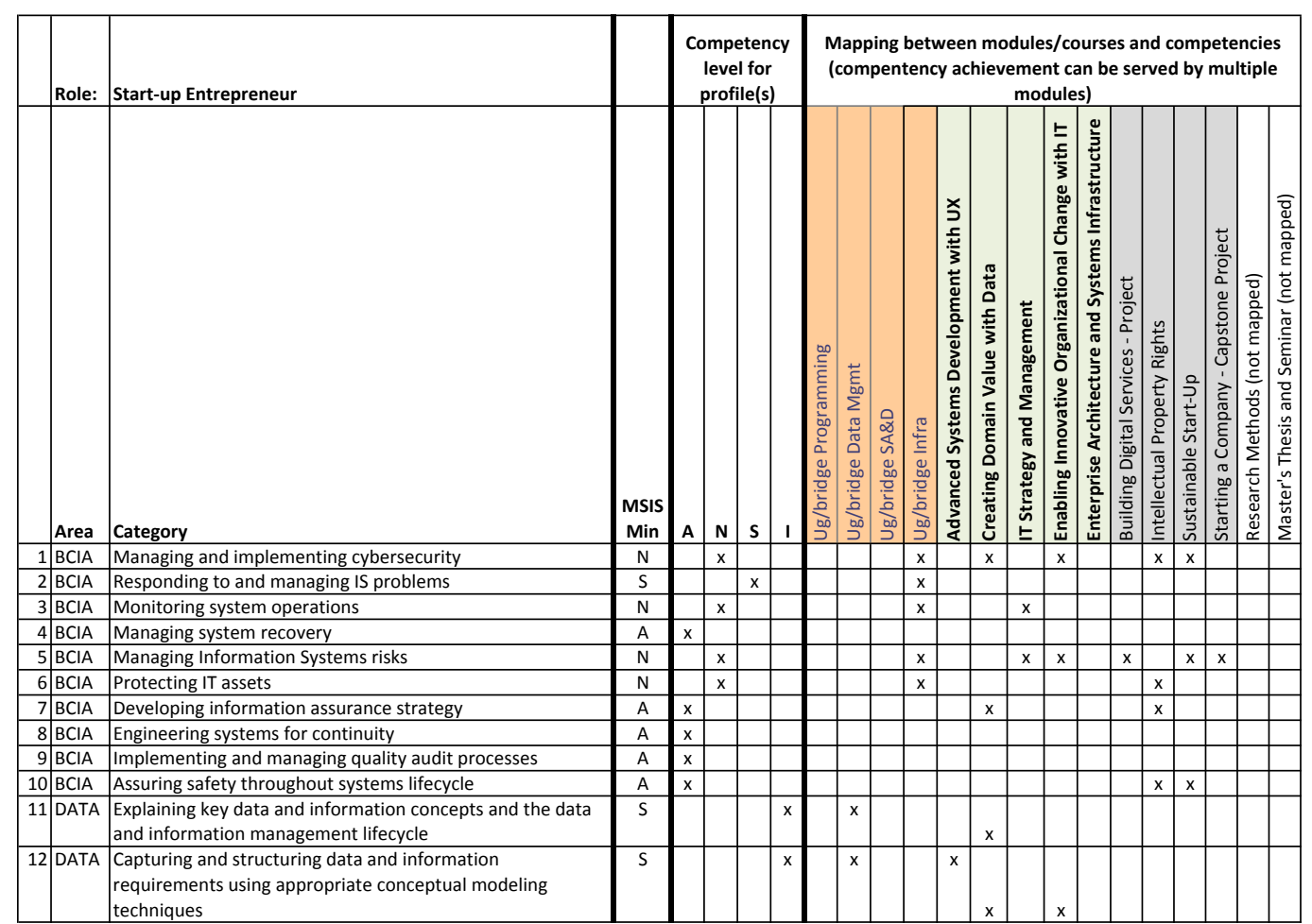

Figure 9. Module-Competency Mapping for the Start-up Entrepreneur Profile 


\subsection{Teaching and Learning Strategies for Building Competencies}

Different kinds of competencies require different teaching and learning strategies. Teaching and learning approaches often differ depending on the targeted competency level. In MSIS 2016 the levels are Awareness, Novice, Supporting [role], and Independent [contributor]. At the Awareness level, knowledge needs to be recalled when needed. Often this requires recognition of the context of the knowledge; that is, the knowledge element and its parents and descendants should be familiar to the learner. To become a Novice, the student needs to have experienced situations and cases. To learn sufficiently for a graduate to be able to play a Supporting role, classroom discussions, case analyses, group assignments, and small projects are valuable. These provide an opportunity to express one's own knowledge and skills in relation to what the others know and can do. Also problemsolving, analysis, and design assignments contribute to this level. To become an Independent contributor, much more extensive unsupervised practice is needed. To gain in-depth knowledge and understanding in a focused area, independent literature analyses and independent research are valuable. Thesis work provides possible means for this, provided it is supported by seminars for presenting and discussing amongst thesis writers.

A large range of teaching and learning strategies are available to support gaining the desired competencies. Lectures are still used by many to convey new information and to demonstrate how it can be understood in the context of the whole program. It is essential to use mechanisms to engage students and encourage them to become active participants in the learning process when lectures are chosen as one of the major teaching approaches. Keeping a learning diary is much used in social sciences.

Flipped classroom requires students to watch videos or in other ways to actively engage with the course material before a class meeting. Class time together can then be used for discussions and both individual and group assignments working on the material. Demonstrations, simulations, documentaries, recorded interviews, and similar approaches bring tangible practical knowledge to the class.

In general, classroom discussions activate, as the incentive to participate can come at any time; therefore not listening to others is not an option. Students learn to understand other perspectives and argue for own views. Cases have long been used in business education. They introduce a real-life situation to the classroom and activate students to problem-solving. Contact to future work can be built also with company visits, guest speakers, and internships. To level the knowledge, book exams can be used in the beginning of the course, perhaps with study groups. Class assignments, in or out of the class, are favored for practicing individually certain methods and tools.

Group assignments give an opportunity to develop skills in collaboration and teamwork, negotiation, and oral communication. Course projects and Capstone projects at the end of the program are very valuable. Group assignments and projects can be organized to follow, for example, the cooperative paradigm. This 
means that the result of the group task is evaluated as one product: "We sink or swim together" (Johnson \& Johnson 1987; Johnson, Johnson, and Houlubec 1993). This requires teaching the groups in different ways to organize the work. The cooperative paradigm is well aligned with the development of supporting and contributor level competencies. In projects for outside clients, the relevance of what has been learned becomes obvious. Deming (1986) and others claim that the quality of an activity can be improved with a cyclical approach of Planning, Doing, Checking, and Acting. This approach can also be used to improve student work, especially in groups.

Many kinds of tools support active participation. Smart phones and tablets can be used to send comments, votes, and other contributions to the shared message spaces. Chat programs (TodaysMeet, Twitter, etc.) can also support discussion. Facebook is one means for coordinating group work. Multiple-choice questions, voting, and formative student evaluation during the course can be collected with applications such as Socrative. The paper flipchart can be replaced with interactive applications such as Padlet. Edmodo, Blackboard, and Moodle are examples of comprehensive learning platforms for collecting all materials together and enabling student collaboration at various levels. They also support student participation and one-to-many messaging. Some of these tools are free and some are open source.

The purpose of MSIS 2016 or other similar recommendations is not to provide detailed guidance on structure, organization, or methods at the course level. It is, however, essential that these questions are carefully considered at the program level, and it is our hope that this section has provided useful perspectives to support local conversations.

\subsection{Master's Thesis or a Research Project as a Form of Pedagogy}

Master's thesis is a part of a master's degree in several countries (see also Chapter 12), especially in Europe, where it is often one-fourth of the program (30 ECTS). Traditionally, the thesis is an opportunity to learn how to do research. Doing research also develops analytical and critical thinking and problem-solving, both foundational individual competencies and important professional skills. Mature professionals consciously reflect on and revise their practices ${ }^{10}$. Research education enables practitioners to rigorously assess the scientific value of their contributions. As an applied field, IS research, also in a thesis, should aim at relevance to professional practice. A thesis is intended to enable the student to develop in-depth knowledge, advanced skills, responsibility and autonomy as part of the program of study. In the context of a thesis, a student works individually and independently on a major task (unlike capstone projects, which are frequently based on teamwork). Thesis work is often supported by a course in research methods, an assigned

10 Reflective practice (Schön, 1983) challenges practitioners to constantly improve on their work by reflecting on their practice, learning from their experiences, and by engaging in problem solving and thereby changing their work. 
supervisor, and seminar sessions for presenting and discussing a student's work with other thesis writers.

A student who has carried out thesis work will be able to

1. Quickly become familiar with a topic in its context. During the work, the student will gain a deeper knowledge of the chosen area

2. Identify a relevant problem and define it as a research problem

3. Identify, evaluate, and discuss current literature on this topic

4. Build and defend chains of argumentation

5. Select, develop, and apply suitable methods to address the problem

6. Analyze and evaluate rigorously their results

7. Understand the significance of their results for practice and for research

8. Document all this in a concise and well-structured thesis

The individual foundational skills to which the thesis work contributes include critical thinking and problem-solving, creativity, ethical analysis, mathematical and statistical competencies (depending on the topic and the methods), and oral and written communication.

In case a research degree is not wanted, it is also possible for a student to do a smaller study to apply the acquired competencies in real life problems. One example of this is the Professional Practice and Research Project at University of Wollongong. In these projects, the novelty and significance of research outcome are much less important than in a traditional thesis, whereas the hands-on practice and critical thinking are emphasized more. The research component credit points equal to oneeighth of the entire two-year degree, which students complete in two separate semesters. Depending on project size, it could be either individual or group based work. The topic is quite often drawn from real research topics from faculty members, who then also supervise the students.

On successful completion of this project, students will be able to

1. Assess the present legal, regulatory, social, and ethical perspectives on the use of information technology.

2. Critically review the exercise of professional ethics in research and industry.

3. Critically analyze a body of literature concerning a specific research question or problem related to professional practices in the IS industry.

4. Plan, design, and implement a research project to address a research question.

5. Communicate research report findings to stakeholders in IS industry and to the general public.

\section{MSIS 2016 Resource Requirements}

The resources required to operate an MSIS degree program have changed since the last curriculum revision a decade ago. Like in the past, having faculty members who 
are subject matter experts is a critical resource. Faculty members teaching in the program must actively update their expertise through continuous learning given the fast pace of change in the field. Other critical resources required to operate an MSIS degree program are Internet and library resources, computing and laboratory resources, and pedagogical support resources.

\subsection{Faculty Expertise and Development}

The expertise of faculty members teaching in the program is a critical determinant of the quality of an MSIS degree program. Such expertise can come from both academic training and industry experience. It is valuable to have a good mix of tenure-track faculty with an academic focus and practice-oriented faculty with strong industry background. Faculty members should be given the freedom to determine teaching and assessment materials as long as these align with program and course learning objectives.

Faculty members teaching in the program must actively update their expertise through continuous learning given the fast pace of change in the field. Therefore, the institution needs to provide faculty members with time, funds, and other resources for professional development. These include support for attending conferences, workshops, and seminars regularly as well as participating in activities such as training, consulting, and industry exchange.

When determining the number of faculty members needed for an MSIS degree program, key factors would be the expected student enrollment, the number of required courses, the number of elective courses, and the teaching load of faculty. A sufficient number of faculty members should have a primary commitment to the MSIS degree program so as to meet the teaching and advising needs of the program. Having adequate course offerings is required to ensure that students are able to complete the degree without unnecessary delays.

\subsection{Internet and Library Resources}

Having reliable and fast Internet connection is critical to an MSIS degree program. Faculty members need to have an Internet connection to be able to gather teaching materials from industry and academic sources as well as to access students and the academic and professional community. Students need to have an Internet connection to access teaching materials as well as to participate in discussion forum involving the class or their project groups.

Library resources are an important part of an MSIS degree program. In a rapidly evolving field, libraries need to provide faculty members and students with roundthe-clock digital access to academic journals, conference proceedings, practitioner magazines, monographs, and reference books. Access to the AIS Electronic Library and the ACM Digital Library is essential. The CS Digital Library by IEEE-CS is also a very useful resource. 


\subsection{Computing Infrastructure and Laboratory Resources}

Having a good computing infrastructure is essential for effective delivery of an MSIS degree program. Students bring to classes a wide variety of computing and mobile devices. It is important that the computing infrastructure accommodates computing and mobile devices running on major operating platforms. Given that new operating platforms can emerge from time to time, the computing infrastructure needs to keep up with such developments.

Contemporary and emerging software packages should be made available to expose students to latest industry practices and standards. Course projects can be designed using such software packages to enhance realism and to better prepare students for the industry. In recent years, there has been a significant increase in the amount and variety of such software packages and other resources available on the cloud. Hence, it is important that resources on the cloud be tapped to facilitate student learning. Having adequate technical support for the use of resources on the cloud lightens the burdens placed on faculty members and allows them to focus on their teaching and research responsibilities. In addition, many cloud-based resources allow access to a rich variety of client devices. MSIS programs should ensure that the computing resources available for their students are sufficient for simulating a professional environment for distributed online work.

It is important that students learn and do their assignments in an environment that reflects the latest industry practices. Such an environment can be simulated in the laboratory with up-to-date hardware and software resources that are replaced or upgraded on a regular basis to avoid obsolescence. The laboratory is particularly useful for supporting courses that require students to work with specialized or licensed hardware or software or with large datasets that their own computing and mobile devices are not able to accommodate. Adequate technical support should be provided for the laboratory.

\subsection{Pedagogical Support Resources}

In many program contexts, a significant proportion of students in an MSIS degree program are working professionals who have a full-time job and who are studying part-time. Given their time commitment and the occasional need to travel for work, flexible pedagogical approaches have to be adopted to facilitate their learning. In recent years, there has been an increase in the use of the flipped classroom approach for courses involving students with schedule constraints. With the flipped classroom approach, course materials are made available in the form of many short video snippets that students can download and view at their convenience.

Classroom time is reserved for discussion, presentation, debate, and other forms of interaction that reinforce the learning experience of students. Rather than always bringing students into the classroom, this approach allows a part of the classroom to be brought out to students, thereby helping students to overcome some of their constraints. 
Faculty members are not always specialists in pedagogy. Therefore, when employing new pedagogical approaches, faculty members need the support and advice of pedagogical specialists for the creation of learning materials, design of course projects and assessments, and management of online discussion forums. There is a growing body of literature on emerging pedagogical approaches that pedagogical specialists can tap in their efforts to help faculty members construct their materials and teach their courses more effectively. 


\section{Part D: Justification, History, and Current Status}

\section{Why an MS in Information Systems?}

There are multiple stakeholder groups for whom the existence and continued wellbeing of master's degrees in IS is important. Those groups include students, graduates and alumni, employers, recruiters, the departments and schools offering the degrees, and society as a whole. Students who are interested in developing professional competencies beyond those provided by a bachelor's degree in IS or in another computing discipline benefit from a master's degree in IS as a well-defined credential that leads to a set of competencies respected and valued by employers. MSIS graduates benefit if the image of their degree stays current and its identity strong. Employers benefit from graduate degrees in IS because these degrees produce graduates who are ready to join project teams addressing real organizational problems or opportunities immediately after graduation. For the schools and departments offering MSIS (or equivalent) degrees, these degrees are an excellent mechanism for giving students a highly valued set of professional capabilities and, thus, providing value to both students and employers. At the societal level, graduate degrees in IS address the continuing shortage of professionals who are able to identify and implement the best connections between problems and opportunities within various domains of human activity and the technology capabilities that can be used to address them.

The most important factor driving the value of graduate-level programs in IS is, however, that human ability to produce computing-based technologies far exceeds human capability to apply these technologies to appropriate organizational and individual contexts in a way that leads to increased value. Master's programs in IS provide environments in which the students can gain the skills and knowledge that are needed to start a successful career in demanding IS roles of planning, designing, and managing of solutions that enable digital transformation. These roles require integration of in-depth domain knowledge with strong understanding of digital technologies.

Pervasiveness of computing technologies is undeniable, and computing solutions are increasingly deeply embedded in products and services that have an impact on a wide variety of aspects of our lives. Transportation technologies, robotics in manufacturing, health care technologies, highly integrated computing and communication tools, commerce platforms that are available everywhere-the number of examples of technology solutions that are significantly changing human lives is increasing every day. Just a few years ago, mobile, cloud computing, the Internet of Things, and social networks were new trends, and now they are foundational components of massive numbers of information systems solutions everywhere. The same is true for big data and analytics. Digitalization and digital disruption are among the most actively discussed organizational topics in 2016. 
Mastery of technology is not sufficient for fully understanding the potential and the risks of digital solutions. In addition to in-depth command of technology, it is essential that professionals responsible for digital technology solutions understand human behavior, organizational structures, business constraints and opportunities, ethical implications of technology applications, etc. A master's degree in IS prepares professionals who are able to deliver technology-based solutions addressing the most relevant problems and taking advantage of the most important opportunities.

Well-implemented master's degrees in IS with a shared identity also serve IS as an academic discipline and community. The professional contributions of the graduates of IS programs collectively form a significant component of what the discipline offers to its stakeholders (together, of course, with the impact of its research output over time). Educational output at the master's level is not inherently more valuable for the field than bachelor's degrees, but graduate degrees have the potential to be more effective in communicating the distinctive contributions of the field. This is particularly valuable in communicating the value and the identity of the IS discipline to prospective employees who might still not have a clear understanding of what IS graduates can offer. High-performing master's degree graduates and a well-defined integrated understanding of the key elements of a master's degree can be highly effective in telling the story of IS.

One of the reasons a master's degree in IS can offer a very important additional qualification compared to a bachelor's degree is that many undergraduate degrees in IS (particularly those offered in business schools) are limited to a relatively small number of modules (such as six to eight) in the major. This type of an undergraduate degree does not make it possible to develop deep, specialized technical or managerial skills related to digital transformation. It does, however, form a good foundation on top of which a master's degree can build competencies that demonstrate better what the IS discipline can offer than an undergraduate degree does.

The value of a graduate degree in IS can also be demonstrated by evaluating IS in the context of other computing degrees. As discussed, for example, in the CC2005 Overview Volume (Shackelford et al. 2006), IS as a discipline has a significantly stronger focus on organizational-level issues and the integration of domain expertise and computing than any other computing degree type (such as Computer Engineering (CE), Computer Science (CS), Information Technology (IT), or Software Engineering (SE)). CE and CS are clearly focused on computing only; SE introduces concerns of human behavior typically at a project level; and IT is primarily concerned about humans as users and sources of security threats. Although all disciplines recognize the importance of requirements specified by humans, IS degrees (particularly at the master's level) are specifically focused on supporting human goals at individual, organizational, and societal levels. Information Science (a discipline emerging from Library Science) is related to both IS and CS, and it shares areas of interest with both. It is, however, not one of the computing disciplines identified as such by, for example, CC2005. 
Finally, it is also important to recognize that there is no single model of a master's degree program in IS. As discussed in Chapter 12, the structure and content of these programs vary significantly depending on the region and the country. Still, many of the general reasons underlying the usefulness of these programs are the same: everywhere in the world, organizations and individuals are working to determine how to best use digital technology to advance their goals.

\section{Expectations for an MS in Information Systems}

Various stakeholders have different outcome expectations for the MSIS degree. The perspectives of students, academic program and degree directors, teaching professors, course administrators, course accreditation agencies, student recruiters, and university marketing staff as well as future employers who are hiring IS graduates, are partially overlapping but also partially independent of each other. In this section, we will discuss the expectations that various stakeholder groups have for an MSIS degree.

\subsection{Student Perspective}

Students with different prior learning and career paths have different expectations for an MSIS degree:

- Students who are entering the MSIS directly from a bachelor's degree in IS or a related field would expect MSIS to update and expand their knowledge and professional competencies related to the IS discipline. The students might also expect an MSIS degree to expand or strengthen their knowledge or skills in topically specialized areas such as data management, analytics, or security.

- MSIS students expect to improve their career prospects through their graduate studies. For some, the MSIS provides an upgrade of knowledge and skill levels with a potential to achieve a more advanced job placement or a career path with faster progression. For others, the MSIS is the entry to the IS profession and a foundation for a career change, thus required to develop essential IS skills. Delicate considerations are necessary to determine the entry requirements, mapping between the students' existing competencies and those required for the program, and, ultimately, bridge courses needed to fill the gaps.

- There are also MSIS programs targeted to experienced computing professionals who expect to play more senior roles in IT management. For these types of degree programs, graduate competencies, entry requirements, course content, and pedagogies will be different from those of programs targeted to fresh graduates of undergraduate programs and career changers. As we discuss in Section 2.3, we recommend that these programs not be offered under the standard MSIS title. At times, these students are served through MBA or Executive Master's programs. 
- Some master's students in IS might not see the degree as a means toward a professional role as a practitioner. Instead, these students could have research-focused or more general individual development goals. For them, a degree with a master's thesis might be the best option.

- Finally, some students interested in an MSIS may not have formal higher education (tertiary) qualifications but are hoping to enter an MSIS program solely based on professional experience with the goal of achieving a formal qualification. Typically, some bachelor's degree is required as a foundation for a master's degree in IS, but professional experience can be considered in lieu of coursework as a mechanism to bypass the IS-related bridge courses.

\subsection{University, School, and Department Perspectives}

Business and computing schools in the universities around the world have witnessed the growth of the IS discipline in the past five decades. These programs are currently serving an important role by satisfying the globally growing need for professionals who are able to address organizational needs with innovative information technology solutions.

By offering MSIS, the relevant academic departments and their degree programs have the opportunity to retain and attract more students, with or without IS background, who will be able to gain more professional and advanced knowledge and skills in the discipline.

A successful and popular MSIS program, which meets demands from both prospective students and IS-driven business sectors, will bring value to the degree and course providers in many ways:

- Better reputation of the university and school regarded by the students, who benefit from the well-defined learning outcomes.

- Promoted recognition from the employers in government, industry, NGO, community and other sectors, who, in turn, benefit from recruiting muchneeded IS professionals.

- Increased revenue sourced from tuition income and/or government funding, and indirect expanded research funding as well as industry engagement supports.

\subsection{Employer Perspective}

The MSIS programs are expected to meet the demand for IS professionals in both traditional and emerging job positions and opportunities.

The number of available career paths for IS professionals has increased significantly with the organizational transformation and new business opportunities through information technology, analytics and big data, cloud computing, and Artificial Intelligence (AI)/Virtual Reality (VR) technologies, among others. Increasingly, any form of organized human activity is broadly enabled by IT-based solutions. 
Among the many job titles, some of the most frequently associated with the MSIS degree include (adapted from CEN, 2012) ${ }^{11}$

- Business Analyst

- Systems Analyst

- Project Manager

- Business Information Manager

- IT Consultant

Job opportunities in IS require students to know both the technology and the domain in which they will work. The career paths for MS graduates are becoming increasingly varied, the knowledge and skills expected from MSIS graduates broader and more challenging.

A key element of the MSIS model is the specification of a core set of competencies that meet the expectations for target professions by potential employers. As discussed earlier in Chapter 6, competency categories form a foundation for curriculum specification at the course and topic levels. Therefore the feedback and input from the employers regarding the competencies are vital for mapping the delivered content of the MSIS degree and professional expectations for different IS job roles.

\subsection{Quality Control Perspective}

The degree accreditations also mandate the direction in which MSIS should move to meet the standards and requirements specified for master's qualifications in IS discipline.

We have identified European e-Competence Framework (e-CF) and Skills Framework for Information Age (SFIA) as the most important sources to mapping the outcome expectations. Complementary to them, various organisations (e.g., CEPIS and CEN in Europe, BCS's CFP, or SOL in Australia) maintain an exhaustive list of IS profession job profiles, which are related to such frameworks. Further, these frameworks often offer a matrix to map the degrees to certain qualification frameworks such as European Qualifications Framework (EQF) or Australian Qualifications Framework (AQF).

These frameworks have already been adopted in various country-level accreditations. For example, the Australian Computer Society uses SFIA and $\mathrm{AQF} /$ Bloom's taxonomy to approve professional and advanced degrees in computing.

MSIS 2016 is the contribution of the worldwide academic IS community to this conversation. It specifies the academic community's current view of the expectations for a graduate degree program in IS and, thus, also supports the process of creating a foundation for quality control processes.

\footnotetext{
11 These profiles are described at http://relaunch.ecompetences.eu/wpcontent/uploads/2013/12/EU_ICT_Professional_Profiles_CWA_updated_by_e_CF_3.0.pdf.
} 


\subsection{Societal Perspective}

The IS discipline has become a driving force accelerating the innovation-based economies around the world. From the most developed to the poorest countries, IS has significantly changed the ways societies maintain and achieve prosperity. IS professions have offered and will continue to provide large numbers of high-paying jobs around the world.

Successful MSIS programs hence are anticipated to train more suitable graduates to fill the gap in the market demand. It is simultaneously critically important and challenging to identify the key knowledge, skills, and competencies that meet the expectations of an IS discipline from the different sectors in the society.

\section{Uses of the MSIS 2016 Competency Model}

The primary objective of this document is to provide those responsible for designing and managing graduate IS programs of study with a set of guidelines. A secondary purpose of MSIS 2016 is to foster collaboration, communication, and alignment between and among the variety of stakeholders in the IS community having an interest in graduate IS education. A detailed description of the benefits to each

\section{Why a Competency Model?}

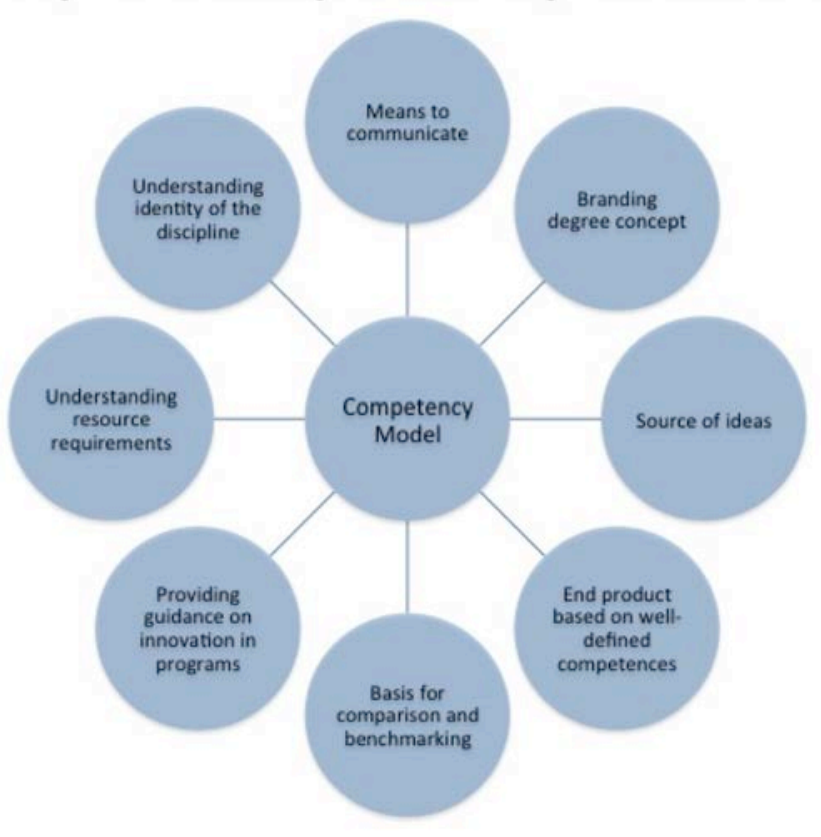

Figure 10. Uses of the Competency Model 
stakeholder community follows. Figure 10 above depicts the role and importance of the IS competency model.

Program designers will find a wide variety of uses for the MSIS 2016 model. It defines three levels of IS competencies-competency areas, competency categories, and competencies. Collectively, these competencies encapsulate and represent IS as a whole (including both computing/IT and IS management dimensions). The resulting repository of IS competencies serves as a starting point for identifying required and elective program material. The competency model is designed to be flexible, providing program designers with suggested approaches rather than prescriptive requirements. The ability to customize programs of study will better enable program designers to meet unique local demands.

Administrators of existing IS programs will also find the competency model useful as this document supports comparison and benchmarking. Administrators of existing programs can map their program to competency model categories to identify similarities, differences, and gaps. In addition, program administrators may choose to publish their mappings to the IS community to promote discussion, collaboration, and development of best practices. The competency model should also foster innovation and improvement regarding program structure, content, and delivery. An understanding of the full range of options to consider when designing a graduate program of study will lead to better, more informed decisions regarding individual IS graduate program design.

The competency model is also designed to promote alignment with industry needs. MSIS 2016 includes competency mappings for several typical IS job profiles. Defining the expected competencies of IS graduates is new to this edition of curriculum guidance and provides a number of unique benefits. Industry partners will better understand the skills and abilities of graduates, thereby more efficiently placing students in correct jobs and reducing the amount of post-hiring training required. The competency perspective allows students to know what to expect in terms of desired outcomes, providing insights into course selection and career paths. This perspective is designed to bridge the gap between the knowledge acquisition focus of a typical graduate educational program to include a focus on skills and capabilities, desired by industry professionals in the workplace. Improved coordination between IS programs and industry partners should lead to more efficient hiring processes and better prepare students who can immediately contribute to the success of the corporate IT function.

MSIS 2016 also provides a means to communicate the content and structure of IS graduate education to a broad audience. Senior academic administrators funding IS programs of study; policymakers promoting science technology, engineering, and math education; and current and prospective students of graduate IS education are all expected to have an interest in the model and benefit from its recommendations. Communicating the competency model should lead to enhanced collaboration and will help program administrators better understand and plan for the resources required to effectively implement a graduate program of study. 
Finally, the model is intended be a spark for innovation. The resources provided in the model should provide a starting point for those looking to develop new and innovative programs. These guidelines along with dynamic stakeholder collaboration will serve as a foundation for the development and evolution of the discipline.

\section{Information Systems Curriculum Guidance-History and Background}

This document is the fifth in a series that was introduced in 1972 with the first master's level curriculum recommendation in IS (Ashenhurst 1972). This recommendation was prepared by the ACM Curriculum Committee on Computer Education for Management with several founders of the IS discipline involved, including Daniel Couger, Gordon Davis, and James McKenney. Interestingly, while this recommendation provided a thorough description of the output characteristics of graduates (essentially graduate competencies) divided into six major categories (people, models, systems, computers, organizations, and society), its main focus was on courses and programs.

In 1982, ACM published an updated IS curriculum recommendation for both undergraduate and graduate levels, prepared by the ACM Curriculum Committee on Information Systems (Nunamaker, Couger, and Davis 1982). This committee was chaired by Jay Nunamaker. Other members included Daniel Couger, Gordon Davis, and Andrew Whinston, among others. The 1982 report utilized the same graduate competencies ("knowledge and abilities") as the 1972 curriculum with the same categorization and essentially the same content as 10 years earlier. The general structure of the curriculum was divided into three main categories: Information Systems Technology, Information Systems Process, and AACSB Common Body of Knowledge (business as the domain). The first two categories of the degree are specified in the recommendation and consist of ten courses three semester hours each; the assumption is that the total length of the program is 16 courses, each three semester hours.

The next comprehensive master's level curriculum recommendation, MSIS 2000 (Gorgone et al. 2000), was the first joint project between ACM and AIS. The project was chaired by John Gorgone (representing ACM) and Paul Gray (representing AIS), and the participants continued to include leading academics in IS (David Feinstein, George Kasper, Jerry Luftman, Ted Stohr, Joe Valacich, and Rolf Wigand). MSIS 2000 paid much less attention to the graduate competencies than the earlier master's level curricula did. It did, however, articulate explicitly the need to focus on three major individual foundational skill categories: communication, interpersonal, and team skills; analytical and critical thinking skills; and career development skills. In addition to these three, MSIS 2000 specified that the graduates should attain a core of IS knowledge, integration of IS and business foundations, and broad business and real-world perspective. The major innovation in MSIS 2000 was the introduction of 
career tracks in addition to IS foundations, business foundations, IS core, and integrative business/technology material. The prescribed program structure consisted of technical foundations (three courses), business foundations (three courses), IS core (six courses), and career electives (four courses). The core courses included data management, SA\&D, data communications and networking, project management, IS strategy and policy, and IS integration.

The next, most recent curriculum recommendation followed soon after MSIS 2000 in 2006. This document-MSIS 2006 (Gorgone et al. 2006) — was produced by a task force chaired again by Gorgone and Gray. It reduced the number of technical and business foundations courses to two each, added two core courses, and reconfigured the technical core courses (most notably by removing separate data management and networking/data communications courses and introducing courses in enterprise models, emerging technologies, and IT infrastructure).

The preparation for this latest volume, MSIS 2016, started in 2010 with a panel discussion at AMCIS 2010 (Topi et al. 2010). The process that led from this early conversation to the completion of this document is described in Chapter 13.

\section{Current Status-Review of Global IS Master's Degree Program Practices by Global Region}

One of the challenges but also important characteristics and sources of richness for MSIS 2016 is its global scope. In this chapter, we will discuss how global MSIS programs differ fundamentally based on the following factors:

- How much and what topics have new students studied before entering the master's program?

- What, how much, and in what ways do the students study for an IS master's degree?

- What is the structure of the IS master's degree, specified as a balance between modules such as courses, industry projects, theses, exchange periods abroad, and other learning experiences?

\subsection{Students Entering the Programs}

In general, entering a master's program in IS requires a bachelor's degree. Some programs are designed to enable a university's own undergraduates to continue on to complete a master's degree. These integrated programs were very prevalent in Europe and Russia before the Bologna process and in some countries in Asia, and they are becoming more common in the US. In Europe, a typical IS master's entry requirement is to have at least 90 ECTS credits in IS or a closely related field in the three-year bachelor's degree. The degree can also be obtained at Universities of Applied Sciences (Polytechnics). Significant work experience in IS (for more than seven years) is also considered qualifying in some countries such as UK and Ireland. These two options may necessitate bridge studies. 
In Asia, most programs have specified a bachelor's degree in IS or a related discipline as an entry requirement. These programs are also flexible in considering candidates who lack such qualifications but have relevant experience. This supports the necessary buildup of the computing professions; most Asian economies face personnel shortages in computing. In Australia and New Zealand, entering a master's degree in IS requires an equivalent three-year bachelor's degree, which may not necessarily be in a computing field, or a shorter sub-degree plus substantial work experience in IS or IT. Because of personnel shortages, Australia recruits students with a variety of prior degrees and then provides bridge studies.

Students who enter master's degree programs in North America are all required to have a four-year bachelor's degree, but they come from a variety of disciplinary backgrounds. That is, the entering students are not required to have any kind of background in IS or related subjects, although in many cases some bridge modules extending the undergraduate experience are needed. In sum, in countries where there are sufficient numbers of applicants with bachelor's degrees, the universities focus on the nature of the degree and the qualifications of the applicant. In countries building up the IS work force, the entry requirements tend to be more flexible.

\subsection{Length of Program and Amount of Student Work}

Typically IS master's programs require one or two years of full-time study, suggesting significant differences between program requirements. Some schools also offer part-time options for working professionals. In addition to the on-site study, distance education appears often as an option. Doing comparisons based on the amount of student work was challenging. However, in Europe, the introduction of ECTS credits gives considerable comparability. A typical European two-year master's degree is 120 ECTS credits, corresponding to 3200 hours student work, with a one-year degree half of that. Also three-semester degrees exist. In France, the MIAGE degrees emphasize three possible modes of attendance: full-time followed by internship after the academic year; apprenticeship, where periods at university are combined with periods in industry; and continuous, where students work for a company and attend courses during their free time.

In Asia, programs are typically between one to two years in duration for full-time students and twice as long for part-time students. There are plenty of programs taught in the evenings and during weekends. The workload required for one credit varies. For example, in Singapore one credit is 32.5 hours, but in reality, students spend about $50 \%$ more time. While the calculated workload is 1400 hours, the real requirement can be even 2800 hours. The length of degrees in Australia and New Zealand (ANZ) is either 1.5 or two years, where two years is more popular as it aligns better with migration requirements. Regarding student working hours, New Zealand universities follow a standard model in which a typical student workload per year is 1200 hours. Among Australian universities, the credit system varies significantly. The workload for Australian master's degree students may range from 900 hours to 1600 hours, where 1200 hours of workload is most common. 
In North America, one credit hour is most often equivalent to 15 classroom contact hours, with the assumption that students will work externally for at least two hours ${ }^{12}$ for each hour in the classroom (leading to a total work requirement of 45 hours per one credit hour). The credit hour requirements for programs range from 30 to 53, which equates to 1350 to 2385 hours of total student work; most programs are between 30 and 36 credit hours. This range of credit and associated work hours is represented in programs lasting 11 to 24 months for full-time students. If we take into consideration the amount of IS studies prior to entering the program and add to that the workload of the program, the potential for variation in terms of IS knowledge and skills by a master's degree holder is considerable.

\subsection{Degree Structures}

A master's degree in IS consists usually of a number of core modules in IS and the domain of practice, augmented with elective modules. In North America and in Asia, the degrees are usually course-based. In Australia, the Australian Computer Society (ACS) mandates that the master's degrees in computing should include a capstone project unit, which is often a practical component rather than a research thesis. The project often requires supervision by and interaction with industry. In France, the MIAGE degree emphasizes professional training, including always internships and possibly projects with industry. In Germany, several programs include a 6 or 12 ECTS project in addition to the thesis.

The Bologna process has significant increased the popularity of exchange periods in Europe, as the credits can be included in the degree. Employers also appreciate international experience. In North America and Asia, a thesis is an option for students interested in a research career. In Europe, the thesis is an essential part of the degree, usually worth 30 ECTS credits (an equivalent of 15 semester hours). To support the independent work required, usually a course in research methods and a seminar is required. In the seminar, each student presents the research carried out so far.

\section{MSIS 2016 Design Process}

This chapter provides a brief description of the key events that took place during the MSIS 2016 development process. Panel discussions at AMCIS 2010 in Peru (Topi et al. 2011) and AIS SIG-ED 2011 in Shanghai (Topi et al. 2013) set the stage for the process so that in $2012 \mathrm{ACM}$ and AIS set a preliminary task force to review the need for revising MSIS 2006. This task force completed its work in 2013 and recommended to AIS and ACM that they launch a comprehensive revision of MSIS 2006.

The program directors and other members of the IS community who provided feedback to the preliminary task force indicated overwhelmingly that there is a need

12 In some contexts, the assumption is three hours of work per each classroom hour at the graduate level. 
to review and revise MSIS 2006. Members of the IS community had found MSIS 2006 to be a useful resource, suggesting that future revisions of the model curriculum would be likely to serve in a similar way. There are several significant differences between the current practice in the leading programs and MSIS 2006. The rich variety of the programs and the lack of the intellectual core is a concern from the perspective of the field. It is very difficult for MS programs in IS to achieve their full promise if prospective employers and other key stakeholders do not have a clear idea of the identity of the programs. A revision of the MSIS model curriculum could serve a role in moving closer to a shared identity.

Decisions to move forward with the revision process were made by AIS (AIS Council Meeting in Milan, Italy in December 13-14, 2013) and ACM (Education Council meeting in October 2013). The ACM/AIS MSIS Task Force was launched in July 1, 2014 and was set to continue for three fiscal years (2014-15; 2015-16; and 201617). ACM selected Heikki Topi (Bentley University, USA) as co-chair in March 2014 and AIS selected Helena Karsten (Åbo Akademi University, Turku, Finland) as their co-chair in June 2014. Starting in August 2014, the co-chairs had weekly conference calls throughout the process.

Both ACM and AIS wanted the task force to be global, as opposed to the earlier US task forces. In addition, the task force was formed based on an open call for expressions of interest. The co-chairs made a membership recommendation in October 2014, approved by ACM and AIS in November 2014. Three members represent ACM and three AIS. Of the members, three are based in US, three in Europe, and two in Asia-Pacific.

The task force started its work in January 2015. In addition to the monthly conference calls, the task force had three face-to-face meetings in April 24-25, 2015 (Amsterdam, Netherlands), December 11-12, 2015 (Fort Worth, USA) and August 12-14, 2016 (San Diego, USA). The task force produced three interim deliverables (June 2015, March 2016, and July 2016), which were made available on the task force website (http://www.msis2016.org) with worldwide calls for feedback.

One of the first tasks the task force undertook was to identify the characteristics of IS programs globally (see Karsten et al. 2015). Based on the variety of programs, a course or topic based approach was found very problematic. During the Amsterdam meeting, the task force was introduced to the ongoing work in Europe and Australia on competencies of IS and IT professionals (such as e-CF and SFIA). This led the task force to consider graduate competencies as the main focus of the work. The task force ended up consulting several international and national competence frameworks and related professional profiles. During this meeting, the required background and the type of the degree to focus on were discussed, as well as the role and place of a thesis. This work was documented and shared in the first interim report. The work was also presented and discussed in panels in ECIS 2015, PACIS 2015, AMCIS 2015, and MIS Academic Leadership Conference (MALC) 2015, in addition to national events. In fall 2015, the task force conducted a survey, soliciting responses from both academic and industry experts. 
During the Fort Worth meeting (organized in the context of ICIS 2015), the main focus was on identifying the core competencies of MSIS graduates. The outcome of this work was the identification of prerequisite competencies to the program and the competency areas and categories that IS graduates are expected to have. In Fort Worth, the task force presented their work as a panel in the AIS SIG-ED conference. After further refinement, the competency structure was presented in the second interim report in March 2016. Soon after this interim report, the task force conducted its second major survey, soliciting feedback from both the academic community (through the AISWorld list and social media networks) and industry experts (through the Society for Information Management community and a purchased list).

The task force continued its work throughout spring and summer 2016 by refining and assessing the competencies based on the feedback it received through the surveys, website, and presentations and discussions at various conferences. A major effort was creating a procedure for forming a degree program with the competencies, target job profiles, and local requirements as the starting point. Again, panels in ECIS 2016, PACIS 2016, and AMCIS 2016 gave valuable feedback.

During the San Diego meeting, the task force finalized the competency structure and worked to complete the model.

\section{Key Differences between MSIS 2006 and MSIS 2016}

This section discusses key differences between the previous master's level curriculum recommendation MSIS 2006 and the current document. The main differences exist in the geographic scope, diversity in domains of practice, prerequisites, and the content.

\subsection{Geographic Scope}

The MSIS 2006 report explicitly acknowledges that the curriculum had been developed with the graduate programs in the United States and Canada in mind. As the authors put it, this approach "avoids the difficulties of considering a large number of educational systems" (Gorgone et al. 2006, 124). However, despite this narrow geographic focus, the authors claim that the MSIS 2006 curriculum rationale and structure can still serve as relevant input for curriculum designers in other regional contexts.

Considering the increasingly global orientation of AIS and ACM, global reach of academic degree programs in IS, and the global nature of the IS supply chain, the MSIS 2016 competency model aims to be recognized as global-that is, free from any particular regional constraints.

This extension of geographic scope brings in a diversity of situations that are worth mentioning (and that have already been addressed in more detail in Chapter 12):

- How much and what topics have students studied before entering the master's program? 
- What, how much, and in what ways do the students study for an IS master's degree?

- What is the structure of the IS master's degree, specified as a balance between elements such as courses, industry projects, thesis, exchange periods abroad, and others?

- Do the students continue directly to master's studies after a bachelor's degree, or are they expected to have work experience before?

The awareness of the diversity of situations influenced several of the decisions of the task force.

\subsection{Broader Range of Domains of Practice}

MSIS 2006 was entirely focused on business as the primary-indeed, the onlydomain of practice. MSIS 2016 explicitly recognizes the significant value that an IS degree program can offer to a variety of domains of human activity in addition to business, including health care, governmental organizations, not-for-profit organizations, law, various scientific fields, etc.

We have included Health Informatics (HI) as a sample domain of practice and provide learning outcome examples for an HI program in Chapter 5.

\subsection{Prerequisites}

MSIS 2006 and MSIS 2016 take a different approach to prerequisites.

MSIS 2006 considered five scenarios for possible backgrounds of students entering the MSIS program (adapted from Gorgone et al., 2006, p. 132):

1. An IS Major-Student with an undergraduate major conforming to IS 2002 and little experience;

2. Business Major-Student with a BA in business, including a general introductory IS course;

3. Computer Science Major-A computer science undergraduate with no IS courses and little experience;

4. Other Undergraduate Major-Undergraduate in science, social science, or humanities;

5. Professional-Professional returning to institution with extensive practical experience.

MSIS 2016 has been developed based on a specific set of required pre-master's competencies in IS, in computing, and in the domain of practice. These can be acquired in a number of ways. The main tenet is that the competencies need to be verified prior to entry and that sufficient bridge studies are provided for the student to accomplish early on during the studies. To be able to study on the master's level, in addition to the language of instruction, the key individual foundational competencies include at least oral and written communication. 
A bachelor's degree in IS (using IS 2010 as reference) is the primary degree background for entering an MSIS program. The undergraduate degree can be also in a computing field plus bridge courses in IS. MSIS 2016 does not require prior work experience. If the undergraduate degree does not include sufficient coverage of the domain of practice, appropriate bridge studies need to be included in the program early on. Considerable work experience can also be used as a way to satisfy domain of practice coverage, but the experience-based competencies need to be mapped with the modules in the undergraduate program to allow for substitution.

\subsection{Content}

The most significant difference between MSIS 2006 and MSIS 2016 is the fundamental architecture of the curriculum. MSIS 2006 was built around courses and their knowledge content, whereas the fundamental structuring element of MSIS 2016 is a graduate competency. Thus MSIS 2016 does not specify the curriculum topics that should be included; instead, the topics will be determined when an actual curriculum implementation is designed.

The focus of the MSIS 2006 curriculum was on the knowledge that should be taught. MSIS 2006 included detailed descriptions of courses fitting within the knowledge areas. MSIS 2006 identified a set of possible career paths in a non-exhaustive list. MSIS 2006 did not, however, provide detailed descriptions of these career paths or an explicit association between the career paths and their knowledge requirements.

In the MSIS 2016 competency model, the approach is quite different. The MSIS 2016 development process identified and developed a set of competency areas with competencies that MSIS graduates should attain by the time of graduation. These competencies are associated with three broad realms: information systems (including both computing/IT and IS Management dimensions), domain of practice, and individual foundational competencies. The competency areas are refined in competency categories with examples of actual competencies. A competency is understood as the ability to use knowledge, skills, and attitudes to successfully perform a task.

A possible procedure and some guidelines are given for how to formulate a curriculum based on job profiles and their competency needs. Examples of how to build a curriculum for a specific job profile are given. Two of these examples- IT consultant/systems analyst and project manager-are based on ICT job profiles (CEN 2012) and one, based on the feedback received, on mapping a program for IS startups to the competency categories. Again, we emphasize that the actual structure of the program needs to be locally decided, due to the wide variety of requirements for programs around the world.

\section{Maintaining the Currency of MSIS 2016}

There is a danger that curriculum guidance created at one point in time will quickly become outdated, particularly one that purports to prepare people for a career in 
technology-related fields. We have taken care to build in some mechanisms that will, hopefully, enable the various programs that adopt the MSIS 2016 model to have both a core and a means of addressing new, relevant topics and competencies that will unavoidably emerge in the near future.

- The recommendation is based on competencies. Rather than focusing on topics or modules, we aimed to identify the competencies that graduates should have attained during their studies. We are providing a frameworknot a mandated structure, but rather an organizing mechanism for the competencies. Some have suggested that the terminology used in competency areas and categories is all too familiar. We agree that many terms are, indeed, familiar. However, in looking at the competencies needed by professionals who lead and implement organizational use of information technology, the core ideas have not changed. Students still need to know the techniques for acquiring, storing, and analyzing data; they still need to know how to elicit requirements and design systems. Today, they may have to also engage in advanced analytics and/or mapping sourcing strategies that not only include offshoring, but might also include crowdsourcing. But the need to differentiate across the sourcing strategies remains.

- In our investigation of the global curricula, we found that the credit requirements for a degree varied greatly. In this competency model, it is our intention to identify the core set of competencies, while also recognizing that the wide variety of jobs available in IS will lead students to specialize in different areas. For example, although all graduates need to understand the basics of data and the basics of security systems, students who specialize in analytics will need to learn more advanced skills associated with analyzing unstructured data as well as sophisticated statistical and visualization tools. Likewise, students aiming to specialize in security will need more and deeper competencies in security-related topics. The curriculum guidelines are flexible enough to enable programs to do both, while also staying in line with the recommendations.

Some have recommended that these recommendations should evolve as the field evolves. In many ways, this makes sense as it allows us to leverage the very thing we teach. An online open dialogue among the community members would certainly enable curricula to be flexible and to evolve. There are also a number of challenges associated with this approach.

One critical challenge is that universities do not move as quickly as our field does. Anyone who has been involved in a curriculum revision knows all too well that it takes time for courses to be changed and new ones to be added. Further, curricula are often tightly interwoven. Courses require prerequisite knowledge, and a change in one can lead to cascading effects. Further, many universities have aligned curricular priorities with the needs of major recruiters. Thus, a change can have long-term (potentially negative) impacts on students' job prospects in certain areas. In the end, the ability of a particular department to respond to guidance that is continually updated is likely to be quite low. 
It is our intention that the competency-based approach of this recommendation provides a solid foundation of knowledge relevant for individuals who will lead and implement IT-based capabilities in organizations. In addition to the core competencies, we have identified potential additional competencies that would be useful for graduates. Ultimately, in order to continue providing education that prepares our students for the evolving sorts of jobs in a variety of professional IS roles, we encourage open, ongoing dialogue regarding teaching-related issues. The results of such community collaboration could periodically be captured in competency and curriculum documents, thus providing the optimal compromise of interaction, evolution, and sufficient stability to enable programs to use the recommendations in the best manner for their situation.

Finally, we would like to acknowledge the important role of the EDUglopedia platform (http://www.Eduglopedia.org), which maintains an updated worldwide collection of educational programs, courses, and pedagogical resources. The program data is published annually in the AIS Global Education Report (vom Brocke et al. 2016).

\section{Conclusion}

The MSIS 2016 task force hopes that this competency model will become a useful resource for a rich variety of master's degree programs in IS around the world. We expect that all programs that use it will modify it to fit their own purposes better, and we applaud this-the guidance this document provides is intended to be inspirational and supportive instead of being normative. We also hope that programs will share their experiences and give back to the IS community in the spirit of continuous education and collaborative learning. Thank you for using this document-if you find it useful, please share it with those who might also benefit from it! We welcome your feedback and thank you for it.

\section{References}

Adelman, C., Ewell, P., Gaston, P., \& Schneider, C. G. (2014). The Degree Qualifications Profile: A Learning-Centered Framework for What College Graduates Should Know and Be Able to Do to Earn the Associate, Bachelor's or Master's Degree. (C. Adelman, P. Ewell, P. Gaston, \& C. G. Schneider, Eds.). Lumina Foundation. Retrieved from http://degreeprofile.org/press_four/wpcontent/uploads/2014/09/DQP-web-download.pdf.

Amabile, T. M., Conti, R., Coon, H., Lazenby, J., \& Herron, M. (1996). Assessing the Work Environment for Creativity. Academy of Management Journal, 39(5), 11541184. http://doi.org/10.2307/256995.

American Medical Informatics Association. (2008). Health Information Management and Informatics Core Competencies for Individuals Working With Electronic 
Health Records. Available at https://www.amia.org/sites/default/files/JointWork-Force-Task-Force-2008.pdf, accessed Oct 20, 2016.

Anderson, J. R. (1980). Cognitive Psychology and Its Implications. San Francisco: Freeman.

Armstrong, M. (2006). A Handbook of Human Resource Management Practice (10 Ed.). London: Kogan Page.

Ashenhurst, R. L. (1972). Curriculum Recommendations for Graduate Professional Programs in Information Systems. Communications of the ACM, 15(5), 364-398.

Vom Brocke, J., Tan, B., Topi, H., \& Weinmann. M. (2016). AIS Global Education Report. Available at eduglopedia.org/report/ais-global-is-educationreport/2016, accessed October 26, 2016.

Von Bertalanffy L. (1968). General Systems Theory. New York: George Braziller.

Bologna Working Group. (2005). A Framework for Qualifications of the European Higher Education Area. Bologna Working Group Report on Qualifications Frameworks, Copenhagen: Danish Ministry of Science, Technology and Innovation.

Connock, S., \& Johns, T. (1995). Ethical Leadership. IPD, London.

2012 Clinger-Cohen Core Competencies \& Learning Objectives. Available at https://cio.gov/wp-content/uploads/downloads/2013/02/2012-LearningObjectives-Final.pdf.

CDC. Competencies for Public Health Informaticians 2009. Available at https://www.cdc.gov/informaticscompetencies/pdfs/phi-competencies.pdf, accessed Oct 20, 2016.

CEN (2012) European ICT Professional Profiles. European Committee for Standardization (CEN) Workshop Agreement CWA 16458, May 2012. Brussels, Belgium. Available at http://relaunch.ecompetences.eu/wpcontent/uploads/2013/12/EU_ICT_Professional_Profiles_CWA_updated_by_e_C F_3.0.pdf.

Chiang, R. H. L., Goes, P., \& Stohr, E. A. (2012). Business Intelligence and Analytics Education, and Program Development. ACM Transactions on Management Information Systems, 3(3), 1-13.

Deardorff, D. K. (2006). Identification and Assessment of Intercultural Competence as a Student Outcome of Internationalization. Journal of Studies in International Education, 10(3), 241-266. http://doi.org/10.1177/1028315306287002

Dreyfus, H. L., \& Dreyfus, S. E. (1986). Mind over Machine: The Power of Human Intuition and Expertise in the Era of the Computer. New York: The Free Press.

Dreyfus, H. L., \& Dreyfus, S. E. (2005). Peripheral Vision: Expertise in Real World Contexts. Organization Studies, 26(5), 779-792. http://doi.org/10.1177/0170840605053102 
The European e-Competence Framework (e-CF) 3.0: a Common European

Framework for ICT Professionals in All Industry Sectors. Available at www.ecompetences.eu.

Gorgone, J. T., Davis, G. B., Valacich, J. S., Topi, H., Feinstein, D. L., \& Longenecker, H. E. (2002). IS 2002 model curriculum and guidelines for undergraduate degree programs in information systems. Communications of the Association for Information Systems, 11(1). Retrieved from http://aisel.aisnet.org/cais/vol11/iss1/1

Gorgone, J. T.; Gray, P.; Feinstein, D. L.; Kasper, G. M.; Luftman, J.; Stohr, E. A.; Valacich, J. S.; and Wigand, R. (2000) "MSIS 2000: Model Curriculum and Guidelines for Graduate Degree Programs in Information Systems," Communications of the Association for Information Systems, 3, Article 1. Available at: http://aisel.aisnet.org/cais/vol3/iss1/1

Gorgone, J. T., Gray, P., Stohr, E. A., Valacich, J. S., \& Wigand, R. T. (2006). MSIS 2006: Model Curriculum and Guidelines for Graduate Degree Programs in Information Systems. Communications of the AIS, 17(17), 1-58.

Gupta, B., Goul, M., \& Dinter, B. (2015). Business Intelligence and Big Data in Higher Education. Communications of the Association for Information Systems, 36, 23, $449-476$.

Halpern, D. F. (2013). Thought and Knowledge. Psychology Press.

Hoffmann, T. (1999). The meanings of competency. Journal of European Industrial Training, 23(6), 275-286. http://doi.org/10.1108/03090599910284650

Johnson, D.W. \& Johnson, F.P. (1987) Joining together: Group theory and group skills. 3rd edition. Prentice Hall.

Johnson, D. W., Johnson, R.T. and Houlubec, E.J. (1993) The New Circles of Learning: Cooperation in the Classroom and School, Interaction Book Co.

Jonassen, D. H. (2000). Toward a Design Theory of Problem Solving. Educational Technology Research and Development, 48(4), 63-85.

Kampov-Polevoi, J., \& Hemminger, B. M. (2011). A curricula-based comparison of biomedical and health informatics programs in the USA. Journal of the American Medical Informatics Association, 18(2), 195-202.

Karsten, H., Topi, H., Brown, S. A., Carvalho, J. A., Donnellan, B., Shen, J., et al. (2015). Master's Degree Programs in Information Systems: A Global View. Presented at the AIS SIG-ED (IAIM) 2015, Fort Worth, TX. Retrieved from http://aisel.aisnet.org/siged2015/14

Lockoff, J., Wegewiis, B., Durkin, K., Wagenaar, R., Gonzales, J., Isaacs, A. K., Donà dale Rose \& Gobbi (Eds.) (2010). A Tuning Guide to Formulating Degree Programme Profiles: Including Programme Competences and Programme Learning Outcomes, Tuning Educational Structures in Europe. TUNING Association, Competences in Education and Recognition Project (CoRE). Retrieved from 
http://core-

project.eu/documents/Tuning\%20G\%20Formulating\%20Degree\%20PR4.pdf.

Nunamaker, J. F., Couger, J. D., \& Davis, G. B. (1982). Information systems curriculum recommendations for the 80s: undergraduate and graduate programs.

Communications of the ACM, 25(11), 781-805.

http://doi.org/10.1145/358690.358698

O*NET (Occupational Information Network) (www.onetonline.org)

Orme, G., \& Ashton, C. (2003). Ethics - a foundation competency. Industrial and Commercial Training, 35(5), 184-190.

http://doi.org/10.1108/00197850310487313

Paquette, G. (2007). An ontology and a software framework for competency modeling and management. Journal of Educational Technology \& Society, 10(3), $1-21$.

Pruitt, D. G. (1981). Negotiation Behavior. Academic Press.

Pyster, A., Olwell, D. H., Ferris, T., Hutchison, N., Enck, S., Anthony, J., \& Henry, D. (2015). Graduate Reference Curriculum for Systems Engineering (GRCSE®) v. 1.1. Hoboken, NJ, USA: Trustees of the Stevens Institute of Technology.

Schon, D. (1983). The Reflective Practitioner. Basic Books.

SFIA (2016). The Skills Framework for the Information Age (SFIA) (www.sfiaonline.org/en).

Shackelford, R., Cross, J. H., Davies, G., Impagliazzo, J., Kamali, R., LeBlanc, R., et al. (2005). Computing Curricula 2005: The Overview Report. Association for Computing Machinery; Association for Information Systems; and IEEE Computer Society.

Squires, A., \& Larson, W. (2009). Improving systems engineering curriculum using a competency-based assessment approach. International Journal of Intelligent Defense Support Systems, 2(3), 184. http://doi.org/10.1504/IJIDSS.2009.030583.

Stevens, M. J., \& Campion, M. A. (1994). The Knowledge, Skill, and Ability Requirements for Teamwork: Implications for Human Resource Management. Journal of Management, 20(2), 503530.http://doi.org/10.1177/014920639402000210.

Stogdill, R. M. (1950). Leadership, membership and organization. Psychological Bulletin, 47(1), 1-14. http://doi.org/10.1037/h0053857

Topi, H. (2014). Program Directors' Perspectives on MSIS Outcome Expectations and Future Directions. Presented at the Proceedings of the 2014 AIS SIG-ED conference, Auckland, New Zealand, December 2014.

Topi, H., Karsten, H., Brown, S. A., Carvalho, J. A., Donnellan, B., Shen, J., et al. (2015). Current MSIS Students' Views on Program Outcomes. Presented at the AIS SIGED (IAIM) 2015, Fort Worth, TX. December 2015. 
Topi, H., Valacich, J. S., Wright, R. T., Kaiser, K., Nunamaker, J. F., Sipior, J. C., \& de Vreede, G. J. (2010a). IS 2010: Curriculum Guidelines for Undergraduate Degree Programs in Information Systems. Communications of the Association for Information Systems, 26(18). Retrieved from http://aisel.aisnet.org/cais/vol26/iss1/18/.

Topi, H., Wright, R. T., Donnellan, B., Schiano, W. T., Valacich, J. S., \& Venkataraman, R. (2010b). Future of Master's Level Education in Information Systems Panel Presentation (pp. 1-4). Presented at the 16th Americas Conference on Information Systems, Lima, Peru. August 2010.

University of Michigan Health Informatics. (2016). Core values and competencies. Available at http://healthinformatics.umich.edu/academics/core-valuescompetencies. Accessed Oct 20, 2016. 


\section{MSIS 2016 Appendix A. Detailed Competency Specifications}

\section{Competencies in the area of Business ${ }^{1}$ Continuity and Information Assurance (BCIA)}

Area Description: Business Continuity and Information Assurance competency area mainly concerns the continuity, auditing, and assurance of the information systems. It generally covers areas such as risk avoidance, security management, and quality auditing. The challenging issues related to business continuity and information assurance span from tactical and strategic to technical and operational levels. They often involve a range of processes from management, such as policy and standard setting, to hands-on skills, such as system contingency and recovery planning.

High-level area competencies

The graduates will be able to

1. Create policies and standards for business continuity and information assurance.

2. Plan and implement procedures, operations, and technologies for managing risk and trust, security and safety as well as business continuity and disaster recovery.

3. Monitor, control, and institutionalize the protection and growth of the hardware, software, and information assets within information systems.

[Note: the individual competencies within the categories below are not intended to be comprehensive and are potentially more time-dependent than the competency areas and categories. The individual competencies descriptions all start with "Graduates will be able to," which is not included to avoid repetition.]

Competency Categories and Competency Examples-Pre-master's

None explicitly expected.

\section{Competency Categories and Competency Examples-Master's}

1. Managing and implementing cybersecurity

a. Develop, implement, and maintain security policy and technical procedures to protect and defend the data and network systems in the organization.

b. Monitor and control security related events, such as detecting intrusion, identifying fraud, and responding to security incidents.

c. Understand essential system and network security-related technologies, including cryptology, security protocols and framework, firewall and IDS tools, etc.

2. Responding to and managing IS problems

\footnotetext{
${ }^{1}$ We use the term Business Continuity here because of its longstanding use to refer to the continuity of all types of domain activities.
} 
a. Respond to problems and incidents raised during domain operations in order to minimize the interruption to the data and system access.

b. Investigate incidents and analyze and report results of these investigations.

c. Apply standard digital forensic and cybercrime prevention techniques.

3. Monitoring system operations

a. Monitor and track system operations in order to ensure smoothness and continuity while avoiding and reducing interruptions and incidents.

b. Track system performance, monitor security, and analyze user behavior.

c. Assess the running conditions of the IT system within an organization and take appropriate actions when unexpected events occur.

4. Managing system recovery

a. Initiate recovery and contingency plans and operations in the event of system failures or security compromises in order to keep the IT assets resilient to any interruptions of normal conditions of the domain.

b. Manage the processes of system isolation and restoration, disaster recovery, and crisis management.

c. Contain system faults and bring the system back up and running from problematic situations.

5. Managing IS risks

a. Assess and identify potential risks to the information systems and execute necessary actions to avoid and reduce the threats from the risks.

b. Identify vulnerabilities and threats.

c. Monitor and mitigate risks.

6. Protecting IT assets

a. Plan and manage IT assets, including the system, network, databases, and established processes and practices within the organization.

b. Protect the IT assets from internal and external damages caused by careless or malicious threats.

c. Maintain Confidentiality, Integrity, and Availability (CIA).

d. Enforce regulatory requirements and contracts.

7. Developing information assurance strategy

a. Develop leadership and oversight in setting corporate-level strategy and policy to assure cost-effective and confident management of the information systems within the organization.

b. Integrate protection from risks and security threats.

8. Engineering systems for continuity

a. Ensure continuous operation of IT assets in all phases of the lifecycle of the information systems.

b. Apply techniques of continuity-aware planning top IT procurement.

c. Execute remedial and contingency planning.

d. Consider human resources implications of continuity planning. 
9. Implementing and managing quality audit processes

a. Assess and audit the integrity and quality of the IT provisions in the organization.

b. Monitor and analyze risks and domain objectives in order to improve domain and IT alignment so that the organization may achieve continuity in domain activities.

c. Use auditing and monitoring tools and measures.

d. Perform impact analysis and assessment.

10. Assuring safety throughout systems lifecycle

a. Assure safety during all phases of systems development, maintenance, and reuse.

b. Anticipate safety hazards and perform risk analyses.

c. Perform hazard analyses and risk assessments.

d. Conduct safety assurance planning and compliance.

e. Incorporate safety in systems architectural design. 


\section{Competencies in the area of Data, Information, and Content Management (DATA)}

Area Description: Data, Information, and Content Management area covers competencies that enable the graduates to be effective contributors in processes that improve the domain's ability to achieve its goals using structured and unstructured data and information effectively.

High-level area competencies

The graduates will be able to

1. Identify data and information management technology alternatives, select the most appropriate options based on the organizational information needs, and manage the implementation of the selected options.

2. Identify, create, and manage organizational policies and processes related to data and information management by balancing multidimensional requirements, such as legal and regulatory requirements, ethical considerations and implications of technology decisions, organizational requirements, data quality issues, and requirements of operating in an international environment.

3. Analyze the needs of a domain and determine how those needs can be best addressed with data, information, and content management solutions.

[Note: the individual competencies within the categories below are not intended to be comprehensive and are potentially more time-dependent than the competency areas and categories. The individual competencies descriptions all start with "Graduates will be able to," which is not included to avoid repetition.]

\section{Competency categories and competency examples-Pre-master's}

11. Explaining key data and information concepts and the data and information management lifecycle

a. Explain the differences between data, information, and knowledge.

b. Explain the reasons why data, information, knowledge, data management, and content management solutions are essential for human activity.

c. Separate the lifecycle stages from each other conceptually.

d. Explain the actions required during each stage.

e. Explain the connection between systems lifecycles and data management lifecycles.

12. Capturing and structuring data and information requirements using appropriate conceptual modeling techniques

a. Interview and observe users to identify their data needs.

b. Evaluate domain activities to understand how they can be improved with effective use of data. 
c. Structure domain data requirements using Enhanced EntityRelationship (EER) modeling and alternative models such as hierarchical, network, cube, etc. as appropriate to the domain.

d. Evaluate appropriateness of different data structures for representing and storing data.

13. Developing a logical level representation of data based on a conceptual model

a. Convert an EER model into a relational data model.

b. Analyze the normalization status of a relational model and convert it to the third normal form.

14. Implementing a database solution to serve systems consisting of multiple applications

a. Articulate the key issues associated with physical design of databases in various environments.

b. Write SQL code to implement a relational database based on a relational data model.

c. Design and maintain an effective indexing solution for a relational database that supports transaction processing.

15. Using a contemporary data manipulation and retrieval language effectively

a. Implement a relational database using the DDL features of SQL.

b. Retrieve data from a complex relational database using the DML features of SQL.

c. Insert, update, and delete data in a relational database using the DML features of SQL.

\section{Competency categories and competency examples-Master's}

16. Selecting appropriate data management technologies based on the needs of the domain

a. Distinguish between technologies for operational databases, structured data warehouses, and repositories for unstructured data.

b. Design a technology architecture for organizational data management.

c. Select appropriate technology options for each of the architectural categories.

17. Securing domain data and protecting both user privacy and organizational intellectual property using appropriate technical solutions

a. Identify appropriate data encryption technologies.

b. Implement data access policies in the context of a database management system.

18. Designing and implementing a data warehouse using a contemporary architectural solution

a. Distinguish between an enterprise data warehouse and data mart and select an appropriate solution for an organization.

b. Design a schema for a data warehouse using one of the standard design approaches (such as star or snowflake schema). 
c. Implement a data warehouse using a contemporary technology solution.

19. Creating a scalable infrastructure for large amounts of data using parallel and distributed technologies

a. Architect solutions for the storage and management of large volumes of heterogeneous data using technologies such as Hadoop.

b. Architect solutions for the storage and management of large volumes of heterogeneous data using emerging data management technologies (such as NoSQL).

20. Developing and implementing organizational information management policies and processes

a. Align information use with the goals of the domain.

b. Ensure proper access to information.

c. Manage the policies regarding security, privacy, compliance with laws and regulations, and quality of data.

21. Creating an information architecture for an organization

a. Make explicit the spatial and temporal dimensions of information.

b. Design organizational structures to categorize information.

c. Develop labeling systems to represent information.

d. Develop navigation systems to enable users to browse or move through information.

e. Develop search systems to help users look for information.

f. Align information architecture with enterprise architecture.

22. Integrating and preparing data captured from various sources for analytical use

a. Identify appropriate data sources in a heterogeneous environment with multiple data types.

b. Design processes for extracting, transforming, and loading (ETL) data to the analytical environment.

c. Implement ETL processes in an organizational environment.

23. Selecting and using appropriate analytics methods

a. Identify appropriate analytics methods for given tasks.

b. Use an analytics platform to perform basic analytics tasks.

c. Report the results of an analytics task.

24. Analyzing data using advanced contemporary methods

a. Select and apply advanced computational approaches to identify meaningful patterns and trends.

b. Build models to support decision-making activities.

c. Create visualizations of large complex data sets to understand meaningful patterns and trends.

25. Designing and implementing architectures for organizational content management systems

a. Identify content providers and identify users' needs, goals, and expectations in documenting, sharing, and publishing organizational content. 
b. Design information architectures for content management system in an organization.

c. Implement application architectures and systems, either through websites or mobile applications, for presenting and managing the content management system internally and externally.

d. Use and manage content management software running on different platforms, such as Software as a Service, off-the-shelf software, and open-source software. 


\section{Competencies in the area of Enterprise Architecture (EARC)}

Area Description: Enterprise architecture has two aims: managing the complexity of information systems and technologies and fitting these with the organization's strategy. The area covers competences that enable graduates to participate in planning, building, using, maintaining, and evaluating the architectures.

\section{High-level area competences}

The graduates will be able to

1. Design an enterprise architecture (EA). This involves identifying and applying a formal approach to EA development, performing the multistage process of developing an EA, identifying the EA change needs, and applying them to the EA. Graduates are able to incorporate information, domain activity processes, technology platforms, applications, software, and hardware in the EA while considering the alignment between domain requirements and technology development.

2. Deploy and maintain an EA. This involves conveying the architecture to domain process owners, software development and maintenance projects, and infrastructure planners and taking into account the current status of the projects and infrastructure. This also includes gathering input from the enterprise and from technology developments for maintaining the architecture and performing architecture maintenance.

[Note: the individual competencies within the categories below are not intended to be comprehensive and are potentially more time-dependent than the competency areas and categories. The individual competencies descriptions all start with "Graduates will be able to," which is not included to avoid repetition.]

\section{Competence categories and competence examples-Pre-master's}

None explicitly expected.

\section{Competence categories and competence examples - Master's}

26. Explaining enterprise architecture principles to justify the value enterprise architecture provides to organizations within various types of domains

a. Justify the value of building and maintaining an EA.

b. Measure and analyze value accruing from an EA.

c. Distinguish various architectural forms (such as SOA, event-driven, peer-to-peer).

d. Use confidently EA taxonomies and concepts.

e. Prepare the organization to have an EA.

f. Apply EA to achieve strategic alignment. 
27. Designing, building, and maintaining an enterprise architecture

a. Suggest and apply an appropriate EA framework and methodologies for an organization (such as The Open Group Architecture Framework [TOGAF], Federal Enterprise Architecture Framework [FEAF], and the Zachman framework).

b. Model the enterprise from various architectural perspectives using a specific architecture framework.

c. Participate effectively in a process of building an EA conducted using a specific framework model.

28. Communicating and deploying an enterprise architecture

a. Select and justify an appropriate deployment strategy (such as replacement or incremental).

b. Manage necessary organizational changes.

c. Establish an EA practice.

d. Communicate the EA effectively to relevant stakeholders.

29. Using an enterprise architecture to influence IS-related organizational improvement projects

a. Bring the EA view into organizational improvement projects that are likely to affect (and be affected by) the EA.

b. Use the EA effectively to support the interoperability of systems and services.

c. Use the EA effectively to support the scalability of systems and services.

d. Support high-level system usability using an EA.

e. Ensure that the development of information systems is aligned with domain changes.

f. Ensure alignment between domain architecture, information architecture, and IT architecture. 


\section{Competencies in the area of Ethics, Impacts, and Sustainability (ETIS)}

Area Description: The ethics and impacts competency area covers the conceptualization and implementation of environmentally and socially sustainable IT solutions that are aligned with the responsibilities of organizations as well as in compliance with legislative and regulatory requirements and industry standards. This competency area addresses key questions such as environmental and social sustainability, safety and health, privacy and integrity. It also covers the impact of IT on the nature of work and workplaces and explores how culture and ethics (internal pertaining to organizations and external pertaining to stakeholders) shape behavior. These areas tend to be aligned with a strategic or a tactical level of organizational decision-making.

High-level area competencies

The graduates will be able to

1. Apply sustainable approaches for IT solutions development, IT procurement, IT operations, IT resources management, and other IT practices.

2. Ensure safety and avoid health hazards for contract arrangements with external parties and internal systems development, maintenance, and reuse.

3. Ensure that privacy and integrity guide all IT practices.

4. Interpret and comply with legislative and regulatory requirements governing IT practices as well as industry standards for IT practices.

[Note: the individual competencies within the categories below are not intended to be comprehensive and are potentially more time-dependent than the competency areas and categories. The individual competencies descriptions all start with "Graduates will be able to," which is not included to avoid repetition.]

\section{Competency categories and competency examples-Pre-master's}

None explicitly expected.

\section{Competency categories and competency examples-Master's}

30. Designing and managing sustainable IT operations

a. Plan for and manage IT assets and systems by using processes and practices that reduce consumption of energy and constrain disposal of materials.

b. Determine relevant methods and tools for addressing energy efficiency issues in IT operations.

c. Establish proper practices for disposal of materials in alignment with regulatory or policy requirements.

31. Aligning IT with organizational sustainability policy

a. Pursue sustainable IT solutions in accordance with the organizational sustainability policy. 
b. Monitor and measure IT energy consumption.

c. Apply latest approaches for sustainable development in IT projects.

d. Master regulatory constraints and international standards pertaining to IT sustainability.

32. Managing IT facilities sustainably

a. Plan and manage IT physical facilities, including conducting environmental monitoring for adverse effects and adhering to health and safety standards at work.

b. Manage the IT estate in accordance with organizational sustainability targets.

c. Take responsibility for adherence to health and safety regulations.

33. Managing sustainable procurement practices

a. Make recommendations to enhance organizational procurement processes to include sustainability, ethical, and compliance perspectives.

b. Analyze the energy efficiency and environmental aspects of procurement proposals.

c. Verify that procurement processes comply with laws such as intellectual property rights.

34. Managing contracts ethically

a. Negotiate contracts in accordance with organizational guidelines.

b. Comply with laws and regulations as well as health and safety standards.

c. Negotiate contract terms and conditions to include health and safety provisions.

d. Apply judgment in contract negotiations in compliance with laws and internal policies.

35. Maintaining compliance with legislation, regulations, and standards

a. Adhere to legislative and regulatory requirements governing IS practices as well as industry standards for IS practices.

b. Interpret relevant laws and regulations correctly to ensure that IS practices comply.

c. Incorporate relevant industry standards into IS practices.

36. Ensuring that protection of privacy and integrity guides all IS practices

a. Analyze privacy implications of key IS decisions.

b. Require technical safeguards to protect individual privacy as part of IS design and implementation.

c. Establish a culture in the IS organization that values privacy and integrity.

37. Fostering an ethical culture

a. Appreciate the roles of culture and ethics, internal or external to organizations, in shaping IS practices in organizations.

b. Analyze how culture and ethics shape behavior towards taking risks.

c. Learn from negative outcomes.

38. Considering ethical implications of IS decisions

a. Select appropriate ethical frameworks for analyzing IS decisions. 
b. Analyze ethical implications of IS-related decisions.

c. Justify abstaining from harmful decisions. 


\section{Competencies in the area of Innovation, Organizational Change, and Entrepreneurship (IOCE)}

Area Description: Innovation, organizational change, and entrepreneurship are concerned with the capability to recognize and exploit the potential afforded by current and upcoming technologies to address existing and new business opportunities. It also includes competencies required to understand and to intervene in different forms of domain activities (e.g., work units, work teams, processes, organizations, markets, society setting) in order to make use of information technologies to improve the way those activities are structured and are performed.

High-level area competencies

The graduates will be able to

1. Monitor the environment in order to identify and evaluate new IS methods and trends in terms of their appropriateness for an organization.

2. Develop innovative domain activity models relying on new uses of existing technology or new technologies themselves.

3. Develop a plan to exploit new and emerging methods and technologies for new purposes in an organization.

4. Devise new ways of structuring and performing domain activities at different levels (individual, team, process, and organization), taking into consideration the enabling and enhancing effects of information technology applications.

5. Estimate the benefits of the new designs, assess, the consequences of their implementation, and anticipate potential adverse consequences.

[Note: the individual competencies within the categories below are not intended to be comprehensive and are potentially more time-dependent than the competency areas and categories. The individual competencies descriptions all start with "Graduates will be able to," which is not included to avoid repetition.]

\section{Competency categories and competency examples-Pre-master's}

None explicitly expected.

\section{Competency categories and competency examples-Master's}

39. Monitoring the technology environment

a. Identify and evaluate sources of information regarding emerging methods and technologies.

b. Identify domain advantages associated with specific emerging methods or technologies.

c. Identify domain concerns associated with specific emerging methods or technologies.

40. Engaging in entrepreneurial thinking 
a. Describe the concept of effectual reasoning2.

b. Leverage effectual reasoning to imagine a set of outputs with a given set of inputs.

c. Map existing and emerging methods and technologies onto the set of inputs in (b) above.

41. Developing a business plan

a. List the components of a business plan.

b. Articulate a value proposition for a business idea.

c. Prepare a SWOT analysis.

d. Perform financial assessment (e.g., ROI, IRR, etc.).

e. Articulate the risks and rewards of business plans.

f. Propose a set of metrics for evaluating a business plan.

42. Innovating by exploiting an emerging method or technology

a. Identify opportunities to transform a domain of human activity by applying emerging technologies innovatively.

b. Identify the appropriate people to involve in an innovation plan.

c. Articulate plan milestones-including key decision points.

d. Describe key metrics that will be used to inform participants at the decision points.

e. Devise novel ways for the provision of domain solutions based on IT products or services.

f. Build prototypes to develop a proof of concept.

43. Promoting diffusion by leveraging differences between adopter groups

a. Explore diffusion and adoption from different perspectives.

b. Analyze the interests of different adopter categories.

c. Develop a plan to engage adopters at various stages along the diffusion curve.

44. Applying creative problem-solving to technology-related issues

a. Select a creative problem-solving approach.

b. Given a problem, apply creative problem-solving techniques to identify possible solutions.

c. Evaluate those solutions for a given context and make a recommendation.

45. Contributing to organizational development and change management

a. Contribute to organizational development initiatives bringing up the perspective of the impact of IT.

b. Manage organizational resistance to change effectively.

c. Modify organizational characteristics to enable domain process transformation.

${ }^{2}$ Effectual reasoning is entrepreneurial decision-making in absence of markets, hence without sufficient information of them. Much of the information required to bring new markets into existence itself does not come into existence until those markets are created. Effectuation rests on logic of control (of future), whereas causation rests on a logic of prediction (Sarasvathy 2001). 
d. Enable organizations to prepare for change through systematic, planned approaches.

46. Analyzing and documenting domain activities

a. Select modeling techniques appropriate to the domain situation and to the interaction with those who will participate in the modeling process.

b. Select inquiry and data collection methods appropriate to the situation.

c. Apply inquiry, data collection methods, and modeling techniques to investigate and describe a domain situation.

d. Validate the internal consistency of the models produced.

e. Validate the adequacy of the models with domain experts.

f. Use computer-based tools to support the creation, editing, sharing, and validation of the models.

47. Identifying opportunities for and designing process improvement

a. Identify opportunities for organizational improvements through process modifications.

b. Create, compare, assess feasibility of, and select from multiple options for organizational process improvements.

c. Deploy process changes throughout the organization.

d. Articulate high-level systems requirements to enable organizational process changes.

e. Apply modern process modeling approaches to identify and document existing and future processes. 


\section{Competencies in the area of IS Management and Operations (ISMO)}

Area Description: IS Management and Operations are concerned with the capability to develop, maintain, and consistently improve domain performance while providing appropriate information systems, services and infrastructure. The capability focuses externally on creating value for the domain and internally on IS staff motivation, performance, and accountability.

High-level area competencies

The graduates will be able to

1. Apply professional management skills to design and manage an effective IS organization.

2. Ensure operational efficiency and effectiveness in service delivery.

3. Govern IS project management principles and support their use in the organization.

4. Manage information systems use.

5. Manage information resources together with line management.

[Note: the individual competencies within the categories below are not intended to be comprehensive and are potentially more time-dependent than the competency areas and categories. The individual competencies descriptions all start with "Graduates will be able to," which is not included to avoid repetition.]

\section{Competency categories and competency examples-Pre-master's}

48. Applying broadly used project management tools and techniques

a. Select from broadly applied project management tools and techniques (such as PERT, GANTT, and their implementations in a widely used tool).

b. Apply successfully broadly applied project management tools and techniques to small- and medium-size projects.

\section{Competency categories and competency examples-Master's}

49. Managing the IS function

a. Manage the financial performance of the IS function.

b. Manage IS service production.

c. Manage IS service marketing.

50. Managing IS staff

a. Establish effective processes for managing IS staff performance.

b. Identify needs for education/training.

c. Offer an effective education/training program.

d. Plan and manage recruiting, hiring, and retention processes.

51. Managing IS service production 
a. Manage the operational processes that must be performed on a dayto-day basis to maintain acceptable IS performance levels.

b. Implement service control processes, including production and distribution scheduling, problem control, and service evaluation.

c. Manage user support so that it serves organizational needs.

d. Manage various types of IS production environments, including cloudbased and mobile.

52. Managing IS sourcing models

a. Identify IS sourcing options.

b. Select the best IS sourcing option for specific requirements and resource constraints.

c. Manage IS service and resource vendors.

d. Align sourcing decisions with other IS management decisions.

53. Managing and coordinating information resources

a. Identify relevant categories of information resources.

b. Determine the relevant focus of control for various information resources (such as centralized, decentralized, mobile).

c. Identify and select from various technology options for information resource management.

d. Manage processes for information resource management.

e. Identify and implement approaches to maximize the value of information resources.

54. Implementing relevant IT governance framework(s) within the organization based on strategic guidance

a. Train employees on the use of IT governance framework(s), such as ITIL and COBIT.

b. Provide guidance regarding framework use appropriate for a specific organizational environment.

c. Monitor organizational alignment with the framework.

55. Complying with laws and regulations directly affecting IS management and operations (such as Sarbanes-Oxley, PCI, CANSPAM, HIPAA in the US)

a. Identify locally and globally relevant laws and regulations.

b. Comply with laws and regulations.

56. Managing IS projects and programs

a. Select IS projects to execute.

b. Determine IS project feasibility.

c. Identify and manage IS project risks.

d. Plan and initiate an IS project, including project scheduling and creation of a work breakdown structure.

e. Determine and acquire IS project resources.

f. Manage IS project execution, including schedule, scope, and resources.

g. Close an IS project.

h. Organize similar or related IS projects into programs.

i. Manage allocation of resources, schedules, and conflicts between projects within a program.

57. Managing IS project portfolios 
a. Organize IS projects into meaningful portfolios that are aligned with organizational objectives.

b. Identify and manage IS project interdependencies.

c. Optimize project timelines within and between IS project portfolios.

d. Integrate IS projects for coordinated delivery of new capabilities.

e. Allocate resources among projects within a portfolio.

58. Managing software and hardware development and maintenance

a. Manage software development and upgrade processes.

b. Manage software procurement and upgrade processes.

c. Manage hardware procurement and upgrade processes.

d. Manage systems maintenance.

e. Manage systems tuning and balancing. 


\section{Competencies in the area of IS Strategy and Governance (ISSG)}

Area Description: IS strategy is concerned with the creation and implementation of long-term plans for designing, delivering, and using organizational information systems to achieve strategic domain goals and objectives. IS governance is concerned with monitoring and controlling organizational IS resources to ensure alignment with and achievement of strategies, goals, and objectives.

High-level area competencies

The graduates will be able to

1. Analyze the effect and impact of IS on industries, firms, and institutions; develop and implement plans of action for maximizing firm benefits associated with IS design, delivery, and use; and manage IS resources financially.

2. Create and manage the oversight mechanisms by which an organization evaluates, directs, and monitors organizational IT. These mechanisms may leverage one or more governance frameworks; hence, understanding the process of applying and analyzing a framework is a critical competency. Distribution of decision rights and organizational decision-making practices are other key components of this competency area.

3. Establish practices for minimizing environmental impacts and planning for long-term firm viability.

[Note: the individual competencies within the categories below are not intended to be comprehensive and are potentially more time-dependent than the competency areas and categories. The individual competencies descriptions all start with "Graduates will be able to," which is not included to avoid repetition.]

\section{Competency categories and competency examples_Pre-master's}

None specifically expected.

\section{Competency categories and competency examples-Master's}

59. Conducting IS strategic analysis

a. Design new and innovative digital capabilities.

b. Analyze industry conditions using broadly accepted models to understand ways in which IS shapes industry forces.

c. Analyze IS resources to identify and create valuable, rare, and inimitable IS resource combinations.

d. Analyze institutional characteristics (e.g., politics, law, societal norms) having an effect on the firm and justify how IS may be used to influence institutional characteristics.

60. Making a financial case for IS 
a. Prepare and develop documents to articulate the business case for investments in IS.

b. Calculate the economic value of IS, taking into consideration tangible and intangible costs and benefits.

c. Calculate the economic value of IS, taking into consideration internal (within firm) costs and benefits as well as external (between firms) costs and benefits.

d. Calculate the economic value of IS taking into account innovative and disruptive solutions.

61. Managing IS sourcing strategies

a. Analyze factors impacting decisions to purchase and outsource IS.

b. Make high-level decisions regarding IS sourcing.

c. Guide tactical IS sourcing decisions.

62. Engaging in IS strategic planning

a. Create strategic plans for IS design, delivery, and use that exploit opportunities identified via IS strategic analysis.

b. Create IS goals and objectives for strategic plans and define mechanisms by which IS goals and objectives may be measured.

c. Create plans for the efficient management of IS platforms and IS markets.

d. Align IT and domain strategic planning.

e. Ensure strategic alignment of IS and the domain.

63. Planning for and implementing IS governance

a. Select relevant governance frameworks (e.g., COBIT, TOGAF, ITIL) to guide, manage, and govern organizational IT resources.

b. Manage the deployment of relevant governance framework within the organization.

64. Planning for and improving sustainability

a. Develop strategic plans of action for minimizing the environmental impact of firm products, operations, and personnel in an economically viable manner.

b. Measure sustainability impact of IS operations and personnel. 


\section{Competencies in the area of IT Infrastructure (INFR)}

Area Description: The IT Infrastructure area covers competencies that allow the graduates to contribute to needs analysis for and design and implementation of effective, technically correct IT infrastructure solutions.

\section{High-level area competencies}

The graduates will be able to

1. Design integrated communication networks for small- and medium-size organizations, including local area networks and the use of wide-area network technologies to connect the local networks.

2. Specify requirements for large-scale network solutions.

3. Design an implementation architecture for organizational data processing and system solutions, using both internal hardware resources and external service solutions.

4. Negotiate and enforce contracts with providers of IT infrastructure services.

[Note: the individual competencies within the categories below are not intended to be comprehensive and are potentially more time-dependent than the competency areas and categories. The individual competencies descriptions all start with "Graduates will be able to," which is not included to avoid repetition.]

\section{Competency categories and competency examples-Pre-master's}

65. Designing data communication networks and data center and server solutions

a. Select an appropriate design approach for local area and wide-area networks in a specific organizational situation.

b. Select appropriate server architecture for the purposes of the domain.

c. Design the characteristics of a network and data center solution based on the needs of the domain.

66. Selecting appropriate client devices to support the needs of a domain

a. Analyze the benefits and disadvantages of various client device types.

b. Select an appropriate set of acceptable client devices for a domain.

c. Determine whether or not the "bring your own device" model is acceptable for an organization.

67. Securing IT infrastructures

a. Analyze the impact of infrastructure design solutions on the security of a specific infrastructure design.

b. Apply security principles and policies effectively during the process of infrastructure design.

c. Implement foundational infrastructure security solutions based on contemporary technologies. 


\section{Competency categories and competency examples-Master's}

68. Specifying and monitoring infrastructure contracts

a. Determine service level agreement (SLA) details based on domain needs, including protections against service disruptions.

b. Evaluate actual service provision compared to the SLAs.

c. Apply relevant quality management tools and techniques.

69. Negotiating contracts and managing infrastructure vendors

a. Identify potential vendors.

b. Select a vendor for a particular infrastructure need and negotiate a contract with the vendor.

c. Maintain mutual understanding of key challenges of the domain.

d. Manage transitions from one vendor to another.

70. Responding to requests for proposals (RFPs) for infrastructure solutions

a. Assess the infrastructure needs of the client

b. Devise an infrastructure solution for the client's request

c. Write a proposal for the infrastructure solution

71. Managing infrastructure risks

a. Consider risks in the context of an infrastructure design solution.

b. Monitor infrastructure status from multiple perspectives and take appropriate action in case of irregularities.

c. Design and document appropriate processes for risk analysis and management.

72. Optimizing infrastructure utilization

a. Select appropriate technologies to ensure effective use of server capacity.

b. Implement a solution and monitor its performance.

73. Designing infrastructure solutions using external service provider(s) (cloud computing)

a. Apply the appropriate factors to determine the suitability of a cloud computing solution for the infrastructure needs of the domain.

b. Analyze the specific infrastructure needs of the domain.

c. Prepare and submit a request for proposal (RFP) based on domain needs analysis.

d. Select a cloud service provider based on responses to the RFP and negotiate the final contract.

e. Implement the cloud computing solution and monitor its operational performance.

74. Maintaining a set of standards and policies to comply with the laws and regulations to relevant infrastructure decisions

a. Identify and specify the key elements of a policy for acquisition of IT resources. 
b. Identify IT standards appropriate for the domain.

c. Identify and monitor laws and regulations relevant for the domain.

75. Monitoring emerging technologies to understand their potential to support the domain

a. Identify emerging technologies that have the potential to transform the domain.

b. Align the use of potential emerging technologies with the needs of the domain.

c. Maintain a mechanism to systematically evaluate emerging technologies. 


\section{Competencies in the area of Systems Development and Deployment (SDAD)}

Area Description: Systems Development and Deployment encompasses the design of information systems and services, including the design of how humans interact with and how they experience IT artifacts. It also includes competencies related to systems implementation and the deployment of systems to organizational use.

\section{High-level area competencies}

The graduates are able to

1. Analyze and specify requirements for IT artifacts through study and documentation of the whole or of part of some form of domain activities (e.g., work unit, work team, process, organization, market, society setting) in terms of the actions they involve and the information they deal with. Define requirements for IT artifacts that are capable of enhancing the way existing domain activities are structured and performed or enabling new forms of domain activities.

2. Design and document IT artifacts that meet specified requirements taking into account non-functional requirements (including user experience design) and organizational, technical, infrastructural and other constraints.

3. In the context of iterative processes that integrate analysis, design, implementation, and operations, develop and deploy IT applications that satisfy user needs.

[Note: the individual competencies within the categories below are not intended to be comprehensive and are potentially more time-dependent than the competency areas and categories. The individual competencies descriptions all start with "Graduates will be able to," which is not included to avoid repetition.]

\section{Competency categories and competency examples_Pre-master's}

76. Documenting existing systems

a. Select appropriate data collection methods and techniques for the investigation of domain activities.

b. Investigate domain activities in order to develop an in-depth understanding of those domain activities.

c. Involve stakeholders in the investigation process, leading to a shared understanding of the domain activities.

d. Document domain activities on their different relevant facets, using appropriate representation techniques.

77. Specifying and documenting systems requirements

a. Identify scenarios of IS artifact use to enable and support domain activities.

b. Document the requirements for IS artifacts based on the domain needs. 
c. Make and document formal agreements with relevant stakeholders regarding project requirements in a form appropriate to the systems development approach.

d. Manage system change requirements in a form appropriate to the systems development approach.

78. Identifying and selecting from systems design and implementation alternatives

a. Identify multiple alternatives for systems design and implementation based on requirements and the systems development approach.

b. Select the most appropriate systems design and implementation approach in a specific organizational and system context.

79. Designing systems and services

a. Determine a design plan based on the requirements, organizational context, and the systems development approach.

b. Design the architecture and the components of IS artifacts.

c. Validate the compatibility of the design with the user requirements using a mechanism appropriate to the systems development approach.

d. Establish and maintain a communication model that is appropriate to the systems development approach with various stakeholders.

e. Apply organizational design methods, tools, and standards.

80. Designing user experiences

a. Design human-computer interfaces and interaction sequences taking into account the envisioned user experience.

b. Refine user interface design based on results of user experience evaluation and feedback from users.

81. Implementing a systems solution using a modern programming language

\section{Competency categories and competency examples-Master's}

82. Selecting between systems development approaches

a. Determine the organizational and domain constraints to the use of plan-based, hybrid, and agile development approaches.

b. Select a development approach for the organization and a system context.

83. Managing plan-based, hybrid, and agile development approaches

a. Manage a simple project following one of the key development approaches.

b. Apply key DevOps concepts to integrate between development and operations and determine when they are relevant for application in a specific domain.

c. Apply DevOps effectively.

84. Implementing and testing an application

a. Use a modern application development environment to produce an IS artifact based on relevant design documentation. 
b. Select a development approach appropriate to the characteristics of the IS application under consideration and to the existing resources and development team and conditions.

c. Plan development work according to the principles and guidelines of the selected development approach.

d. Document the implemented product for later reference and maintenance.

e. Plan and carry out tests for functional and non-functional requirements.

f. Carry out various tests (unit, integration, migration) of new software, new software modules, and upgrades in a realistic environment.

85. Installing and integrating applications

a. Perform acceptance testing of the application.

b. Install the application onto a computing platform.

c. Configure the application so it fits with the supporting computing platform and with other applications with which it must interact.

d. Configure the application so it fits to the organizational environment.

e. Plan and carry out tests to installation and configuration.

f. Migrate information stored in pre-existing applications to the new application.

86. Acquiring IS applications from the market

a. Search for suitable solutions and vendors.

b. Assess and select solutions and the way they are provided (licensing, SaaS, etc.)

c. Negotiate contracts for application provision

87. Managing external systems development resources

a. Communicate requirements and designs effectively with external development resources.

b. Monitor the progress of external development resources.

c. Validate the outcomes of the work of external development resources.

88. Deploying a new system to organizational use

a. Adjust organizational processes and/or procedures

b. Train users to use the new application

c. Promote the adoption and use of the new application

d. Monitor the usage of the new application 


\begin{tabular}{|c|c|c|c|c|c|c|c|c|c|c|c|c|c|c|c|c|c|c|c|}
\hline \multirow{3}{*}{ ( } & \multirow[b]{2}{*}{\begin{tabular}{|l|} 
Role: \\
\\
Area \\
\end{tabular}} & \multirow[b]{2}{*}{\begin{tabular}{|l} 
IT Consultant/Systems Analyst \\
\\
Category
\end{tabular}} & \multirow[b]{2}{*}{\begin{tabular}{|c|c|} 
& \\
& \\
& \\
MSIS \\
Min
\end{tabular}} & \multicolumn{4}{|c|}{$\begin{array}{l}\text { Competency } \\
\text { level for } \\
\text { profile(s) }\end{array}$} & \multicolumn{12}{|c|}{$\begin{array}{l}\text { Mapping between modules/courses and competencies } \\
\text { (compentency achievement can be served by multiple } \\
\text { modules) }\end{array}$} \\
\hline & & & & A & $\mathbf{N}$ & $S$ & 1 & 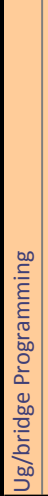 & 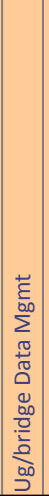 & 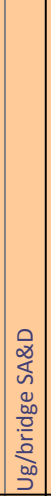 & 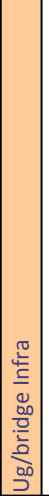 & 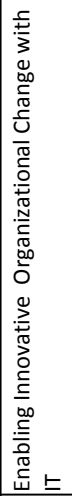 & 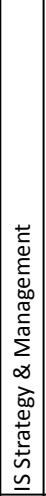 & 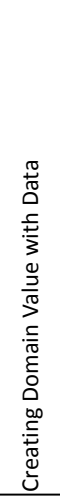 & 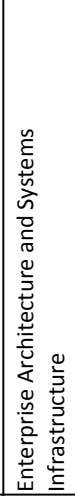 & 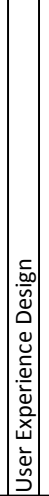 & 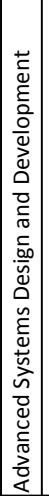 & 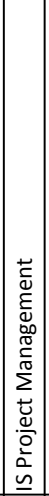 & 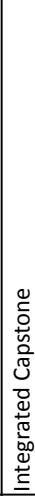 \\
\hline & $\mathrm{BCIA}$ & Managing and implementing cybersecurity & $\mathrm{N}$ & & $x$ & & & & & & $x$ & & & $\mathrm{x}$ & $\mathrm{x}$ & & & $x$ & \\
\hline 2 & $\mathrm{BClA}$ & Responding to and managing IS problems & $\mathrm{S}$ & & & $x$ & & & & & & & & $\mathrm{x}$ & & & & $x$ & \\
\hline 3 & $\mathrm{BCIA}$ & Monitoring system operations & $\mathrm{N}$ & & $x$ & & & & & & & & & & & & & & \\
\hline 4 & $\mathrm{BCIA}$ & Managing system recovery & A & $x$ & & & & & & & & & & & & & & & \\
\hline 5 & $\mathrm{BCIA}$ & Managing Information Systems risks & $\mathrm{N}$ & & $x$ & & & & & & & $\mathrm{x}$ & $\mathrm{X}$ & & $\mathrm{x}$ & $\mathrm{x}$ & & $x$ & \\
\hline 6 & $\mathrm{BCIA}$ & Protecting IT assets & $\mathrm{N}$ & & $x$ & & & & & & & & & & & & & & \\
\hline 7 & $\mathrm{BCIA}$ & Developing information assurance strategy & A & & $x$ & & & & & & & & & $\mathrm{x}$ & & & & & \\
\hline 8 & $\mathrm{BCIA}$ & Engineering systems for continuity & A & $\mathrm{x}$ & & & & & & & & & & & $\mathrm{X}$ & & & & \\
\hline 9 & $\mathrm{BCIA}$ & Implementing and managing quality audit processes & A & $\mathrm{X}$ & & & & & & & & & $\mathrm{X}$ & & & & & & \\
\hline 10 & $\mathrm{BCIA}$ & Assuring safety throughout systems lifecycle & A & $\mathrm{X}$ & & & & & & & & & & & & & & & \\
\hline 11 & DATA & $\begin{array}{l}\text { Explaining key data and information concepts and the data } \\
\text { and information management lifecycle }\end{array}$ & $\mathrm{S}$ & & & $x$ & & & $x$ & & & & & $\mathrm{x}$ & & & & & \\
\hline 12 & DATA & $\begin{array}{l}\text { Capturing and structuring data and information } \\
\text { requirements using appropriate conceptual modeling } \\
\text { techniques }\end{array}$ & $\mathrm{S}$ & & & $x$ & & & $\mathrm{x}$ & & & $\mathrm{X}$ & & $\mathrm{x}$ & & & & & \\
\hline 13 & DATA & $\begin{array}{l}\text { Developing a logical level representation of data based on a } \\
\text { conceptual model }\end{array}$ & $\mathrm{S}$ & & & $x$ & & & $x$ & & & & & $\mathrm{x}$ & & & & & \\
\hline 14 & DATA & $\begin{array}{l}\begin{array}{l}\text { Implementing a database solution to serve systems } \\
\text { consisting of multiple applications }\end{array} \\
\end{array}$ & $\mathrm{N}$ & & $x$ & & & & $x$ & & & & & $\mathrm{X}$ & & & & & \\
\hline 15 & DATA & $\begin{array}{l}\text { Using a contemporary data manipulation and retrieval } \\
\text { language effectively }\end{array}$ & $\mathrm{S}$ & & & $x$ & & & $x$ & & & & & $x$ & & & & & \\
\hline 16 & DATA & $\begin{array}{l}\text { Selecting appropriate data management technologies based } \\
\text { on the needs of the domain }\end{array}$ & $\mathrm{S}$ & & & $x$ & & & & & & & $x$ & $x$ & $x$ & & $x$ & & $x$ \\
\hline 17 & DATA & $\begin{array}{l}\text { Securing domain data and protecting user privacy and } \\
\text { organizational intellectual property using appropriate } \\
\text { technical solutions }\end{array}$ & $\mathrm{N}$ & & $x$ & & & & & & & & & $x$ & $x$ & & & & \\
\hline 18 & DATA & $\begin{array}{l}\text { Designing and implementing a data warehouse using a } \\
\text { contemporary architectural solution }\end{array}$ & $\mathrm{N}$ & & $x$ & & & & & & & & & $x$ & & & $P$ & & $P$ \\
\hline 19 & DATA & $\begin{array}{l}\text { Creating a scalable infrastructure for large amounts of data } \\
\text { using parallel and distributed technologies }\end{array}$ & $\mathrm{N}$ & & $x$ & & & & & & & & & $x$ & $x$ & & $x$ & & $x$ \\
\hline 20 & DATA & $\begin{array}{l}\text { Developing and implementing organizational information } \\
\text { management policies and processes }\end{array}$ & $\mathrm{N}$ & & & $x$ & & & & & & & $x$ & $x$ & $x$ & \begin{tabular}{l|l}
$x$ \\
\end{tabular} & $x$ & & $x$ \\
\hline 21 & DATA & Creating an information architecture for an organization & $\mathrm{N}$ & & $\mathrm{X}$ & & & & $x$ & & & & $\mathrm{X}$ & & $\mathrm{X}$ & & $\mathrm{P}$ & & $\mathrm{P}$ \\
\hline 22 & DATA & $\begin{array}{l}\text { Integrating and preparing data captured from various } \\
\text { sources for analytical use }\end{array}$ & $\mathrm{N}$ & & $x$ & & & & & & & & & $\mathrm{x}$ & & & & & \\
\hline 23 & DATA & Selecting and using appropriate analytics methods & $\mathrm{N}$ & & $\mathrm{X}$ & & & & & & & & & $\mathrm{X}$ & & $\mathrm{x}$ & & & \\
\hline 24 & DATA & Analyzing data using advanced contemporary methods & $\mathrm{N}$ & & $x$ & & & & $\mathrm{X}$ & & & & & $\mathrm{X}$ & & & & & \\
\hline 25 & DATA & $\begin{array}{l}\text { Designing and implementing architectures for organizational } \\
\text { content management systems }\end{array}$ & $\mathrm{N}$ & & $\mathrm{x}$ & & & & & & & & & $\mathrm{x}$ & $\mathrm{X}$ & & $\mathrm{x}$ & & \\
\hline 26 & EARC & $\begin{array}{l}\text { Explaining enterprise architecture principles to justify the } \\
\text { value enterprise architecture provides to organizations } \\
\text { within various types of domains }\end{array}$ & $\mathrm{S}$ & & & $x$ & & & & & & & & & $\mathrm{x}$ & & $\mathrm{P}$ & $P$ & $P$ \\
\hline 27 & EARC & $\begin{array}{l}\text { Designing, building and maintaining an enterprise } \\
\text { architecture }\end{array}$ & $\mathrm{N}$ & & $x$ & & & & & & & & & & $\mathrm{X}$ & & $P$ & $P$ & $P$ \\
\hline 28 & EARC & Communicating and deploying an enterprise architecture & $\mathrm{N}$ & & $\mathrm{X}$ & & & & & & & $\mathrm{X}$ & $\mathrm{X}$ & & $\mathrm{X}$ & & $\mathrm{P}$ & $P$ & $\mathrm{P}$ \\
\hline 29 & EARC & $\begin{array}{l}\text { Using an enterprise architecture to influence IS related } \\
\text { organizational improvement projects }\end{array}$ & A & & $x$ & & & & & & & $\mathrm{X}$ & $\mathrm{x}$ & $\mathrm{x}$ & $\mathrm{x}$ & & $\mathrm{P}$ & $P$ & $P$ \\
\hline 30 & ETIS & Designing and managing sustainable IT operations & $\mathrm{A}$ & $x$ & & & & & & & & & & & & & & $\mathrm{X}$ & \\
\hline 31 & ETIS & Aligning IT with organizational sustainability policy & $\mathrm{A}$ & $x$ & & & & & & & & & $\mathrm{X}$ & & $\mathrm{X}$ & & & & \\
\hline 32 & ETIS & Managing IT facilities sustainably & A & $\mathrm{X}$ & & & & & & & & & $\mathrm{X}$ & & & & & $x$ & \\
\hline 33 & ETIS & Managing sustainable procurement practices & $\mathrm{A}$ & $x$ & & & & & & & & & $\mathrm{X}$ & & & & & $x$ & \\
\hline 34 & ETIS & Managing contracts ethically & $\mathrm{N}$ & & $\mathrm{X}$ & & & & & & & & $\mathrm{X}$ & & & & & & \\
\hline 35 & ETIS & $\begin{array}{l}\text { Maintaining compliance with legislation, regulations, and } \\
\text { standards }\end{array}$ & $\mathrm{N}$ & & $x$ & & & & & $x$ & & & & $\mathrm{X}$ & & & & & \\
\hline 36 & ETIS & $\begin{array}{l}\text { Ensuring that protection of privacy and integrity guides all IS } \\
\text { practices }\end{array}$ & $\mathrm{N}$ & & $x$ & & & & & & & & $\mathrm{x}$ & & & $\mathrm{x}$ & & & \\
\hline 37 & ETIS & Fostering an ethical culture & $\mathrm{N}$ & & & $x$ & & & & & & $\mathrm{X}$ & $\mathrm{x}$ & $\mathrm{x}$ & $\mathrm{X}$ & $\mathrm{x}$ & & & \\
\hline 38 & ETIS & Considering ethical implications of IS decisions & $\mathrm{S}$ & & & $\mathrm{X}$ & & & & & & $\mathrm{X}$ & & & $\mathrm{X}$ & \begin{tabular}{l|l}
$x$ & -1 \\
\end{tabular} & & & \\
\hline
\end{tabular}




\begin{tabular}{|c|c|c|c|c|c|c|c|c|c|c|c|c|c|c|c|c|c|c|c|}
\hline 39 & IOCE & Monitoring the technology environment & $\mathrm{S}$ & & & & $\mathrm{X}$ & & & & & $\mathrm{X}$ & & & & & & $\mathrm{X}$ & $x$ \\
\hline 40 & IOCE & Engaging in entrepreneurial thinking & $\mathrm{N}$ & & & & $x$ & & & & & $\mathrm{X}$ & $\mathrm{x}$ & & $\mathrm{X}$ & & & & \\
\hline 41 & IOCE & Developing a business plan & $\mathrm{N}$ & & & $x$ & & & & & & $\mathrm{x}$ & & & $\mathrm{X}$ & & & & \\
\hline 42 & IOCE & Innovating by exploiting an emerging method or technology & $\mathrm{S}$ & & & & $x$ & & & & & $\mathrm{X}$ & & & & & & & \\
\hline 43 & IOCE & $\begin{array}{l}\text { Promoting diffusion by leveraging differences between } \\
\text { adopter groups }\end{array}$ & $\mathrm{N}$ & & & $\mathrm{X}$ & & & $\mathrm{X}$ & $x$ & $x$ & $\mathrm{X}$ & & & & & & $x$ & $\mathrm{X}$ \\
\hline 44 & IOCE & $\begin{array}{l}\text { Applying creative problem solving to technology-related } \\
\text { issues }\end{array}$ & $\mathrm{S}$ & & & & $x$ & & & & & $\mathrm{X}$ & & $\bar{x}$ & $\mathrm{X}$ & & $x$ & & $\mathrm{x}$ \\
\hline 45 & IOCE & $\begin{array}{l}\text { Contributing to organizational development and change } \\
\text { management }\end{array}$ & $\mathrm{N}$ & & & & $x$ & & & & & $\mathrm{X}$ & $\mathrm{x}$ & & & $x$ & $\mathrm{X}$ & & \\
\hline 46 & IOCE & Analyzing and documenting business activities & $\mathrm{S}$ & & & & $x$ & & & & & $\mathrm{X}$ & & & $\mathrm{X}$ & $\mathrm{x}$ & & & $\mathrm{X}$ \\
\hline 47 & IOCE & $\begin{array}{l}\text { Identifying opportunities for and designing process } \\
\text { improvement }\end{array}$ & $\mathrm{N}$ & & & & $x$ & & & & & $\mathrm{X}$ & & & $\mathrm{x}$ & $\mathrm{x}$ & $x$ & & $x$ \\
\hline 48 & ISMO & $\begin{array}{l}\text { Applying broadly used Project Management tools and } \\
\text { techniques }\end{array}$ & $\mathrm{S}$ & & & $\mathrm{X}$ & & & & & & & & & $\mathrm{x}$ & & & $x$ & $\mathrm{X}$ \\
\hline 49 & ISMO & Managing the IS function & $\mathrm{A}$ & & $\mathrm{X}$ & & & & & & & & $\mathrm{X}$ & & & & & $x$ & \\
\hline 50 & ISMO & Managing IS staff & $\mathrm{A}$ & & $x$ & & & & & & & & $x$ & & & & & $x$ & \\
\hline 51 & ISMO & Managing IS service production & $\mathrm{A}$ & & $x$ & & & & & & & & $\mathrm{x}$ & & & & & $x$ & \\
\hline 52 & ISMO & Managing IS sourcing models & $\mathrm{A}$ & & $\mathrm{X}$ & & & & & & & & $\mathrm{x}$ & & & & & $x$ & \\
\hline 53 & ISMO & Managing and coordinating information resources & $\mathrm{A}$ & & $\mathrm{x}$ & & & & & & & & $\mathrm{X}$ & $\mathrm{X}$ & & & & $x$ & \\
\hline 54 & ISMO & $\begin{array}{l}\text { Implementing relevant IT governance frameworks within the } \\
\text { organization based on strategic guidance }\end{array}$ & A & & $x$ & & & & & & & & $\mathrm{x}$ & & $\mathrm{X}$ & & & $x$ & \\
\hline 55 & ISMO & $\begin{array}{l}\text { Complying with laws and regulations directly affecting IS } \\
\text { management and operations }\end{array}$ & $\mathrm{S}$ & & & $\mathrm{X}$ & & & & & & & $\mathrm{X}$ & & & $\mathrm{x}$ & & $x$ & $\mathrm{X}$ \\
\hline 56 & ISMO & Managing IS projects and programs & $\mathrm{S}$ & & & $x$ & & & & & & & & & $\mathrm{X}$ & & & $x$ & $\mathrm{X}$ \\
\hline 57 & ISMO & Managing IS project portfolios & $\mathrm{N}$ & & $\mathrm{X}$ & & & & & & & & & & $\mathrm{X}$ & & & $x$ & $\mathrm{X}$ \\
\hline 58 & ISMO & $\begin{array}{l}\text { Managing software and hardware development and } \\
\text { maintenance }\end{array}$ & $\mathrm{N}$ & & $x$ & & & & & & & & $\mathrm{x}$ & & & & & $x$ & $\mathrm{x}$ \\
\hline 59 & ISSG & Conducting IS strategic analysis & $\mathrm{N}$ & & & $x$ & & & & & & & $\mathrm{X}$ & & $\mathrm{X}$ & & & & \\
\hline 60 & ISSG & Making a financial case for IS & $\mathrm{S}$ & & & & $x$ & & & & & & $\mathrm{x}$ & & $\mathrm{X}$ & & & & \\
\hline 61 & ISSG & Managing IS/IT sourcing strategies & $\mathrm{N}$ & & & $x$ & & & & & & & $\mathrm{X}$ & & $\mathrm{X}$ & & & & \\
\hline 62 & ISSG & Engaging in IS strategic planning & $\mathrm{N}$ & & & $x$ & & & & & & & $\mathrm{x}$ & & & & & & \\
\hline 63 & ISSG & Planning for and implementing IS governance & A & & $\mathrm{X}$ & & & & & & & & $\mathrm{X}$ & & & & & & \\
\hline 64 & ISSG & Planning for and improving sustainability & $\mathrm{A}$ & & $\mathrm{X}$ & & & & & & & & $\mathrm{X}$ & & & & & & \\
\hline 65 & INFR & $\begin{array}{l}\text { Designing data communication networks and data center } \\
\text { and server solutions }\end{array}$ & $\mathrm{N}$ & & $x$ & & & & & & $x$ & & & & & & $x$ & & $\mathrm{x}$ \\
\hline 66 & INFR & $\begin{array}{l}\text { Selecting appropriate client devices to support the needs of } \\
\text { an application area }\end{array}$ & $\mathrm{S}$ & & & $\mathrm{X}$ & & & & & $x$ & & & & & & & & $\mathrm{x}$ \\
\hline 67 & INFR & Securing IT infrastructures & $\mathrm{N}$ & & $\mathrm{X}$ & & & & & & $x$ & & & & $\mathrm{X}$ & & & & $x$ \\
\hline 68 & INFR & Specifying and monitoring infrastructure contracts & $\mathrm{N}$ & & $\mathrm{X}$ & & & & & & & & & & & & & & $x$ \\
\hline 69 & INFR & Negotiating contracts and managing infrastructure vendors & A & $x$ & & & & & & & & & $\mathrm{X}$ & & & & $\mathrm{X}$ & & $\mathrm{X}$ \\
\hline 70 & INFR & $\begin{array}{l}\text { Responding to Requests for Proposals (RFPs) for } \\
\text { infrastructure solutions }\end{array}$ & $\mathrm{N}$ & & $x$ & & & & & & & & & & & & & & $\mathrm{X}$ \\
\hline 71 & INFR & Managing infrastructure risks & A & $\mathrm{X}$ & & & & & & & & & & & & & & $x$ & $\mathrm{X}$ \\
\hline 72 & INFR & Optimizing infrastructure utilization & A & $\mathrm{X}$ & & & & & & & & & & & $\mathrm{X}$ & & $\mathrm{P}$ & $\mathrm{P}$ & $\mathrm{P}$ \\
\hline 73 & INFR & $\begin{array}{l}\text { Designing infrastructure solutions using external service } \\
\text { provider(s) (cloud computing) }\end{array}$ & $\mathrm{N}$ & & $x$ & & & & & & & & & & $\mathrm{X}$ & & $\mathrm{P}$ & $\mathrm{P}$ & $P$ \\
\hline 74 & INFR & $\begin{array}{l}\text { Maintaining a set of standards and policies and understand } \\
\text { the key laws and regulations to relevant infrastructure } \\
\text { decisions }\end{array}$ & A & $x$ & & & & & & & & & & & & & & $x$ & $\mathrm{X}$ \\
\hline 75 & SDAD & $\begin{array}{l}\text { Monitoring emerging technologies to understand their } \\
\text { potential to support the domain }\end{array}$ & $\mathrm{S}$ & & & & $x$ & & & & & $\mathrm{X}$ & & & & & $x$ & & $\mathrm{X}$ \\
\hline 76 & SDAD & Documenting existing systems & $\mathrm{S}$ & & & $x$ & & & & $x$ & & & & & & $\mathrm{x}$ & $\mathrm{X}$ & & $\mathrm{x}$ \\
\hline 77 & SDAD & Specifying and documenting systems requirements & $\mathrm{S}$ & & & & $\mathrm{x}$ & & & $x$ & & & & & $\mathrm{x}$ & $\mathrm{x}$ & $\mathrm{X}$ & & $x$ \\
\hline 78 & SDAD & $\begin{array}{l}\text { Identifying and selecting from systems design and } \\
\text { implementation alternatives }\end{array}$ & $\mathrm{N}$ & & & & $x$ & & & $x$ & & & & & $\mathrm{x}$ & $\mathrm{x}$ & $x$ & & $x$ \\
\hline 79 & SDAD & Designing systems and services & $\mathrm{N}$ & & $\mathrm{X}$ & & & & & $x$ & & & & & $\mathrm{x}$ & & $\mathrm{X}$ & & $\mathrm{X}$ \\
\hline 80 & SDAD & Designing user experiences & $\mathrm{N}$ & & & $\mathrm{x}$ & & & & $x$ & & & & & & $\mathrm{x}$ & $\mathrm{X}$ & & $x$ \\
\hline 81 & SDAD & $\begin{array}{l}\text { Implementing a systems solution using a modern } \\
\text { programming language }\end{array}$ & $\mathrm{N}$ & & $x$ & & & $\mathrm{x}$ & & & & & & & & & $x$ & & $x$ \\
\hline 82 & SDAD & Selecting between systems development approaches & $\mathrm{S}$ & & & & $x$ & & & $\mathrm{X}$ & & & & & $\mathrm{X}$ & & $\mathrm{X}$ & & $x$ \\
\hline 83 & SDAD & $\begin{array}{l}\text { Managing plan-based, hybrid, and agile development } \\
\text { processes }\end{array}$ & $\mathrm{N}$ & & & & $x$ & & & & & & $\mathrm{X}$ & & $\mathrm{X}$ & & $x$ & $x$ & $x$ \\
\hline 84 & SDAD & Implementing and testing an application & $\mathrm{N}$ & & & $x$ & & $x$ & & & & & & & & & $\mathrm{X}$ & & $x$ \\
\hline 85 & SDAD & Installing and integrating a new application & $\mathrm{N}$ & & $x$ & & & $x$ & & & & & & & & & $x$ & & $\mathrm{X}$ \\
\hline 86 & SDAD & Managing external systems development resources & $\mathrm{N}$ & & & $\mathrm{x}$ & & & & $x$ & & & $\mathrm{X}$ & & & $\mathrm{x}$ & $\mathrm{X}$ & $x$ & $x$ \\
\hline 87 & SDAD & Managing IS development projects & $\mathrm{N}$ & & & $x$ & & & & $x$ & & & & & $\mathrm{X}$ & & $x$ & $\mathrm{X}$ & $x$ \\
\hline 88 & SDAD & Deploying a new system to organizational use & $\mathrm{N}$ & & & $\mathrm{x}$ & & & & & & & & & $\mathrm{X}$ & & $\mathrm{X}$ & & $x$ \\
\hline
\end{tabular}




\begin{tabular}{|c|c|c|c|c|c|c|c|c|c|c|c|c|c|c|c|c|c|}
\hline & \multirow[b]{2}{*}{\begin{tabular}{|l|} 
Role: \\
\\
Area
\end{tabular}} & \multirow[b]{2}{*}{\begin{tabular}{|l} 
Project Manager \\
\\
Category
\end{tabular}} & \multirow[b]{2}{*}{$\begin{array}{c}\text { MSIS } \\
\text { Min }\end{array}$} & \multicolumn{4}{|c|}{$\begin{array}{c}\text { Competency } \\
\text { level for } \\
\text { profile(s) }\end{array}$} & \multicolumn{10}{|c|}{$\begin{array}{l}\text { Mapping between modules/courses and competencies } \\
\text { (compentency achievement can be served by multiple } \\
\text { modules) }\end{array}$} \\
\hline & & & & A & $\mathbf{N}$ & $\mathbf{s}$ & $\mathbf{I}$ & 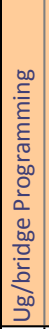 & 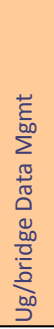 & 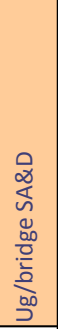 & 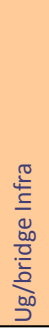 & 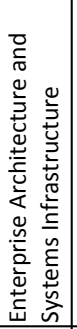 & 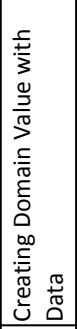 & 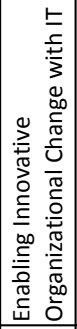 & 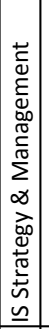 & 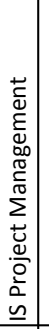 & 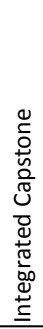 \\
\hline 1 & $\mathrm{BClA}$ & Managing and implementing cybersecurity & $\mathrm{N}$ & & $\mathrm{x}$ & & & & & & $\mathrm{X}$ & $\mathrm{P}$ & $\mathrm{X}$ & $\mathrm{x}$ & & $\mathrm{x}$ & \\
\hline 2 & $\mathrm{BClA}$ & Responding to and managing IS problems & $\mathrm{S}$ & & & & $\mathrm{X}$ & & & & & & $\mathrm{X}$ & & & $\mathrm{X}$ & $\mathrm{X}$ \\
\hline 3 & $\mathrm{BClA}$ & Monitoring system operations & $\mathrm{N}$ & & $\mathrm{x}$ & & & & & & & $\mathrm{P}$ & & & & & \\
\hline 4 & $\mathrm{BClA}$ & Managing system recovery & $\mathrm{A}$ & $\mathrm{X}$ & & & & & & & & $\mathrm{P}$ & & & & & \\
\hline 5 & $\mathrm{BClA}$ & Managing Information Systems risks & $\mathrm{N}$ & & & & $\mathrm{x}$ & & & & & $\mathrm{X}$ & & $\mathrm{X}$ & $\mathrm{X}$ & $\mathrm{X}$ & $\mathrm{x}$ \\
\hline 6 & $\mathrm{BClA}$ & Protecting IT assets & $\mathrm{N}$ & & $\mathrm{x}$ & & & & & & & $\mathrm{X}$ & & & & & \\
\hline 7 & $\mathrm{BClA}$ & Developing information assurance strategy & $\mathrm{A}$ & & $\mathrm{x}$ & & & & & & & & $\mathrm{x}$ & & $\mathrm{X}$ & & \\
\hline 8 & $\mathrm{BClA}$ & Engineering systems for continuity & A & $\mathrm{x}$ & & & & & & & & $P$ & & & & & \\
\hline 9 & $\mathrm{BClA}$ & Implementing and managing quality audit processes & $\mathrm{A}$ & $\mathrm{X}$ & & & & & & & & & & & $\mathrm{P}$ & & \\
\hline 10 & $\mathrm{BClA}$ & Assuring safety throughout systems lifecycle & $\mathrm{A}$ & & $\mathrm{x}$ & & & & & & & $\mathrm{P}$ & & & & & \\
\hline 11 & DATA & $\begin{array}{l}\text { Explaining key data and information concepts and the } \\
\text { data and information management lifecycle }\end{array}$ & $\mathrm{S}$ & & & $x$ & & & $\mathrm{x}$ & & & & $\mathrm{P}$ & & & & $x$ \\
\hline 12 & DATA & $\begin{array}{l}\text { Capturing and structuring data and information } \\
\text { requirements using appropriate conceptual modeling } \\
\text { techniques }\end{array}$ & $\mathrm{S}$ & & & $x$ & & & $\mathrm{x}$ & & & & $\mathrm{P}$ & $x$ & & & $x$ \\
\hline 13 & DATA & $\begin{array}{l}\text { Developing a logical level representation of data } \\
\text { based on a conceptual model }\end{array}$ & S & & & $x$ & & & $x$ & & & & $P$ & & & & $x$ \\
\hline 14 & DATA & $\begin{array}{l}\text { Implementing a database solution to serve systems } \\
\text { consisting of multiple applications }\end{array}$ & $\mathrm{N}$ & & $x$ & & & & $x$ & & & & $\mathrm{P}$ & & & & $x$ \\
\hline 15 & DATA & $\begin{array}{l}\text { Using a contemporary data manipulation and retrieval } \\
\text { language effectively }\end{array}$ & $S$ & & & $x$ & & & $\mathrm{X}$ & & & & $\mathrm{P}$ & & & & $x$ \\
\hline 16 & DATA & $\begin{array}{l}\text { Selecting appropriate data management technologies } \\
\text { based on the needs of the domain }\end{array}$ & $S$ & & & $x$ & & & & & & $x$ & $P$ & & $x$ & & $x$ \\
\hline 17 & DATA & $\begin{array}{l}\text { Securing domain data and protecting user privacy and } \\
\text { organizational intellectual property using appropriate } \\
\text { technical solutions }\end{array}$ & $\mathrm{N}$ & & $x$ & & & & & & & $x$ & $\mathrm{P}$ & & & & $x$ \\
\hline 18 & DATA & $\begin{array}{l}\text { Designing and implementing a data warehouse using } \\
\text { a contemporary architectural solution }\end{array}$ & $\mathrm{N}$ & & $x$ & & & & & & & & $\mathrm{P}$ & & & & \\
\hline 19 & DATA & $\begin{array}{l}\text { Creating a scalable infrastructure for large amounts of } \\
\text { data using parallel and distributed technologies }\end{array}$ & $\mathrm{N}$ & & $x$ & & & & & & & $x$ & $P$ & & & & \\
\hline 20 & DATA & $\begin{array}{l}\text { Developing and implementing organizational } \\
\text { information management policies and processes }\end{array}$ & $\mathrm{N}$ & & & $x$ & & & & & & $x$ & $\mathrm{P}$ & & $x$ & & \\
\hline 21 & DATA & $\begin{array}{l}\text { Creating an information architecture for an } \\
\text { organization }\end{array}$ & $\mathrm{N}$ & & $x$ & & & & $x$ & & & & $P$ & & $x$ & & \\
\hline 22 & DATA & $\begin{array}{l}\text { Integrating and preparing data captured from various } \\
\text { sources for analytical use }\end{array}$ & $\mathrm{N}$ & & $x$ & & & & & & & & $P$ & & & & \\
\hline 23 & DATA & Selecting and using appropriate analytics methods & $\mathrm{N}$ & & $\mathrm{x}$ & & & & & & & & $\mathrm{P}$ & & & & \\
\hline 24 & DATA & $\begin{array}{l}\text { Analyzing data using advanced contemporary } \\
\text { methods }\end{array}$ & $\mathrm{N}$ & & $x$ & & & & $x$ & & & $x$ & P & & & & \\
\hline 25 & DATA & $\begin{array}{l}\text { Designing and implementing architectures for } \\
\text { organizational content management systems }\end{array}$ & $\mathrm{N}$ & & $x$ & & & & & & & P & & & & & \\
\hline 26 & EARC & $\begin{array}{l}\text { Explaining enterprise architecture principles to justify } \\
\text { the value enterprise architecture provides to } \\
\text { organizations within various types of domains }\end{array}$ & S & & & $x$ & & & & & & P & & & & & $x$ \\
\hline 27 & EARC & $\begin{array}{l}\text { Designing, building and maintaining an enterprise } \\
\text { architecture }\end{array}$ & $\mathrm{N}$ & & $x$ & & & & & & & P & & $x$ & $x$ & & \\
\hline 28 & EARC & $\begin{array}{l}\text { Communicating and deploying an enterprise } \\
\text { architecture }\end{array}$ & $\mathrm{N}$ & & $\mathrm{x}$ & & & & & & & $P$ & $x$ & $x$ & $x$ & $\mathrm{x}$ & $x$ \\
\hline 29 & EARC & $\begin{array}{l}\text { Using an enterprise architecture to influence IS } \\
\text { related organizational improvement projects }\end{array}$ & A & & & $x$ & & & & & & $\mathrm{P}$ & & & & & \\
\hline 30 & ETIS & Designing and managing sustainable IT operations & A & $\mathrm{X}$ & & & & & & & & $\mathrm{X}$ & & & $\mathrm{P}$ & & \\
\hline 31 & ETIS & Aligning IT with organizational sustainability policy & A & $\mathrm{X}$ & & & & & & & & & & & $\mathrm{P}$ & & \\
\hline 32 & ETIS & Managing IT facilities sustainably & $\mathrm{A}$ & $\mathrm{X}$ & & & & & & & & & & & $\mathrm{P}$ & & \\
\hline 33 & ETIS & Managing sustainable procurement practices & $\mathrm{A}$ & $\mathrm{X}$ & & & & & & & & & & & $\mathrm{P}$ & $\mathrm{X}$ & \\
\hline 34 & ETIS & Managing contracts ethically & $\mathrm{N}$ & & & & $\mathrm{X}$ & & & & & $\mathrm{X}$ & $\mathrm{X}$ & & & $\mathrm{X}$ & \\
\hline 35 & ETIS & $\begin{array}{l}\text { Maintaining compliance with legislation, regulations, } \\
\text { and standards }\end{array}$ & $\mathrm{N}$ & & & & $\mathrm{X}$ & & & $x^{\prime}$ & & & & & & $\mathrm{x}$ & $\mathrm{X}$ \\
\hline 36 & ETIS & $\begin{array}{l}\text { Ensuring that protection of privacy and integrity } \\
\text { guides all IS practices }\end{array}$ & $\mathrm{N}$ & & $x$ & & & & & & & $x$ & $x$ & $x$ & $x$ & $x$ & $x$ \\
\hline 37 & ETIS & Fostering an ethical culture & $\mathrm{N}$ & & $\mathrm{x}$ & & & & & & & $\mathrm{X}$ & $\mathrm{x}$ & $\mathrm{x}$ & \begin{tabular}{|l|l}
$x$ \\
\end{tabular} & $\mathrm{X}$ & $\mathrm{X}$ \\
\hline
\end{tabular}




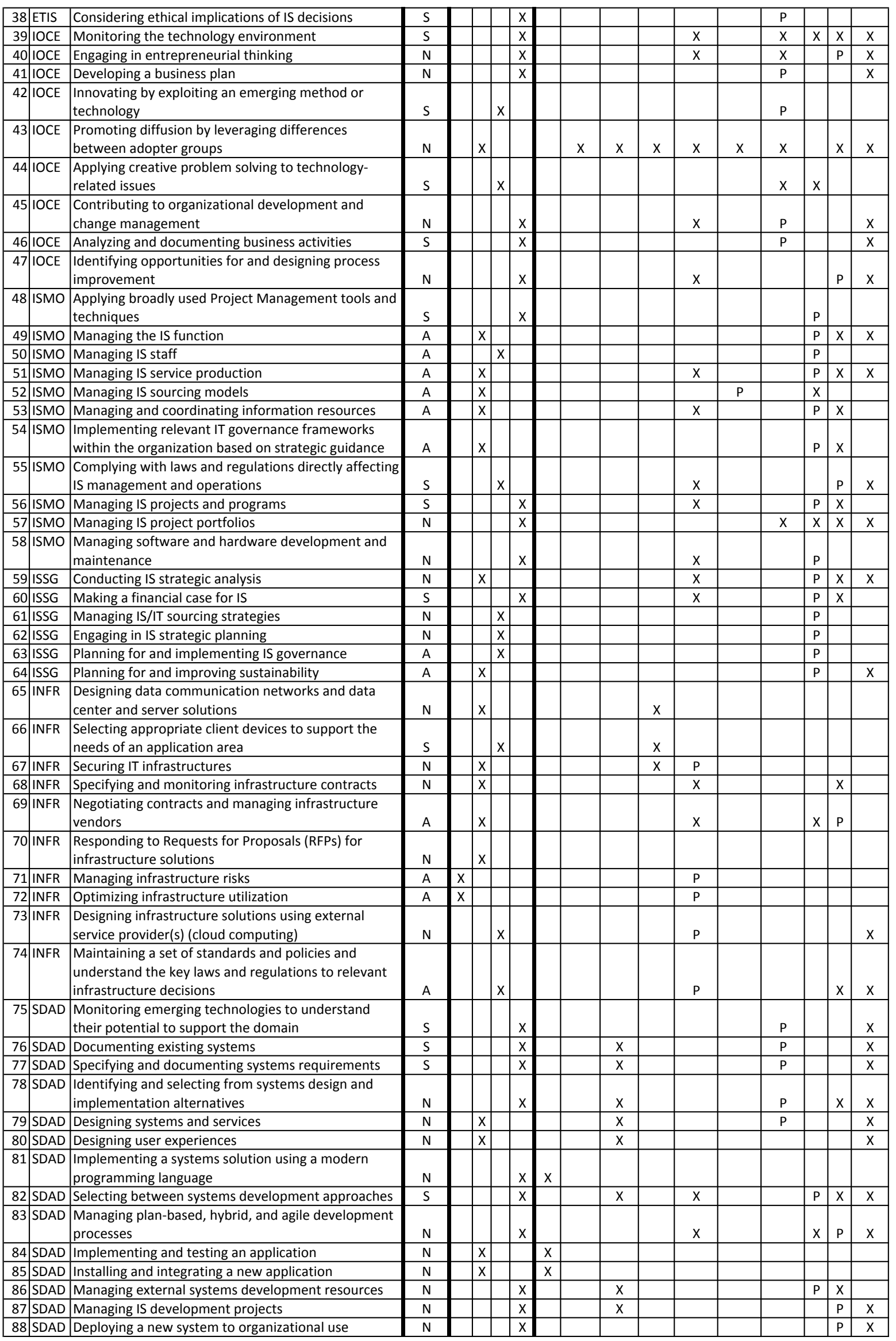




\begin{tabular}{|c|c|c|c|c|c|c|c|c|c|c|c|c|c|c|c|c|c|c|c|c|}
\hline & Role: & Analytics Specialist & & & $\begin{array}{l}\text { mpe } \\
\text { leve } \\
\text { orofi }\end{array}$ & & & & $\begin{array}{l}\text { Mapp } \\
\text { (com }\end{array}$ & $\begin{array}{l}\text { ping } \\
\text { ipen }\end{array}$ & betv & $\begin{array}{l}\text { weer } \\
\text { cy ac }\end{array}$ & n mo & $\begin{array}{l}\text { dules/c } \\
\text { modul }\end{array}$ & $\begin{array}{l}\text { cours } \\
\text { can b } \\
\text { es) }\end{array}$ & es an & $\begin{array}{l}\text { nd co } \\
\text { rved }\end{array}$ & $\begin{array}{l}\text { ompe } \\
\text { by } m\end{array}$ & tenc & \\
\hline & Area & Category & $\begin{array}{l}\text { MSIS } \\
\text { Min }\end{array}$ & A & $\mathbf{N}$ & $\mathbf{s}$ & 1 & 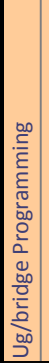 & 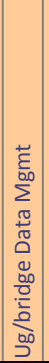 & 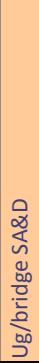 & 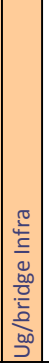 & 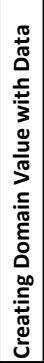 & 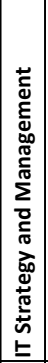 & 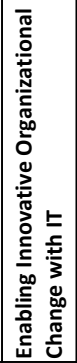 & 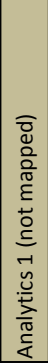 & 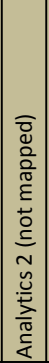 & 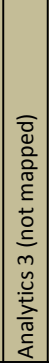 & 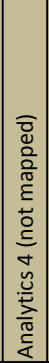 & 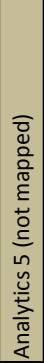 & 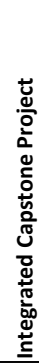 \\
\hline 1 & $\mathrm{BCIA}$ & Managing and implementing cybersecurity & $\mathrm{N}$ & & $\mathrm{X}$ & & & & & & $\mathrm{x}$ & $\mathrm{x}$ & & $\mathrm{x}$ & & & & & & \\
\hline 2 & $\mathrm{BClA}$ & Responding to and managing IS problems & $\mathrm{S}$ & & & $\mathrm{x}$ & & & & & $x$ & & & & & & & & & $\mathrm{x}$ \\
\hline 3 & $\mathrm{BCIA}$ & Monitoring system operations & $\mathrm{N}$ & & $\mathrm{X}$ & & & & & & $\mathrm{x}$ & & $\mathrm{x}$ & & & & & & & \\
\hline 4 & $\mathrm{BClA}$ & Managing system recovery & A & $\mathrm{X}$ & & & & & & & & & & & & & & & & \\
\hline 5 & $\mathrm{BCIA}$ & Managing Information Systems risks & $\mathrm{N}$ & & $\mathrm{X}$ & & & & & & & & $x$ & $\mathrm{x}$ & & & & & & \\
\hline 6 & $\mathrm{BCIA}$ & Protecting IT assets & $\mathrm{N}$ & & $\mathrm{x}$ & & & & & & & & & & & & & & & \\
\hline 7 & $\mathrm{BClA}$ & Developing information assurance strategy & A & & $\mathrm{X}$ & & & & & & & $\mathrm{x}$ & & & & & & & & \\
\hline 8 & $\mathrm{BCIA}$ & Engineering systems for continuity & A & $x$ & & & & & & & & & & & & & & & & \\
\hline 9 & $\mathrm{BClA}$ & $\begin{array}{l}\text { Implementing and managing quality audit } \\
\text { processes }\end{array}$ & A & $x$ & & & & & & & & & & & & & & & & \\
\hline 10 & $\mathrm{BCIA}$ & Assuring safety throughout systems lifecycle & A & $\mathrm{X}$ & & & & & & & & & & & & & & & & \\
\hline 11 & DATA & $\begin{array}{l}\text { Explaining key data and information concepts and } \\
\text { the data and information management lifecycle }\end{array}$ & $\mathrm{s}$ & & & $x$ & & & $x$ & & & $\mathrm{x}$ & & & & & & & & \\
\hline 12 & DATA & $\begin{array}{l}\text { Capturing and structuring data and information } \\
\text { requirements using appropriate conceptual } \\
\text { modeling techniques }\end{array}$ & $\mathrm{S}$ & & & $\mathrm{x}$ & & & $x$ & & & $\mathrm{x}$ & & $\mathrm{x}$ & & & & & & $\mathrm{x}$ \\
\hline 13 & DATA & $\begin{array}{l}\text { Developing a logical level representation of data } \\
\text { based on a conceptual model }\end{array}$ & $S$ & & & $x$ & & & $x$ & & & $\mathrm{x}$ & & & & & & & & $\mathrm{x}$ \\
\hline 14 & DATA & $\begin{array}{l}\text { Implementing a database solution to serve } \\
\text { systems consisting of multiple applications }\end{array}$ & $\mathrm{N}$ & & $x$ & & & & $x$ & & & $x$ & & & & & & & & $x$ \\
\hline 15 & DATA & $\begin{array}{l}\text { Using a contemporary data manipulation and } \\
\text { retrieval language effectively }\end{array}$ & $\mathrm{S}$ & & & $\mathrm{x}$ & & & $x$ & & & $\mathrm{x}$ & & & & & & & & $x$ \\
\hline 16 & DATA & $\begin{array}{l}\text { Selecting appropriate data management } \\
\text { technologies based on the needs of the domain }\end{array}$ & $\mathrm{S}$ & & & $\mathrm{x}$ & & & & & & $\mathrm{x}$ & $x$ & & & & & & & $x$ \\
\hline 17 & DATA & $\begin{array}{l}\text { Securing domain data and protecting user privacy } \\
\text { and organizational intellectual property using } \\
\text { appropriate technical solutions }\end{array}$ & $\mathrm{N}$ & & $x$ & & & & & & & $\mathrm{x}$ & & & & & & & & $x$ \\
\hline 18 & DATA & $\begin{array}{l}\text { Designing and implementing a data warehouse } \\
\text { using a contemporary architectural solution }\end{array}$ & $\mathrm{N}$ & & $x$ & & & & & & & $x$ & & & & & & & & \\
\hline 19 & DATA & $\begin{array}{l}\text { Creating a scalable infrastructure for large } \\
\text { amounts of data using parallel and distributed } \\
\text { technologies }\end{array}$ & $\mathrm{N}$ & & $x$ & & & & & & & $\mathrm{x}$ & & & & & & & & $x$ \\
\hline 20 & DATA & $\begin{array}{l}\text { Developing and implementing organizational } \\
\text { information management policies and processes }\end{array}$ & $\mathrm{N}$ & & & $\mathrm{x}$ & & & & & & $x$ & $x$ & & & & & & & \\
\hline 21 & DATA & $\begin{array}{l}\text { Creating an information architecture for an } \\
\text { organization }\end{array}$ & $\mathrm{N}$ & & $x$ & & & & & & & & $x$ & & & & & & & \\
\hline 22 & DATA & $\begin{array}{l}\text { Integrating and preparing data captured from } \\
\text { various sources for analytical use }\end{array}$ & $\mathrm{N}$ & & $x$ & & & & & & & $x$ & & & & & & & & $x$ \\
\hline 23 & DATA & Selecting and using appropriate analytics methods & $\mathrm{N}$ & & $\mathrm{x}$ & & & & & & & $\mathrm{x}$ & & & & & & & & $\mathrm{x}$ \\
\hline 24 & DATA & $\begin{array}{l}\text { Analyzing data using advanced contemporary } \\
\text { methods }\end{array}$ & $\mathrm{N}$ & & $\mathrm{X}$ & & & & & & & $\mathrm{x}$ & & & & & & & & $x$ \\
\hline 25 & DATA & $\begin{array}{l}\text { Designing and implementing architectures for } \\
\text { organizational content management systems }\end{array}$ & $\mathrm{N}$ & & $\mathrm{X}$ & & & & & & & $\mathrm{x}$ & & & & & & & & \\
\hline 26 & EARC & $\begin{array}{l}\text { Explaining enterprise architecture principles to } \\
\text { justify the value enterprise architecture provides } \\
\text { to organizations within various types of domains }\end{array}$ & $\mathrm{S}$ & & & $\mathrm{x}$ & & & & & & & & & & & & & & \\
\hline 27 & EARC & $\begin{array}{l}\text { Designing, building and maintaining an enterprise } \\
\text { architecture }\end{array}$ & $\mathrm{N}$ & & $\mathrm{x}$ & & & & & & & & & & & & & & & \\
\hline 28 & EARC & $\begin{array}{l}\text { Communicating and deploying an enterprise } \\
\text { architecture }\end{array}$ & $\mathrm{N}$ & & $\mathrm{x}$ & & & & & & & & $\mathrm{x}$ & $\mathrm{x}$ & & & & & & \\
\hline 29 & EARC & $\begin{array}{l}\text { Using an enterprise architecture to influence IS } \\
\text { related organizational improvement projects }\end{array}$ & A & & $\mathrm{x}$ & & & & & & & $\mathrm{x}$ & $\mathrm{x}$ & $\mathrm{x}$ & & & & & & \\
\hline 30 & ETIS & Designing and managing sustainable IT operations & A & $\mathrm{x}$ & & & & & & & & & $\mathrm{x}$ & & & & & & & \\
\hline 31 & ETIS & Aligning IT with organizational sustainability policy & A & $\mathrm{X}$ & & & & & & & & & $\mathrm{x}$ & & & & & & & \\
\hline 32 & ETIS & Managing IT facilities sustainably & $\mathrm{A}$ & $\mathrm{X}$ & & & & & & & & & $\mathrm{x}$ & & & & & & & \\
\hline 33 & ETIS & Managing sustainable procurement practices & A & $\mathrm{X}$ & & & & & & & & & $\mathrm{x}$ & & & & & & & \\
\hline 34 & ETIS & Managing contracts ethically & $\mathrm{N}$ & & $\mathrm{X}$ & & & & & & & & $\mathrm{x}$ & & & & & & & \\
\hline 35 & ETIS & $\begin{array}{l}\text { Maintaining compliance with legislation, } \\
\text { regulations, and standards }\end{array}$ & $\mathrm{N}$ & & $\mathrm{X}$ & & & & & & & $\mathrm{x}$ & & & & & & & & $\mathrm{x}$ \\
\hline 36 & ETIS & $\begin{array}{l}\text { Ensuring that protection of privacy and integrity } \\
\text { guides all IS practices }\end{array}$ & $\mathrm{N}$ & & $\mathrm{X}$ & & & & & & & & $\mathrm{x}$ & & & & & & & $\mathrm{x}$ \\
\hline
\end{tabular}




\begin{tabular}{|c|c|c|c|c|c|c|c|c|c|c|c|c|c|c|c|c|c|c|}
\hline 37 & ETIS & Fostering an ethical culture & $\mathrm{N}$ & & & $\mathrm{X}$ & & & & & & $\mathrm{x}$ & $\mathrm{x}$ & $\mathrm{x}$ & & & & $x$ \\
\hline 38 & ETIS & Considering ethical implications of IS decisions & $\mathrm{S}$ & & & $\mathrm{x}$ & & & & & & & & $\mathrm{x}$ & & & & $x$ \\
\hline 39 & IOCE & Monitoring the technology environment & $\mathrm{S}$ & & & & $\mathrm{x}$ & & & & & & & $\mathrm{x}$ & & & & $x$ \\
\hline 40 & IOCE & Engaging in entrepreneurial thinking & $\mathrm{N}$ & & & & $\mathrm{x}$ & & & & & & $\mathrm{x}$ & $\mathrm{x}$ & & & & $x$ \\
\hline 41 & IOCE & Developing a business plan & $\mathrm{N}$ & & & $\mathrm{x}$ & & & & & & & & $\mathrm{x}$ & & & & $\mathrm{x}$ \\
\hline 42 & IOCE & $\begin{array}{l}\text { Innovating by exploiting an emerging method or } \\
\text { technology }\end{array}$ & $\mathrm{s}$ & & & & $\mathrm{x}$ & & & & & & & $\mathrm{x}$ & & & & $\mathrm{x}$ \\
\hline 43 & IOCE & $\begin{array}{l}\text { Promoting diffusion by leveraging differences } \\
\text { between adopter groups }\end{array}$ & $\mathrm{N}$ & & & $x$ & & & & & & & & $\mathrm{x}$ & & & & \\
\hline 44 & IOCE & $\begin{array}{l}\text { Applying creative problem solving to technology- } \\
\text { related issues }\end{array}$ & $\mathrm{S}$ & & & & $\mathrm{x}$ & & & & & $\mathrm{x}$ & & $\mathrm{x}$ & & & & $\mathrm{x}$ \\
\hline 45 & IOCE & $\begin{array}{l}\text { Contributing to organizational development and } \\
\text { change management }\end{array}$ & $\mathrm{N}$ & & & & $x$ & & & & & & $\mathrm{x}$ & $\mathrm{x}$ & & & & \\
\hline 46 & IOCE & Analyzing and documenting business activities & $\mathrm{S}$ & & & & $\mathrm{x}$ & & & $\mathrm{x}$ & & & & & & & & $x$ \\
\hline 47 & IOCE & $\begin{array}{l}\text { Identifying opportunities for and designing } \\
\text { process improvement }\end{array}$ & $\mathrm{N}$ & & & & $\mathrm{x}$ & & & & & & & & & & & $\mathrm{x}$ \\
\hline 48 & ISMO & $\begin{array}{l}\text { Applying broadly used Project Management tools } \\
\text { and techniques }\end{array}$ & $\mathrm{S}$ & & & $\mathrm{x}$ & & $\mathrm{x}$ & $\mathrm{x}$ & $x$ & $x$ & $\mathrm{x}$ & $\mathrm{x}$ & $\mathrm{x}$ & & & & $\mathrm{x}$ \\
\hline 49 & ISMO & Managing the IS function & $\mathrm{A}$ & & $\mathrm{x}$ & & & & & & & & $\mathrm{x}$ & & & & & \\
\hline 50 & ISMO & Managing IS staff & $\mathrm{A}$ & & $\mathrm{x}$ & & & & & & & & $\mathrm{x}$ & & & & & \\
\hline 51 & ISMO & Managing IS service production & A & & $\mathrm{X}$ & & & & & & & & $\mathrm{x}$ & & & & & \\
\hline 52 & ISMO & Managing IS sourcing models & A & & $\mathrm{X}$ & & & & & & & & $\mathrm{x}$ & & & & & \\
\hline 53 & ISMO & Managing and coordinating information resources & A & & $\mathrm{x}$ & & & & & & & $\mathrm{x}$ & $\mathrm{x}$ & & & & & \\
\hline 54 & ISMO & $\begin{array}{l}\text { Implementing relevant IT governance frameworks } \\
\text { within the organization based on strategic } \\
\text { guidance }\end{array}$ & A & & $\mathrm{x}$ & & & & & & & & $\mathrm{x}$ & & & & & \\
\hline 55 & ISMO & $\begin{array}{l}\text { Complying with laws and regulations directly } \\
\text { affecting IS management and operations }\end{array}$ & $\mathrm{S}$ & & & $x$ & & & & & & & $\mathrm{x}$ & & & & & \\
\hline 56 & ISMO & Managing IS projects and programs & $\mathrm{S}$ & & & $\mathrm{x}$ & & & & & & & & $\mathrm{x}$ & & & & $x$ \\
\hline 57 & ISMO & Managing IS project portfolios & $\mathrm{N}$ & & $\mathrm{x}$ & & & & & & & & & $\mathrm{x}$ & & & & \\
\hline 58 & ISMO & $\begin{array}{l}\text { Managing software and hardware development } \\
\text { and maintenance }\end{array}$ & $\mathrm{N}$ & & $\mathrm{X}$ & & & & & & & & $\mathrm{x}$ & & & & & \\
\hline 59 & ISSG & Conducting IS strategic analysis & $\mathrm{N}$ & & & $\mathrm{x}$ & & & & & & & $\mathrm{x}$ & & & & & \\
\hline 60 & ISSG & Making a financial case for IS & $\mathrm{S}$ & & & & $\mathrm{x}$ & & & & & & $\mathrm{x}$ & & & & & \\
\hline 61 & ISSG & Managing IS/IT sourcing strategies & $\mathrm{N}$ & & & $\mathrm{x}$ & & & & & & & $\mathrm{x}$ & & & & & \\
\hline 62 & ISSG & Engaging in IS strategic planning & $\mathrm{N}$ & & & $\mathrm{x}$ & & & & & & & $\mathrm{x}$ & & & & & \\
\hline 63 & ISSG & Planning for and implementing IS governance & $\mathrm{A}$ & & $\mathrm{X}$ & & & & & & & & $\mathrm{x}$ & & & & & \\
\hline 64 & ISSG & Planning for and improving sustainability & $\mathrm{A}$ & & $\mathrm{x}$ & & & & & & & & $\mathrm{x}$ & & & & & \\
\hline 65 & INFR & $\begin{array}{l}\text { Designing data communication networks and data } \\
\text { center and server solutions }\end{array}$ & $\mathrm{N}$ & & $\mathrm{x}$ & & & & & & $x$ & & $\mathrm{x}$ & & & & & \\
\hline 66 & INFR & $\begin{array}{l}\text { Selecting appropriate client devices to support the } \\
\text { needs of an application area }\end{array}$ & $\mathrm{S}$ & & & $\mathrm{x}$ & & & & & $x$ & & & $\mathrm{x}$ & & & & \\
\hline 67 & INFR & Securing IT infrastructures & $\mathrm{N}$ & & $\mathrm{X}$ & & & & & & $\mathrm{x}$ & & $\mathrm{x}$ & & & & & \\
\hline 68 & INFR & Specifying and monitoring infrastructure contracts & $\mathrm{N}$ & & $\mathrm{x}$ & & & & & & $x$ & & $\mathrm{x}$ & & & & & \\
\hline 69 & INFR & $\begin{array}{l}\text { Negotiating contracts and managing } \\
\text { infrastructure vendors }\end{array}$ & A & $\mathrm{x}$ & & & & & & & & & & & & & & \\
\hline 70 & INFR & $\begin{array}{l}\text { Responding to Requests for Proposals (RFPs) for } \\
\text { infrastructure solutions }\end{array}$ & $\mathrm{N}$ & & $\mathrm{x}$ & & & & & & $x$ & & $\mathrm{x}$ & & & & & \\
\hline 71 & INFR & Managing infrastructure risks & A & $\mathrm{x}$ & & & & & & & $\mathrm{x}$ & & & & & & & \\
\hline 72 & INFR & Optimizing infrastructure utilization & $\mathrm{A}$ & $\mathrm{x}$ & & & & & & & $\mathrm{x}$ & & & & & & & \\
\hline 73 & INFR & $\begin{array}{l}\text { Designing infrastructure solutions using external } \\
\text { service provider(s) (cloud computing) }\end{array}$ & $\mathrm{N}$ & & $\mathrm{X}$ & & & & & & $x$ & & $\mathrm{x}$ & & & & & \\
\hline 74 & INFR & $\begin{array}{l}\text { Maintaining a set of standards and policies and } \\
\text { understand the key laws and regulations to } \\
\text { relevant infrastructure decisions }\end{array}$ & A & $\mathrm{x}$ & & & & & & & $x$ & & & & & & & $\mathrm{x}$ \\
\hline 75 & SDAD & $\begin{array}{l}\text { Monitoring emerging technologies to understand } \\
\text { their potential to support the domain }\end{array}$ & $\mathrm{S}$ & & & & $x$ & & & $\mathrm{x}$ & & & $\mathrm{x}$ & $\mathrm{x}$ & & & & $x$ \\
\hline 76 & SDAD & Documenting existing systems & $\mathrm{S}$ & & & $\mathrm{x}$ & & & & $\mathrm{x}$ & & & & $\mathrm{x}$ & & & & \\
\hline 77 & SDAD & $\begin{array}{l}\text { Specifying and documenting systems } \\
\text { requirements }\end{array}$ & $\mathrm{s}$ & & & & $\mathrm{x}$ & & & $\mathrm{x}$ & & & & $\mathrm{x}$ & & & & $\mathrm{x}$ \\
\hline 78 & SDAD & $\begin{array}{l}\text { Identifying and selecting from systems design and } \\
\text { implementation alternatives }\end{array}$ & $\mathrm{N}$ & & & & $x$ & & & $x$ & & & & $\mathrm{x}$ & & & & $\mathrm{x}$ \\
\hline 79 & SDAD & Designing systems and services & $\mathrm{N}$ & & $\mathrm{X}$ & & & & & $\mathrm{x}$ & & & & $\mathrm{x}$ & & & & $\mathrm{x}$ \\
\hline 80 & SDAD & Designing user experiences & $\mathrm{N}$ & & & $\mathrm{x}$ & & & & $\mathrm{x}$ & & & & & & & & $\mathrm{x}$ \\
\hline 81 & SDAD & $\begin{array}{l}\text { Implementing a systems solution using a modern } \\
\text { programming language }\end{array}$ & $\mathrm{N}$ & & $\mathrm{X}$ & & & $\mathrm{x}$ & & & & & & & & & & \\
\hline 82 & SDAD & $\begin{array}{l}\text { Selecting between systems development } \\
\text { approaches }\end{array}$ & $\mathrm{S}$ & & & & $x$ & $\mathrm{x}$ & & $x$ & & & & & & & & \\
\hline 83 & SDAD & $\begin{array}{l}\text { Managing plan-based, hybrid, and agile } \\
\text { development processes }\end{array}$ & $\mathrm{N}$ & & & & $x$ & $\mathrm{x}$ & & $\mathrm{x}$ & & & $\mathrm{x}$ & & & & & \\
\hline 84 & SDAD & Implementing and testing an application & $\mathrm{N}$ & & & $\mathrm{x}$ & & $\mathrm{x}$ & & $\mathrm{x}$ & & & & & & & & \\
\hline 85 & SDAD & Installing and integrating a new application & $\mathrm{N}$ & & $\mathrm{x}$ & & & $\mathrm{x}$ & $x$ & & $\mathrm{x}$ & & & & & & & \\
\hline 86 & SDAD & $\begin{array}{l}\text { Managing external systems development } \\
\text { resources }\end{array}$ & $\mathrm{N}$ & & & $\mathrm{x}$ & & & & & & & $\mathrm{x}$ & & & & & \\
\hline 87 & SDAD & Managing IS development projects & $\mathrm{N}$ & & & $\mathrm{x}$ & & & & $\mathrm{x}$ & & & & & & & & \\
\hline 88 & SDAD & Deploying a new system to organizational use & $\mathrm{N}$ & & & $\mathrm{x}$ & & & & & & & & $\mathrm{x}$ & & & & \\
\hline
\end{tabular}




\begin{tabular}{|c|c|c|c|c|c|c|c|c|c|c|c|c|c|c|c|c|c|c|c|c|c|c|}
\hline & \multirow[b]{2}{*}{\begin{tabular}{|l} 
Role: \\
\\
Area \\
\end{tabular}} & \multirow[b]{2}{*}{\begin{tabular}{|l} 
Start-up Entrepreneur \\
\\
Category \\
\end{tabular}} & \multirow[b]{2}{*}{\begin{tabular}{|c} 
\\
\\
\\
MSIS \\
Min \\
\end{tabular}} & \multicolumn{4}{|c|}{$\begin{array}{c}\text { Competency } \\
\text { level for } \\
\text { profile(s) }\end{array}$} & \multicolumn{15}{|c|}{$\begin{array}{c}\text { Mapping between modules/courses and competencies } \\
\text { (compentency achievement can be served by multiple } \\
\text { modules) }\end{array}$} \\
\hline & & & & A & $\mathbf{N}$ & $\mathbf{S}$ & I & 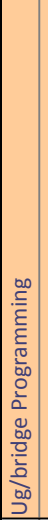 & 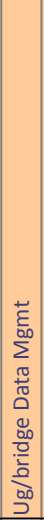 & 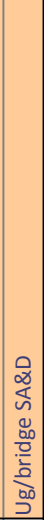 & 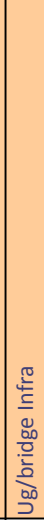 & 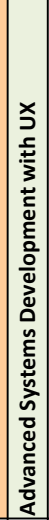 & 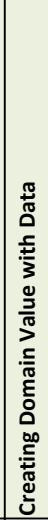 & 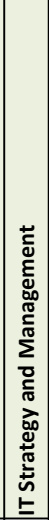 & 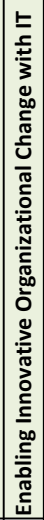 & 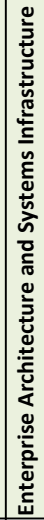 & 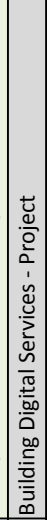 & 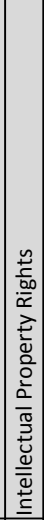 & 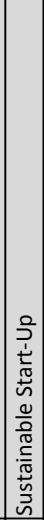 & 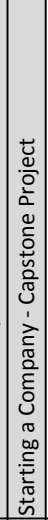 & 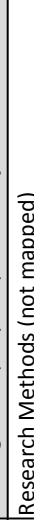 & 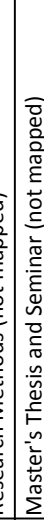 \\
\hline 1 & $\mathrm{BCIA}$ & Managing and implementing cybersecurity & $\mathrm{N}$ & & $\mathrm{x}$ & & & & & & $\mathrm{x}$ & & $\mathrm{x}$ & & $x$ & & & $\mathrm{x}$ & $x$ & & & \\
\hline 2 & $2 \mathrm{BCIA}$ & Responding to and managing IS problems & $\mathrm{S}$ & & & $\mathrm{x}$ & & & & & $\mathrm{x}$ & & & & & & & & & & & \\
\hline 3 & $\mathrm{BClA}$ & Monitoring system operations & $\mathrm{N}$ & & $\mathrm{x}$ & & & & & & $\mathrm{x}$ & & & $x$ & & & & & & & & \\
\hline 4 & $\mathrm{BClA}$ & Managing system recovery & A & $\mathrm{x}$ & & & & & & & & & & & & & & & & & & \\
\hline 5 & $\mathrm{BClA}$ & Managing Information Systems risks & $\mathrm{N}$ & & $\mathrm{x}$ & & & & & & $\mathrm{x}$ & & & $\mathrm{x}$ & $\mathrm{x}$ & & $\mathrm{x}$ & & $\mathrm{x}$ & $\mathrm{x}$ & & \\
\hline 6 & $\mathrm{BClA}$ & Protecting IT assets & $\mathrm{N}$ & & $\mathrm{x}$ & & & & & & $\mathrm{x}$ & & & & & & & $\mathrm{x}$ & & & & \\
\hline 7 & $7 \mathrm{BClA}$ & Developing information assurance strategy & A & $x$ & & & & & & & & & $\mathrm{x}$ & & & & & $\mathrm{x}$ & & & & \\
\hline 8 & $\mathrm{BClA}$ & Engineering systems for continuity & $\mathrm{A}$ & $\mathrm{x}$ & & & & & & & & & & & & & & & & & & \\
\hline 9 & $\mathrm{BClA}$ & Implementing and managing quality audit processes & $\mathrm{A}$ & $\mathrm{x}$ & & & & & & & & & & & & & & & & & & \\
\hline 10 & $\mathrm{BClA}$ & Assuring safety throughout systems lifecycle & $\mathrm{A}$ & $\mathrm{x}$ & & & & & & & & & & & & & & $\mathrm{x}$ & $\mathrm{x}$ & & & \\
\hline 11 & 1 DATA & $\begin{array}{l}\text { Explaining key data and information concepts and the data } \\
\text { and information management lifecycle }\end{array}$ & $\mathrm{S}$ & & & & $x$ & & $x$ & & & & $\mathrm{x}$ & & & & & & & & & \\
\hline 12 & DATA & $\begin{array}{l}\text { Capturing and structuring data and information } \\
\text { requirements using appropriate conceptual modeling } \\
\text { techniques }\end{array}$ & $\mathrm{S}$ & & & & $x$ & & $x$ & & & $\mathrm{x}$ & $\mathrm{x}$ & & $\mathrm{x}$ & & & & & & & \\
\hline 13 & \begin{tabular}{l|l} 
DATA \\
\end{tabular} & $\begin{array}{l}\text { Developing a logical level representation of data based on a } \\
\text { conceptual model }\end{array}$ & $\mathrm{S}$ & & & & $x$ & & $x$ & & & & $x$ & & & & & & & & & \\
\hline 14 & 4 DATA & $\begin{array}{l}\text { Implementing a database solution to serve systems } \\
\text { consisting of multiple applications }\end{array}$ & $\mathrm{N}$ & & $\mathrm{x}$ & & & & $x$ & & & $\mathrm{x}$ & $\mathrm{x}$ & & & & & & & & & \\
\hline 15 & DATA & $\begin{array}{l}\text { Using a contemporary data manipulation and retrieval } \\
\text { language effectively }\end{array}$ & $\mathrm{S}$ & & & $\mathrm{x}$ & & & $x$ & & & $\mathrm{x}$ & $\mathrm{x}$ & & & & & & & & & \\
\hline 16 & DATA & $\begin{array}{l}\text { Selecting appropriate data management technologies based } \\
\text { on the needs of the domain }\end{array}$ & $\mathrm{S}$ & & & $x$ & & & & & & $\mathrm{x}$ & $\mathrm{x}$ & $\mathrm{x}$ & & $\mathrm{x}$ & & & & & & \\
\hline 17 & \begin{tabular}{l|l} 
DATA \\
\end{tabular} & $\begin{array}{l}\text { Securing domain data and protecting user privacy and } \\
\text { organizational intellectual property using appropriate } \\
\text { technical solutions }\end{array}$ & $\mathrm{N}$ & & $\mathrm{x}$ & & & & & & & $\mathrm{x}$ & $\mathrm{x}$ & & & & $\mathrm{x}$ & $\mathrm{x}$ & & & & \\
\hline 18 & DATA & $\begin{array}{l}\text { Designing and implementing a data warehouse using a } \\
\text { contemporary architectural solution }\end{array}$ & $\mathrm{N}$ & & $x$ & & & & $x$ & & & & $\mathrm{x}$ & & & $P$ & & & & & & \\
\hline 19 & DATA & $\begin{array}{l}\text { Creating a scalable infrastructure for large amounts of data } \\
\text { using parallel and distributed technologies }\end{array}$ & $\mathrm{N}$ & & & $\mathrm{x}$ & & & & & & $\mathrm{x}$ & $\mathrm{x}$ & & & $\mathrm{P}$ & & & & & & \\
\hline 20 & DATA & $\begin{array}{l}\text { Developing and implementing organizational information } \\
\text { management policies and processes }\end{array}$ & $\mathrm{N}$ & $x$ & & & & & $x$ & & & $\mathrm{x}$ & $\mathrm{x}$ & $\mathrm{x}$ & & $x$ & & & & & & \\
\hline 21 & 1 DATA & Creating an information architecture for an organization & $\mathrm{N}$ & & $\mathrm{x}$ & & & & $x$ & & & $P$ & & $\mathrm{x}$ & & $P$ & & & & & & \\
\hline 22 & 2 DATA & $\begin{array}{l}\text { Integrating and preparing data captured from various } \\
\text { sources for analytical use }\end{array}$ & $\mathrm{N}$ & & & $x$ & & & & & & & $\mathrm{x}$ & & & & & & & & & \\
\hline 23 & DATA & Selecting and using appropriate analytics methods & $\mathrm{N}$ & & & $x$ & & & & & & & $\mathrm{x}$ & & & & & & & & & \\
\hline 24 & 4 DATA & Analyzing data using advanced contemporary methods & $\mathrm{N}$ & & & $x$ & & & & & & & $\mathrm{x}$ & & & & & & & & & \\
\hline 25 & DATA & $\begin{array}{l}\text { Designing and implementing architectures for organizational } \\
\text { content management systems }\end{array}$ & $\mathrm{N}$ & & $x$ & & & & $x$ & & & $\mathrm{x}$ & $\mathrm{x}$ & & & $\mathrm{x}$ & $\mathrm{x}$ & & & & & \\
\hline 26 & EARC & $\begin{array}{l}\text { Explaining enterprise architecture principles to justify the } \\
\text { value enterprise architecture provides to organizations } \\
\text { within various types of domains }\end{array}$ & $\mathrm{S}$ & & & $\mathrm{x}$ & & & & & & & & & & $\mathrm{P}$ & & & & & & \\
\hline 27 & EARC & $\begin{array}{l}\text { Designing, building and maintaining an enterprise } \\
\text { architecture }\end{array}$ & $\mathrm{N}$ & & $x$ & & & & & & & & & & & $\mathrm{P}$ & & & & & & \\
\hline 28 & EARC & Communicating and deploying an enterprise architecture & $\mathrm{N}$ & & $\mathrm{x}$ & & & & & & & & & $\mathrm{x}$ & $\mathrm{x}$ & $\mathrm{P}$ & & & & & & \\
\hline 29 & EARC & $\begin{array}{l}\text { Using an enterprise architecture to influence IS related } \\
\text { organizational improvement projects }\end{array}$ & A & $x$ & & & & & & & & & $\mathrm{x}$ & $\mathrm{x}$ & $\mathrm{x}$ & $P$ & & & & & & \\
\hline 30 & ETIS & Designing and managing sustainable IT operations & A & $\mathrm{x}$ & & & & & & & $\mathrm{x}$ & & & $\mathrm{x}$ & & & & & & & & \\
\hline 31 & 1 ETIS & Aligning IT with organizational sustainability policy & A & $\mathrm{x}$ & & & & & & & $\mathrm{x}$ & & & $\mathrm{x}$ & & & & & $\mathrm{x}$ & & & \\
\hline 32 & 2 ETIS & Managing IT facilities sustainably & A & $\mathrm{x}$ & & & & & & & $\mathrm{x}$ & & & $\mathrm{x}$ & & & & & $\mathrm{x}$ & & & \\
\hline 33 & ETIS & Managing sustainable procurement practices & $\mathrm{A}$ & $\mathrm{x}$ & & & & & & & $\mathrm{x}$ & & & $\mathrm{x}$ & & & & & $\mathrm{x}$ & & & \\
\hline 34 & 4 ETIS & Managing contracts ethically & $\mathrm{N}$ & & $x$ & & & & & & & & & $\mathrm{x}$ & & & & $\mathrm{x}$ & $\mathrm{x}$ & $\mathrm{x}$ & & \\
\hline 35 & ETIS & $\begin{array}{l}\text { Maintaining compliance with legislation, regulations, and } \\
\text { standards }\end{array}$ & $\mathrm{N}$ & & $x$ & & & & & & & & $\mathrm{x}$ & & & & $\mathrm{x}$ & $\mathrm{x}$ & $P$ & $P$ & & \\
\hline 36 & ETIS & $\begin{array}{l}\text { Ensuring that protection of privacy and integrity guides all IS } \\
\text { practices }\end{array}$ & $\mathrm{N}$ & & $\mathrm{x}$ & & & & & & & & & $\mathrm{x}$ & & & $\mathrm{x}$ & $\mathrm{x}$ & $\mathrm{P}$ & $P$ & & \\
\hline 37 & 7 ETIS & Fostering an ethical culture & $\mathrm{N}$ & & $x$ & & & & & & & & $\mathrm{x}$ & $\mathrm{x}$ & $\mathrm{x}$ & & & $\mathrm{x}$ & $\mathrm{x}$ & & & \\
\hline 38 & ETIS & Considering ethical implications of IS decisions & $\mathrm{S}$ & & & & & & & & & & & & $x$ & & $x$ & $\mathrm{x}$ & $\mathrm{x}$ & & & \\
\hline
\end{tabular}




\begin{tabular}{|c|c|c|c|c|c|c|c|c|c|c|c|c|c|c|c|c|c|c|c|c|c|c|}
\hline & IOCE & Monitoring the technology environment & $\mathrm{S}$ & & & & $\mathrm{x}$ & & & & & $\mathrm{x}$ & & & $\mathrm{x}$ & $\mathrm{P}$ & $\mathrm{P}$ & $x$ & $\mathrm{P}$ & & & \\
\hline 40 & IOCE & Engaging in entrepreneurial thinking & $\mathrm{N}$ & & & & $\mathrm{x}$ & & & & & & & $\mathrm{x}$ & $\mathrm{x}$ & & $\mathrm{x}$ & & $\mathrm{P}$ & $\mathrm{P}$ & & \\
\hline 41 & IOCE & Developing a business plan & $\mathrm{N}$ & & & & $\mathrm{x}$ & & & & & & & & $\mathrm{x}$ & & $x$ & & $P$ & $P$ & & \\
\hline 42 & IOCE & Innovating by exploiting an emerging method or technology & $\mathrm{S}$ & & & $\mathrm{x}$ & & & & & & $\mathrm{x}$ & & & $\mathrm{x}$ & $\mathrm{x}$ & $\mathrm{P}$ & & $\mathrm{x}$ & $\mathrm{x}$ & & \\
\hline 43 & IOCE & $\begin{array}{l}\text { Promoting diffusion by leveraging differences between } \\
\text { adopter groups }\end{array}$ & $\mathrm{N}$ & & & $\mathrm{x}$ & & & & & & & & & $x$ & $\mathrm{x}$ & $\mathrm{x}$ & & $\mathrm{x}$ & & & \\
\hline 44 & IOCE & $\begin{array}{l}\text { Applying creative problem solving to technology-related } \\
\text { issues }\end{array}$ & $\mathrm{S}$ & & & $\mathrm{x}$ & & & & & & $x$ & $\mathrm{x}$ & & $\mathrm{x}$ & $P$ & $\mathrm{x}$ & & & $\mathrm{x}$ & & \\
\hline 45 & IOCE & $\begin{array}{l}\text { Contributing to organizational development and change } \\
\text { management }\end{array}$ & $\mathrm{N}$ & & $\mathrm{x}$ & & & & & & & $x$ & & $\mathrm{x}$ & $\mathrm{x}$ & & & & $\mathrm{x}$ & & & \\
\hline 46 & IOCE & Analyzing and documenting business activities & $\mathrm{S}$ & & & $x$ & & & & & & $\mathrm{x}$ & & & & & & & $\mathrm{x}$ & & & \\
\hline 47 & IOCE & $\begin{array}{l}\text { Identifying opportunities for and designing process } \\
\text { improvement }\end{array}$ & $\mathrm{N}$ & & $x$ & & & & & & & $x$ & & & & $\mathrm{x}$ & $\mathrm{x}$ & & & & & \\
\hline 48 & ISMO & $\begin{array}{l}\text { Applying broadly used Project Management tools and } \\
\text { techniques }\end{array}$ & $\mathrm{S}$ & & & & $\mathrm{x}$ & & & & & $x$ & $\mathrm{x}$ & $\mathrm{x}$ & $\mathrm{x}$ & & $\mathrm{P}$ & & $P$ & $P$ & & \\
\hline 49 & ISMO & Managing the IS function & A & & $\mathrm{x}$ & & & & & & & & & $\mathrm{x}$ & & & & & $\mathrm{x}$ & & & \\
\hline 50 & ISMO & Managing IS staff & $\mathrm{A}$ & & $\mathrm{x}$ & & & & & & & & & $\mathrm{x}$ & & & & & $\mathrm{x}$ & & & \\
\hline 51 & ISMO & Managing IS service production & $\mathrm{A}$ & & $\mathrm{x}$ & & & & & & & & & $x$ & & & $\mathrm{x}$ & & $\mathrm{x}$ & & & \\
\hline 52 & ISMO & Managing IS sourcing models & $\mathrm{A}$ & & $\mathrm{x}$ & & & & & & & & & $\mathrm{x}$ & & & & & $\mathrm{x}$ & & & \\
\hline 53 & ISMO & Managing and coordinating information resources & $\mathrm{A}$ & & $\mathrm{x}$ & & & & & & & & $\mathrm{x}$ & $\mathrm{x}$ & & & & & $\mathrm{x}$ & & & \\
\hline 54 & ISMO & $\begin{array}{l}\text { Implementing relevant IT governance frameworks within the } \\
\text { organization based on strategic guidance }\end{array}$ & A & & $\mathrm{x}$ & & & & & & & & & $\mathrm{x}$ & & & & & $\mathrm{x}$ & $\mathrm{x}$ & & \\
\hline 55 & ISMO & $\begin{array}{l}\text { Complying with laws and regulations directly affecting IS } \\
\text { management and operations }\end{array}$ & $\mathrm{S}$ & & & $\mathrm{x}$ & & & & & & $\mathrm{x}$ & & $\mathrm{x}$ & & & & $\mathrm{x}$ & $\mathrm{P}$ & $P$ & & \\
\hline 56 & ISMO & Managing IS projects and programs & $\mathrm{S}$ & & & $\mathrm{x}$ & & & & $\mathrm{x}$ & & $\mathrm{x}$ & & & $\mathrm{x}$ & & & & $\mathrm{P}$ & $\mathrm{P}$ & & \\
\hline 57 & ISMO & Managing IS project portfolios & $\mathrm{N}$ & & $\mathrm{x}$ & & & & & $\mathrm{x}$ & & $\mathrm{x}$ & & & $\mathrm{x}$ & & & & $\mathrm{P}$ & $\mathrm{x}$ & & \\
\hline 58 & ISMO & $\begin{array}{l}\text { Managing software and hardware development and } \\
\text { maintenance }\end{array}$ & $\mathrm{N}$ & & $x$ & & & & & $\mathrm{x}$ & & $x$ & & $\mathrm{x}$ & & $\mathrm{x}$ & & & & & & \\
\hline 59 & ISSG & Conducting IS strategic analysis & $\mathrm{N}$ & & $\mathrm{x}$ & & & & & $\mathrm{x}$ & & & & $\mathrm{x}$ & & $\mathrm{x}$ & & & $\mathrm{x}$ & & & \\
\hline 60 & ISSG & Making a financial case for IS & $\mathrm{S}$ & & & & $\mathrm{x}$ & & & & & & & $\mathrm{x}$ & & & & & $\mathrm{x}$ & $\mathrm{x}$ & & \\
\hline 61 & ISSG & Managing IS/IT sourcing strategies & $\mathrm{N}$ & & & $\mathrm{x}$ & & & & & & $\mathrm{x}$ & & $\mathrm{x}$ & & $\mathrm{x}$ & & & $\mathrm{x}$ & & & \\
\hline 62 & ISSG & Engaging in IS strategic planning & $\mathrm{N}$ & & & $\mathrm{x}$ & & & & & & & & $\mathrm{x}$ & & & & & $\mathrm{x}$ & & & \\
\hline 63 & ISSG & Planning for and implementing IS governance & A & & $\mathrm{x}$ & & & & & & & & & $x$ & & & & & $\mathrm{x}$ & $\mathrm{x}$ & & \\
\hline 64 & ISSG & Planning for and improving sustainability & $\mathrm{A}$ & & $\mathrm{x}$ & & & & & & & $\mathrm{x}$ & & $x$ & & & & & $\mathrm{x}$ & & & \\
\hline 65 & INFR & $\begin{array}{l}\text { Designing data communication networks and data center } \\
\text { and server solutions }\end{array}$ & $\mathrm{N}$ & & $\mathrm{x}$ & & & & & & $\mathrm{x}$ & & & $\mathrm{x}$ & & $\mathrm{P}$ & & & & & & \\
\hline 66 & INFR & $\begin{array}{l}\text { Selecting appropriate client devices to support the needs of } \\
\text { an application area }\end{array}$ & $\mathrm{S}$ & & & $\mathrm{x}$ & & & & & $\mathrm{x}$ & $\mathrm{x}$ & & & $\mathrm{x}$ & $\mathrm{P}$ & & & & & & \\
\hline $67 \mid$ & INFR & Securing IT infrastructures & $\mathrm{N}$ & & $\mathrm{x}$ & & & & & & $\mathrm{x}$ & & & $\mathrm{x}$ & & $\mathrm{x}$ & & & & & & \\
\hline 68 & INFR & Specifying and monitoring infrastructure contracts & $\mathrm{N}$ & & $\mathrm{x}$ & & & & & & $\mathrm{x}$ & & & $\mathrm{x}$ & & $\mathrm{x}$ & & & & $\mathrm{x}$ & & \\
\hline 69 & INFR & Negotiating contracts and managing infrastructure vendors & $\mathrm{A}$ & & $\mathrm{x}$ & & & & & & $\mathrm{x}$ & & & & & $\mathrm{x}$ & & & & $\mathrm{P}$ & & \\
\hline 70 & INFR & $\begin{array}{l}\text { Responding to Requests for Proposals (RFPs) for } \\
\text { infrastructure solutions }\end{array}$ & $\mathrm{N}$ & & $x$ & & & & & & $\mathrm{x}$ & & & $\mathrm{x}$ & & $\mathrm{x}$ & & & & & & \\
\hline 71 & INFR & Managing infrastructure risks & $\mathrm{A}$ & $\mathrm{x}$ & & & & & & & $\mathrm{x}$ & & & & & $\mathrm{x}$ & & & & $\mathrm{P}$ & & \\
\hline 72 & INFR & Optimizing infrastructure utilization & $\mathrm{A}$ & $\mathrm{x}$ & & & & & & & & $\mathrm{P}$ & & & & $\mathrm{P}$ & & & & $\mathrm{x}$ & & \\
\hline 73 & INFR & $\begin{array}{l}\text { Designing infrastructure solutions using external service } \\
\text { provider(s) (cloud computing) }\end{array}$ & $\mathrm{N}$ & & $x$ & & & & & & & $P$ & & $\mathrm{x}$ & & $P$ & $x$ & & & $\mathrm{P}$ & & \\
\hline 74 & INFR & $\begin{array}{l}\text { Maintaining a set of standards and policies and understand } \\
\text { the key laws and regulations to relevant infrastructure } \\
\text { decisions }\end{array}$ & A & $x$ & & & & & & & & & & & & $x$ & $x$ & $\mathrm{x}$ & $\mathrm{x}$ & $P$ & & \\
\hline 75 & SDAD & $\begin{array}{l}\text { Monitoring emerging technologies to understand their } \\
\text { potential to support the domain }\end{array}$ & $\mathrm{S}$ & & & & $x$ & & & & & $x$ & & $\mathrm{x}$ & $\mathrm{x}$ & $x$ & $\mathrm{P}$ & & $x$ & & & \\
\hline 76 & SDAD & Documenting existing systems & $\mathrm{S}$ & & & $\mathrm{x}$ & & & & $\mathrm{x}$ & & $\mathrm{x}$ & & & $\mathrm{x}$ & $\mathrm{x}$ & & & & & & \\
\hline 77 & SDAD & Specifying and documenting systems requirements & $\mathrm{S}$ & & & $\mathrm{x}$ & & & & $\mathrm{x}$ & & $\mathrm{x}$ & & & $\mathrm{x}$ & $\mathrm{x}$ & & & & & & \\
\hline 78 & SDAD & $\begin{array}{l}\text { Identifying and selecting from systems design and } \\
\text { implementation alternatives }\end{array}$ & $\mathrm{N}$ & & $\mathrm{x}$ & & & & & $\mathrm{x}$ & & $x$ & & & $\mathrm{x}$ & $x$ & $\mathrm{x}$ & & & & & \\
\hline 79 & SDAD & Designing systems and services & $\mathrm{N}$ & & & $\mathrm{x}$ & & & & $\mathrm{x}$ & & $\mathrm{P}$ & & & $\mathrm{x}$ & & $\mathrm{x}$ & & & & & \\
\hline 80 & SDAD & Designing user experiences & $\mathrm{N}$ & & & $\mathrm{x}$ & & & & $\mathrm{x}$ & & $\mathrm{P}$ & & & & & $x$ & $\mathrm{x}$ & & & & \\
\hline 81 & SDAD & $\begin{array}{l}\text { Implementing a systems solution using a modern } \\
\text { programming language }\end{array}$ & $\mathrm{N}$ & & $\mathrm{x}$ & & & $x$ & & $\mathrm{x}$ & & $x$ & & & & & $\mathrm{x}$ & & & & & \\
\hline 82 & SDAD & Selecting between systems development approaches & $\mathrm{S}$ & & & $x$ & & & & $\mathrm{x}$ & & $\mathrm{x}$ & & & & $\mathrm{x}$ & $\mathrm{x}$ & & & & & \\
\hline 83 & SDAD & $\begin{array}{l}\text { Managing plan-based, hybrid, and agile development } \\
\text { processes }\end{array}$ & $\mathrm{N}$ & & $\mathrm{x}$ & & & & & $\mathrm{x}$ & & $\mathrm{x}$ & & $\mathrm{x}$ & & $\mathrm{x}$ & $\mathrm{x}$ & & & & & \\
\hline 84 & SDAD & Implementing and testing an application & $\mathrm{N}$ & & $\mathrm{x}$ & & & $\mathrm{x}$ & & $\mathrm{x}$ & & $\mathrm{x}$ & & & & $\mathrm{x}$ & $\mathrm{x}$ & & & & & \\
\hline 85 & SDAD & Installing and integrating a new application & $\mathrm{N}$ & & $\mathrm{x}$ & & & $\mathrm{x}$ & & & & $\mathrm{x}$ & & & & $\mathrm{x}$ & & & & & & \\
\hline 86 & SDAD & Managing external systems development resources & $\mathrm{N}$ & & $\mathrm{x}$ & & & & & & & $\mathrm{x}$ & & $\mathrm{x}$ & & $\mathrm{x}$ & & & & $\mathrm{x}$ & & \\
\hline 87 & SDAD & Managing IS development projects & $\mathrm{N}$ & & $\mathrm{x}$ & & & & & & & $\mathrm{x}$ & & & & $\mathrm{x}$ & $\mathrm{x}$ & & & $x$ & & \\
\hline 88 & SDAD & Deploying a new system to organizational use & $\mathrm{N}$ & & $\mathrm{x}$ & & & & & & & $\mathrm{x}$ & & & $\mathrm{x}$ & $\mathrm{x}$ & & & $\mathrm{x}$ & $\mathrm{x}$ & & \\
\hline
\end{tabular}

